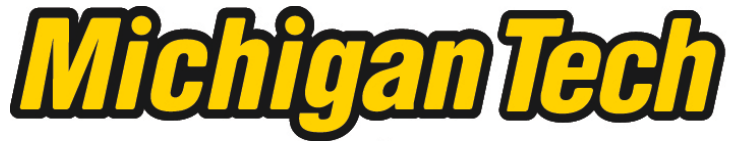 \\ Michigan Technological University Create the Future Digital Commons @ Michigan Tech
}

Dissertations, Master's Theses and Master's Reports - Open

Dissertations, Master's Theses and Master's

Reports

2015

CLIMATE ANOMALIES AND PRIMARY PRODUCTION IN LAKE SUPERIOR

Marcel L. Dijkstra

Michigan Technological University

Follow this and additional works at: https://digitalcommons.mtu.edu/etds

Part of the Biogeochemistry Commons, Ecology and Evolutionary Biology Commons, and the Engineering Commons

Copyright 2015 Marcel L. Dijkstra

\section{Recommended Citation}

Dijkstra, Marcel L., "CLIMATE ANOMALIES AND PRIMARY PRODUCTION IN LAKE SUPERIOR", Dissertation, Michigan Technological University, 2015.

https://doi.org/10.37099/mtu.dc.etds/1010

Follow this and additional works at: https://digitalcommons.mtu.edu/etds

Part of the Biogeochemistry Commons, Ecology and Evolutionary Biology Commons, and the Engineering Commons 


\title{
CLIMATE ANOMALIES AND PRIMARY PRODUCTION IN LAKE SUPERIOR
}

\author{
By \\ Marcel L. Dijkstra \\ A DISSERTATION \\ Submitted in partial fulfillment of the requirements for the degree of \\ DOCTOR OF PHILOSOPHY \\ In Environmental Engineering
}


This dissertation has been approved in partial fulfillment of the requirements for the Degree of DOCTOR OF PHILOSOPHY in Environmental Engineering

Department of Civil and Environmental Engineering

Dissertation Advisor: Dr. Martin T. Auer

Committee Member: Dr. Nancy A. Auer

Committee Member: $\quad$ Dr. Joseph V. DePinto

Committee Member: Dr. Noel A. Urban

Department Chair: $\quad$ Dr. David W. Hand 


\section{Contents}

List of Figures

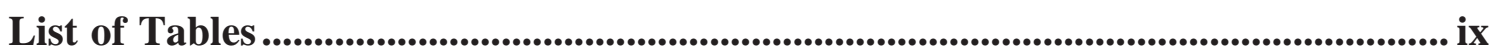

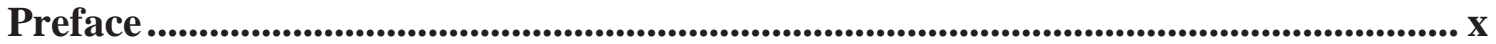

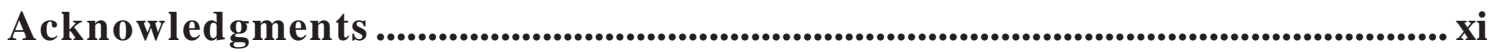

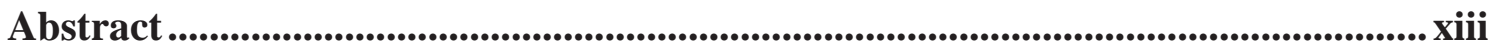

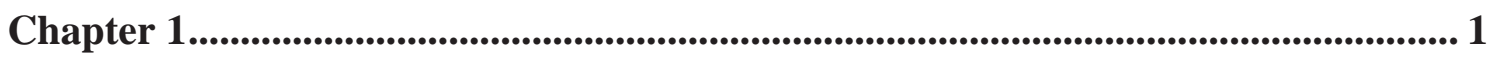

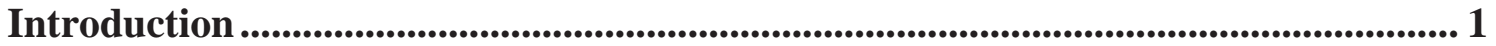

1.1 Primary Production modeling ....................................................................

1.2 Ecosystem dynamics in Lake Superior ................................................................ 2

1.3 Context of the dissertation..........................................................................

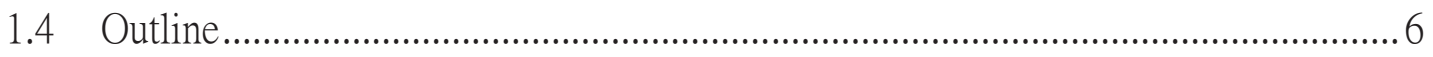

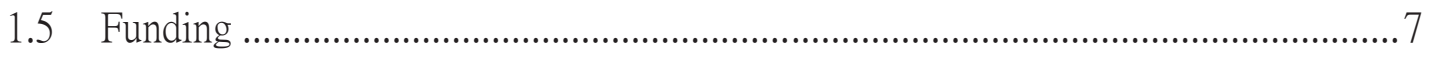

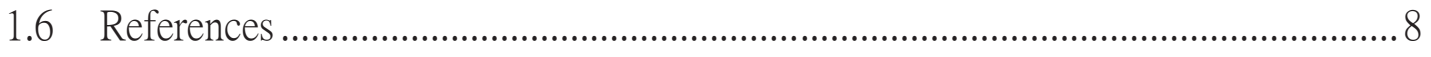

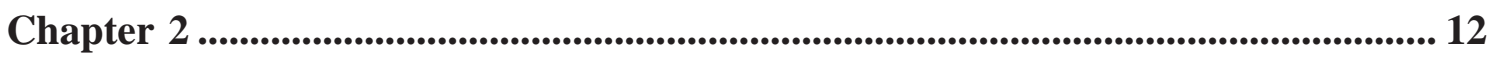

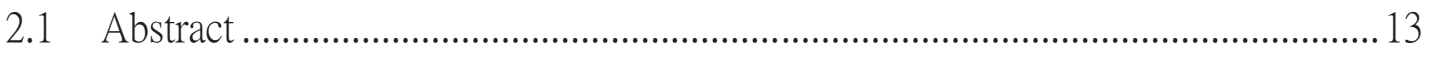

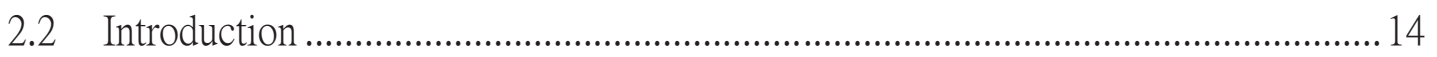

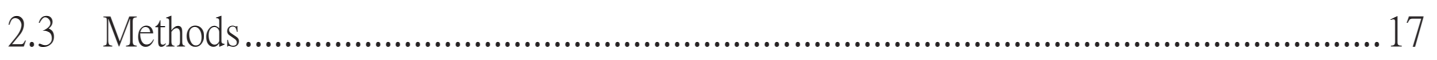

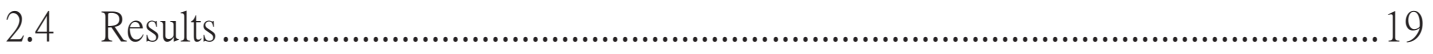


2.4.1 Algorithm Selection and Parameterization

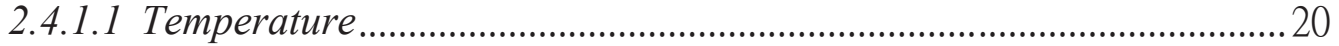

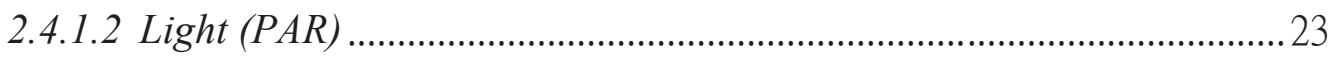

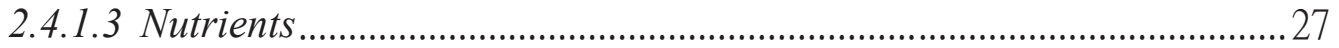

2.4.1.4 Maximum specific rate of primary production ...................................... 30

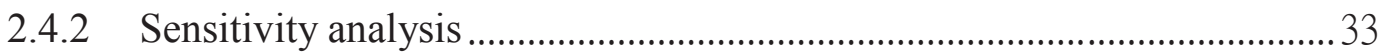

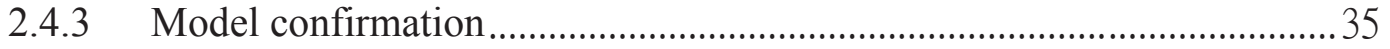

2.4.3.1 Model inputs, algorithms and coefficients ........................................... 35

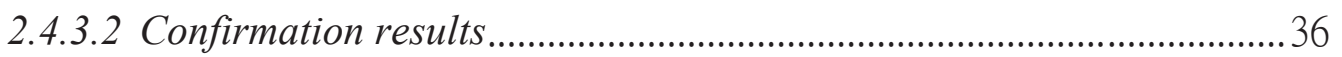

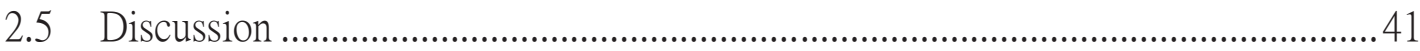

2.5.1 Model inputs, algorithms and coefficients ............................................. 41

2.5.2 Vertical heterogeneity in primary production......................................... 42

2.5.3 Horizontal heterogeneity in areal primary production ............................. 45

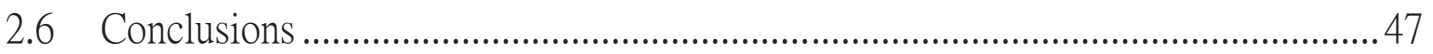

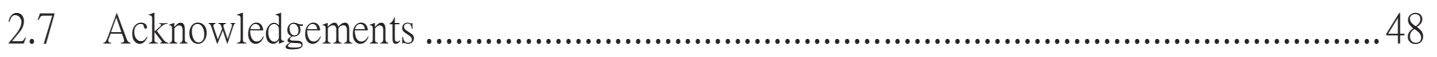

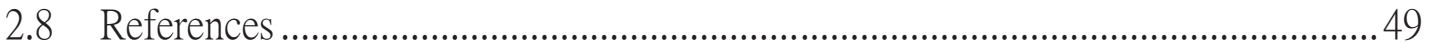

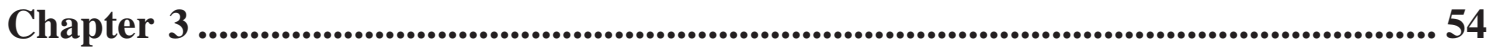

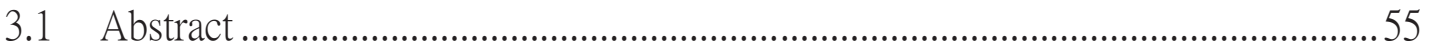

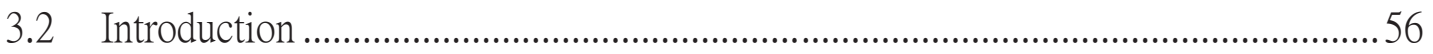

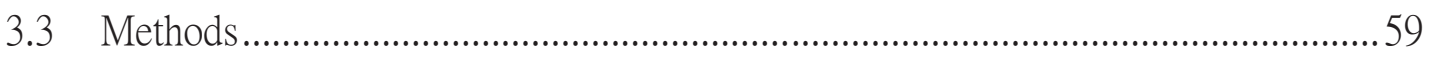

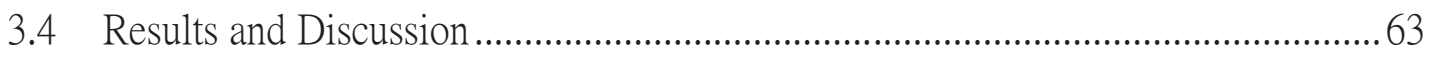


3.4.1 Temporal dynamics

3.4.1.1 Seasonal dynamics in temperature

3.4.1.2 Seasonal dynamics in phytoplankton biomass ..........................................65

3.4.1.3 Seasonal dynamics in the light regime ..................................................66

3.4.1.4 Seasonal dynamics in phosphorus.......................................................... 70

3.4.1.5 Seasonal dynamics in phytoplankton stoichiometry...............................74

3.4.1.6 Seasonal dynamics in growth mediation ................................................77

3.4.2 Spatial dynamics in phosphorus, algal biomass and production ................81

3.4.2.1 Thermal bar mediated phosphorus retention in the nearshore .............81

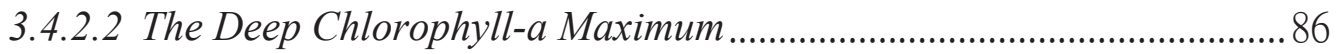

3.4.2.3 Areal primary production ......................................................................93

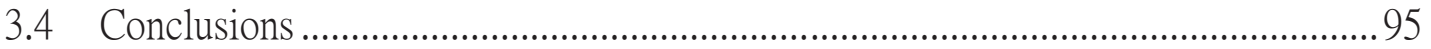

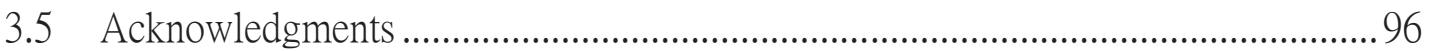

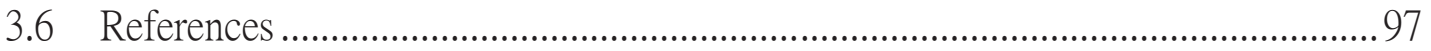

Chapter 4 ......................................................................................................................................... 102

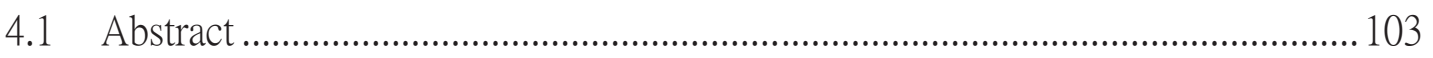

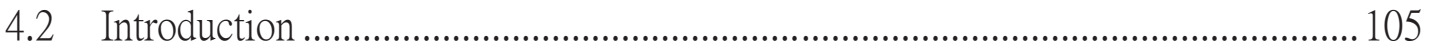

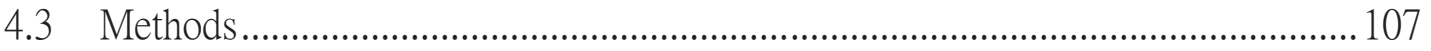

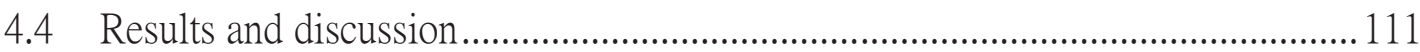

4.4.1 Temporal Dynamics in the surface water ...............................................111

4.4.1.1 Dynamics in climate and thermal regime ...........................................111 
4.4.1.2 Dynamics in phytoplankton biomass.

4.4.1.3 Dynamics in the carbon to chlorophyll-a ratio .................................. 115

4.4.1.4 Dynamics in the light regime ............................................................ 116

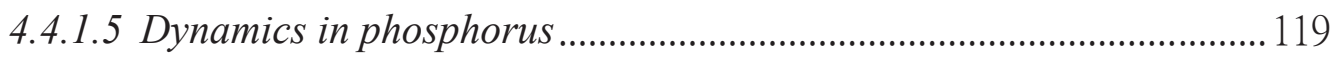

4.4.1.6 Dynamics in the carbon to phosphorus ratio ..................................... 122

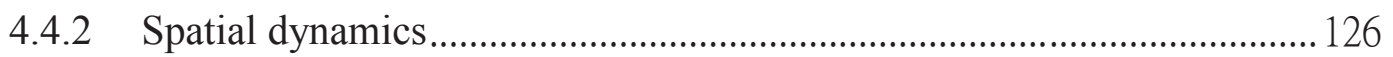

4.4.2.1 Thermal bar dynamics in 2012 and 2014 .......................................... 126

4.4.2.2 Thermal bar mediated phosphorus retention in the nearshore .......... 127

4.4.2.3 The Deep Chlorophyll-a Maximum ................................................... 131

4.4.3 Climatic impacts on water column biomass, forcings and production ... 135

4.4.4 Areal primary production..................................................................... 140

4.4.5 Quality of primary production .......................................................... 142

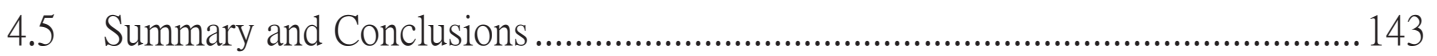

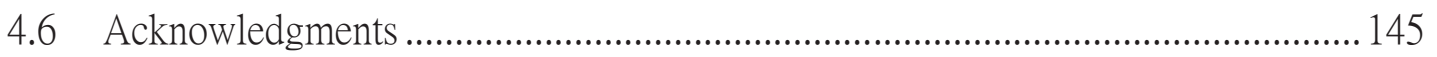

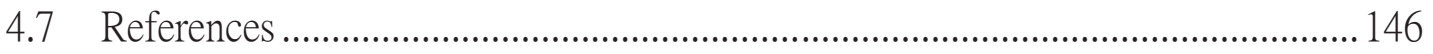

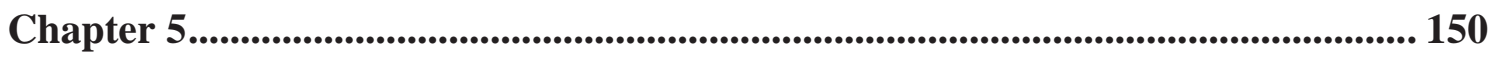

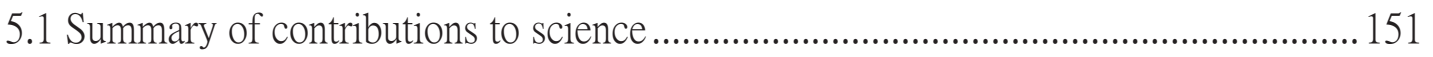

5.2 Recommendations for future work .............................................................. 155

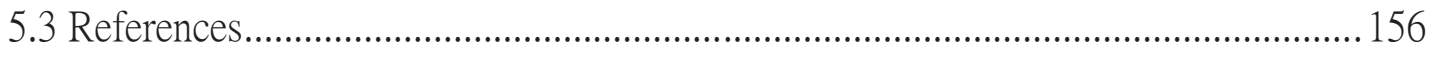

Appendix I: field and lab data ............................................................................. 157 


\section{List of Figures}

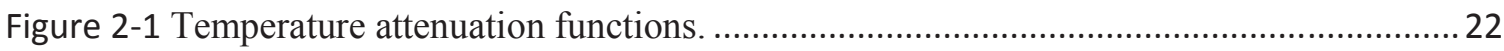

Figure 2-2 Light attenuation functions for Lake Superior. ........................................................... 26

Figure 2-3. Nutrient attenuation function for Lake Superior. ................................................... 29

Figure 2-4 Maximum specific rate of primary production. ..................................................... 31

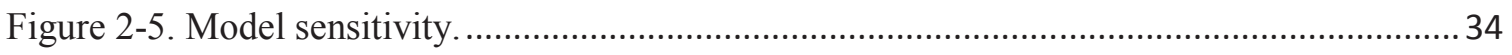

Figure 2-6. Observed versus model derived specific rates of primary production. .......................37

Figure 2-7. Comparison of in-situ measured rates of areal primary production to model derived

rates.

Figure 2-8 Comparison of in-situ measured rates of specific primary production to model

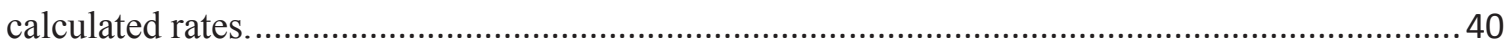

Figure 2-9 Water column dynamics in forcing conditions, biomass and primary production....... 44

Figure 2-10 Areal primary production at EPA's offshore stations in August 1998.......................46

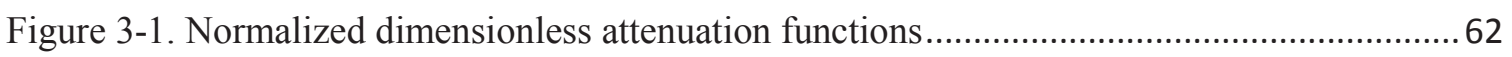

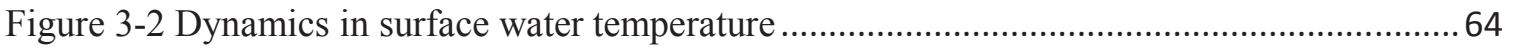

Figure 3-3. Description of nearshore and offshore dynamics in surface water biomass................66

Figure 3-4. Dynamics in nearshore and offshore water transparency........................................69

Figure 3-5. Surface water dynamics in phosphorus constituents............................................. 73

Figure 3-6. Seasonality in the surface water carbon to phosphorus ratio (molar)........................ 76

Figure 3-7. Surface water dynamics in growth limiting factors................................................... 80

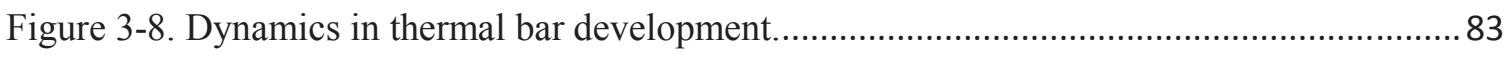

Figure 3-9. Timing of thermal bar formation in relation to the spring runoff event...................... 85

Figure 3-10. Dynamics in the manifestation of the deep chlorophyll-a maximum........................88 
Figure 3-11. Offshore water column dynamics.

Figure 3-12. Seasonality in calculated areal primary production. ............................................... 94

Figure 4-1. Temperature, light and nutrients effects on production ........................................ 110

Figure 4-2. Pattern in lake averaged surface water temperature............................................. 112

Figure 4-3. Dynamics in surface water parameters............................................................ 118

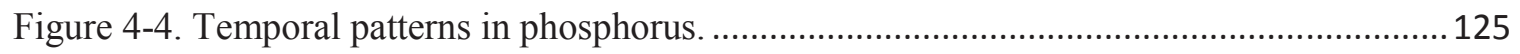

Figure 4-5. Spatiotemporal development of the thermal bar in 2012 and $2014 \ldots \ldots \ldots \ldots \ldots \ldots \ldots \ldots \ldots . . . . . . . . .127$

Figure 4-6. Timing of thermal bar formation in relation to the spring runoff event................... 130

Figure 4-7. Spatiotemporal dynamics in the manifestation of the deep chlorophyll-a maximum

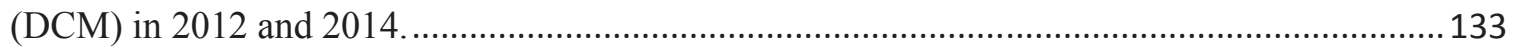

Figure 4-8. Manifestation of the deep chlorophyll-a maximum in 2011, 2012 and 2014...........134

Figure 4-9. Offshore spatiotemporal dynamics in temperature, growth limitation indicated by f(TIN), particulate organic carbon biomass and primary production for 2011, 2012 and 2014. . 137

Figure 4-10. Temporal dynamics in offshore areal primary production in 2011, 2012 and 2014. 


\section{List of Tables}

Table 1. Derived site-specific model kinetics.......................................................................... 32

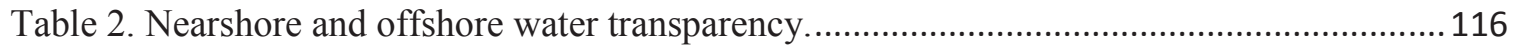

Table 3. Field and lab data for 2011, 2012 and 2014 measured in the nearshore and offshore of

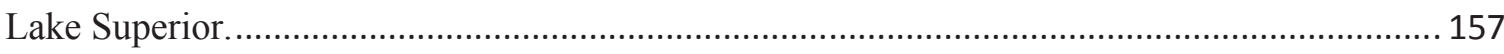




\section{Preface}

The content of this dissertation is nearly (95\%) all my own work; the contribution of my coauthor (M.T. Auer) was in an editorial and advising capacity. 


\section{Acknowledgments}

This dissertation would not have come to fruition without the support of many individuals and I would like to use this opportunity to thank them for their assistance.

First, I am very grateful to Dr. Marty Auer, my advisor. Dr. Auer provided me with the resources and guidance to perform this research and his clear insight and vision has kept me on target. As a true mentor and coach he has helped me reach above and beyond what I thought was possible.

I want to thank my advisory committee: Drs. Nancy Auer, Joe DePinto and Noel Urban for their suggestions and insights, I could not have wished for a more qualified committee to assist me on this journey.

This research greatly benefited from the temperature and light experiments Laura Bub performed on phytoplankton from Lake Superior and the measurements made by PeiFun Siew. I am very grateful for the EPA data I received from Dr. Rick Barbiero (Lake Superior chlorophyll-a and temperature profiles and carbon and phosphorus measurements) and Dr. Peder Yurista (Lake Superior zooplankton profile) and data received from Dr. Robert Sterner (Lake Superior primary production profiles, water temperatures, nutrient concentrations and solar radiation) and Ontonagon River phosphorus loadings to Lake Superior calculated by Dr. Dale Robertson from the USGS.

I would also like to thank Stephen Roblee, Captain of the $R / V$ Agassis, for his vital role in collecting field samples and those that helped out with the sampling, filtration and sample analysis especially, Miles Corcoran, Aaron Dayton, Ben Downer, Anika Kuczynski, Sue Larson, Chuck Ouellette, Varsha Raman and Nate Zgnilec. I am also grateful for the opportunity to reflect on ideas regarding primary production, modeling and kinetics with Dr. Steve Chapra, Dr. Steve Effler, Dr. Cory McDonald and Ed Verhamme. 
It has been a joy to collaborate over the last 5 years with Rasika Gawde, my office partner and research team member. Her positive and cheerful attitude was much appreciated and I am grateful for her friendship.

I am indebted to my parents; Hendrik and Christa, my sister; Valeska, my brother; Govert, and in-laws, Doug and Connie Davis, they have been very supportive of my endeavors and never ceased to assist me in every way possible.

Finally, I want to thank Chris, my wife, Anna-Irene, Mathijs and Thomas, my children, for being part of my life. Their love and support is my greatest blessing and strengthened me when I most needed it. They have travelled with me on this journey and I feel we have reached this milestone together. 


\section{Abstract}

This dissertation supports the modeling of primary production in Lake Superior by offering site specific kinetics and algorithms developed from lab experiments performed on the natural phytoplankton assemblage of Lake Superior. Functions, developed for temperature, light and nutrient conditions and the maximum specific rate of primary production, were incorporated in a 1D specific primary production model and confirmed to published in-situ measured rates of primary production.

An extensive data set (supporting model calibration and confirmation), with a fine spatiotemporal resolution, was developed from field measurements taken bi-weekly during the sampling seasons of 2011, 2012 and 2014; considered to be meteorologically average, extremely warm and cold years, respectively. Samplings were taken at 11 stations along a $26 \mathrm{~km}$ transect extending lakeward from Michigan's Keweenaw Peninsula covering the nearshore to offshore gradient. Measurements included: temperature, solar radiation, transparency, beam attenuation, chlorophyll-a fluorescence, colored dissolved organic matter, suspended solids and phosphorus and carbon constituents. Based on these measurements and application of the developed primary production model, patterns in primary production and driving forces (i.e. temperature, light and nutrients) are described in a seasonal, spatial, and interannual fashion.

The signal feature in 2011 was the development of a mid-summer "desert" in the offshore surface waters (a period of suboptimal temperatures coincident with a high degree of phosphorus limitation). The manifestation of the "summer desert", however, was most extreme during the warm year and nonexistent during the cold year. Offshore primary production in all years manifested a subsurface maximum in the upper area of the metalimnion, distinctly above the deep chlorophyll maximum, with rates of production 
being highest in $2011\left(\sim 20 \mathrm{mg} \mathrm{C} \mathrm{m}^{-3} \mathrm{~d}^{-1}\right)$ followed by $2012\left(\sim 17 \mathrm{mg} \mathrm{Cm}^{-3} \mathrm{~d}^{-1}\right)$ and lowest in $2014\left(\sim 12 \mathrm{mg} \mathrm{Cm}^{-3} \mathrm{~d}^{-1}\right)$. Driven by variances in biomass and forcing conditions, offshore areal primary production manifested differences in seasonal patterns between years as well. In 2011 and 2014 a negatively skewed bell-shape pattern was observed, differing in magnitude and timing. The pattern in 2012 differed from these years in magnitude and timing, manifesting elevated production in April and decreased production in September. Greatest areal production in 2012 occurred in July and August ( $\sim 320 \mathrm{mg}$ $\left.\mathrm{Cm}^{-2} \mathrm{~d}^{-1}\right)$, in 2014 in August $\left(\sim 265 \mathrm{mg} \mathrm{Cm}^{-2} \mathrm{~d}^{-1}\right)$ and in 2011 production was greatest in July (253 $\left.\mathrm{mg} \mathrm{C} \mathrm{m}^{-2} \mathrm{~d}^{-1}\right)$. Areal production in the summer of 1998, calculated for EPA's 19 offshore stations in Lake Superior, manifested comparable rates and averaged $224 \pm$ $90 \mathrm{mg} \mathrm{C} \mathrm{m}{ }^{-2} \cdot \mathrm{d}^{-1}$.

Although in all years the development of the thermal bar (TB) occurred after the spring runoff event, an increase in chlorophyll-a concentration during the presence of the TB was observed in 2012. Rates of primary production during this period, however, decreased while the opposite occurred in 2014, signifying that changes in chlorophyll-a concentration should be interpreted carefully (especially if used to identify spring blooms).

The information presented in this work not only offers site specific kinetics, appropriate algorithms in support of primary production modeling and an extensive dataset supporting model calibration and confirmation, it also offers new insights into the dynamics of the Lake Superior ecosystem and the forces driving its function. 


\section{Chapter 1}

\section{Introduction}

\subsection{Primary Production modeling}

Primary production has received much attention in the last decades for its role in mediating excessive production of $\mathrm{CO} 2$, generally understood to be a driver of climate change. Primary production has also increased in importance due to a shift in focus from a top down to a bottom-up approach by ecosystem management. This increase in prominence requires an equal response in the capacity to determine spatial and temporal dynamics in primary production. Ecosystem models can assist in this area and offer the ability to evaluate "what if" scenarios of management alternatives.

The development of primary production models was facilitated by advancement in digital computing in the 1960s-1970s, allowing for the development of models incorporating multiple processes thus better reflecting observed system dynamics. The emergence of environmental issues stemming from cultural eutrophication prompted the development of mechanistic nutrient-phytoplankton-zooplankton-detritus (NPZD) models (e.g., DiToro et al. 1971 and Canale et al. 1976). This stimulated the development of algorithms and kinetics more accurately describing ecosystem processes (see, for example, the summary given by Bowie et. al. 1985). As computational capacity has advanced further, models have become more complex, i.e. 3-D water quality models are now routinely linked to 3-D hydrodynamic models and applied to the Great Lakes for a range of uses (e.g. Lake Michigan, Chen et al. 2002, Ji et al. 2002; Lake Erie, Leon et al. 2011, DePinto et al. 2000; and Lake Superior, White et al. 2012). 
As our understanding of ecosystem processes expands, incorporation of sophisticated treatment of biokinetics, in an attempt to improve model accuracy, often adds to additional model complexity (Le Quere 2006). Addition of biokinetic algorithms, however, increases the need for "exotic" kinetics, rarely available for most systems. Meanwhile no consensus exists among scientists on how to best describe and parameterize fundamental biological processes such as those representing limitation by light, nutrients and temperature (Tian 2006), Lake Superior included.

\subsection{Ecosystem dynamics in Lake Superior}

Lake Superior is a near pristine ecosystem, close to its native state, especially in regards to its food web structure e.g., native species of fish, benthos and plankton (Auer et al. 2013). Its large volume (i.e. long retention time) and proportionally small and undeveloped watershed have, to date, spared Lake Superior from many of the impacts experienced in the other Great Lakes. However, the lake has suffered and continues to suffer and change due to a number of anthropogenic induced stressors, including trace metal and organic chemical contamination and invasive species (e.g. sea lamprey).

Corrective actions taken by lake managers have met with some success, especially in relation to point sources (e.g. those associated with the paper and mining industries). Although the struggle against the sea lamprey has not been without result, threats from other non-indigenous species (88 non-native aquatic species have been found in Lake Superior, EPA 2009) have not been met with the same rigor. The primary reason for this being that the damage caused by the sea lamprey (i.e. devastation of the fisheries in the early 1960 's; GLFC 2000) was readily apparent to stakeholders. However, the recent and sudden appearance of a suite of ecosystem stressors in the Great Lakes (e.g. decline of Diporeia populations, (Nalepa et al. 2009); threats from Asian carp, (Anderson et 
al. 2015); proliferation of HABs, (Smith et al. 2015) argues for a more systematic and proactive approach to Great Lakes management. Decision makers are challenged in predicting the effects of management actions on Lake Superior as the ecosystem is not only delicate and complex but is also experiencing unprecedented change in the forces that drive its function. For example, perturbations induced by climate change are evidenced by decreasing ice cover, (Assel et al. 2003; Assel 2009) and increasing water temperatures, (Austin and Coleman 2007; 2008) potentially leading to an alteration in the timing of thermal bar formation (Auer and Gatzke 2004), summer stratification and a reduction of annual primary production (Lehman 2002).

In addition to physical/chemical phenomena, several important biologicallydriven phenomena have been recognized as fundamental to understanding ecosystem function in Lake Superior. Among these signals are the deep chlorophyll maximum (Barbiero and Tuchman 2004), the benthic nepheloid layer (BNL; Urban et al. 2004a), heterogeneity in the vertical distribution of zooplankton (Yurista 2009), the distribution of the amphipod Diporeia (Auer et al. 2013) and an inability to balance the carbon budget (Cotner et al. 2004, Urban et al. 2004b 2005, Urban et al. 2009, Sterner 2010).

Descriptions of these dynamics are often limited in either their spatial or temporal resolution, constraining the pool of data required to calibrate and confirm developed ecosystem models. For example, the most complete and representative water quality record for the Lake Superior ecosystem (gathered by Sterner 2011), lacks in spatial and temporal coverage. This lack is caused by the fact that most of the monitoring and much of the research effort has focused on the offshore waters over relatively short and widely spaced intervals (e.g. EPA's sampling of offshore stations 
is limited to one visit in early May and one in mid-August). This, despite the fact that the nearshore has a higher rate of primary production ( $>60 \%$; Auer et al. 2010), is hostto the highest densities of the amphipod Diporeia (Auer et al.2013) and is used by virtually all species of Great Lakes fish during one or more critical life stages (Gamble et al. 2011; Edsall and Charlton 1997).

Ideally model calibration and confirmation are performed with a dataset consisting of sufficient spatiotemporal resolution and system dynamics. Inclusion of dynamics during extreme conditions, representing the boundaries of the system variability, may serve to test the robustness of the model. Observations of ecosystem dynamics during extreme conditions would also benefit our mechanistic understanding of the effects of climate change (Brooks and Zastrow 2002). Such an understanding is much needed as projections of the effects of climate change have been contradictory (cf. White et al. 2012 and Lehman 2002). Unfortunately, due to the inherent unpredictability of extreme events vis-à-vis monitoring programs, few studies have reported on the ecosystem response to such phenomena.

\subsection{Context of the dissertation}

In response to the challenges described above, funding was obtained from the EPA-Great Lakes Research Initiative under project number GL-00E00560/0 by PI and project director Dr. N.A. Auer and co-PI Dr. M.T. Auer. The goal of this project was to develop a linked hydrodynamics-water quality-bioenergetics model to support lake management with predictive capacity regarding ecosystem perturbations (related to climate, nutrients and invasive species). In order to develop this model, an extensive field sampling program was designed to overcome the lack of sufficient spatiotemporal data against which to calibrate and confirm the model. To improve model performance 
it was decided to determine site-specific kinetic algorithms and attendant coefficients for the water quality model segment. These were to be derived from the results ofpreviously conducted experiments on the Lake Superior phytoplankton assemblage (KITES dataset described in Auer and Bub 2004) and confirmed against in-situ measured rates of primary production reported by Sterner (2010).

My personal interest in the Lake Superior ecosystem and the development and application of ecosystem models, especially those pertaining to the mechanistic description of primary production, aligned well with the projects needs especially in regards to the field and lab work and modeling efforts for the water quality segment of the linked model. Prior to the first sampling season the project director offered this opportunity to me, resulting in the following contributions to the GLRI project;

1. The development of site-specific kinetic algorithms and attendant coefficients describing phytoplankton response to environmental forcing conditions (i.e. temperature, light and nutrients);

2. The planning, coordination and execution of an extensive field and lab program to create a dataset with a high spatiotemporal resolution for the purpose of model calibration and confirmation;

3. The parameterization, calibration and confirmation of the water quality model section of the linked model.

Participation in this project has allowed me to develop my skills as a research scientist especially regarding project planning, data collection and data analysis (including collection under adverse conditions related to weather and equipment). It also taught me lab techniques and procedures needed to preserve and analyze field samples (e.g. 
measurement of low dissolved phosphorus concentrations). During this project I also learned to interpret dynamics manifested in the developed dataset and to parameterize, calibrate and confirm a simple 1D and a complex 3D ecosystem model to these dynamics. My contributions to the GLRI project, organized as three manuscripts intended for publication in the peer-reviewed literature, are presented in this work.

\subsection{Outline}

Each of the following chapters examines a component of primary production and modeling thereof in Lake Superior:

- In Chapter 2, algorithms describing primary production are selected, and a series of site specific kinetic coefficients for these algorithms is developed from experiments performed by Laura Bub on the natural phytoplankton assemblage of Lake Superior and measurements made by Pei-Fun Siew (experiments and measurements were conducted and made during the KITES project, see for example Auer and Bub 2004 and Urban et al. 2005). These parameterized algorithms, incorporated in a simple 1D primary production model, were tested using published in-situ measured rates of primary production. The correlation between modeled and measured rates of primary production demonstrated their reliability.

- In Chapter 3, spatiotemporal dynamics in primary production and its driving forces (temperature, light and nutrients) are evaluated for 2011 (meteorologically an average year) using the model developed in Chapter 2. 
Two prominent signals, one observed in the nearshore (thermal bar) and one in the offshore (deep chlorophyll-a maximum) are described as well.

- In Chapter 4, the response of the Lake Superior ecosystem to meteorologically extremely warm (2012) and cold (2014) years is described with a focus on interannual differences in spatiotemporal dynamics of primary production and their driving forces. The description includes the development of the thermal bar in relation to the spring runoff event and its potential to entrain nutrient rich runoff in the nearshore and the dynamics of the deep chlorophyll-a maximum in the offshore.

- In chapter 5 , an overview is presented of the contributions of this work to science and recommendations for future work.

Contributions, described in chapter 2, 3 and 4 of this work satisfy the GLRI project objectives (regarding this topic) and support the long term management of Lake Superior.

\subsection{Funding}

Funding was provided through the EPA-GLRI grant (\#GL-00E00560/0), the Great Lakes Observing System, the NSF funded GK-12 fellowship program and a teaching assistant stipend provided by MTU. 


\subsection{References}

Anderson, K.R., Chapman, D.C., Wynne, T.T., Masagounder, K., Paukert, C.P., 2015. Suitability of Lake Erie for bigheaded carps based on bioenergetic models and remote sensing. Journal of Great Lakes Research.

Assel, R., Cronk, K., Norton, D. 2003. Recent trends in Laurentian Great Lakes ice cover. Climatic Change 57, 185-204.

Assel, R.A. 2009. Contemporary Lake Superior ice cover climatology. Aquatic Ecosystem Health and Management Society, Ecovision World Monograph Series, Canada 51-66.

Auer, M.T., Bub, L.A. 2004. Selected features of the distribution of chlorophyll along the southern shore of Lake Superior. Journal of Great Lakes Research 30: 269284 .

Auer, M.T., Auer, N.A., Urban, N.R., Auer, T. 2013. Distribution of the Amphipod Diporeia in Lake Superior: The Ring of Fire. Journal of Great Lakes Research 39, $33-46$.

Auer, M.T., Auer, N.A., Urban, N.R., Bub, L.A. 2010. Primary production, carbonflux and the distribution of the amphipod Diporeia in Lake Superior. Verh. Internat. Verein. Limnol. 30, 1499-1504.

Auer, M.T., Gatzke, T.L. 2004. The Spring Runoff Event, Thermal Bar Formation, and Cross Margin Transport in Lake Superior. Journal of Great Lakes Research $30,64-81$.

Austin, J., Colman, S. 2008. A century of temperature variability in Lake Superior. Limnology and Oceanography 53, 2724.

Austin, J.A., Colman, S.M. 2007. Lake Superior summer water temperatures are increasing more rapidly than regional air temperatures: A positive ice-albedo feedback. Geophysical Research Letters 34, L06604.

Barbiero, R.P., Tuchman, M.L. 2004. The deep chlorophyll maximum in Lake Superior. Journal of Great Lakes Research 30, 256-268.

Bowie, G. L., Mills, W. B., Porcella, D. B., Campbell, C. L., Pagenkopf, J. R., Rupp, G. L., Johnson, K. M., Chan, P. W., Gherini, S. A., and Chamberlain, C. E. (1985). Rates, constants, and kinetics formulations in surface water quality modeling (second edition). United States Environmental Protection Agency, Athens, GA. EPA/600/3-85/040. 
Brooks, A.S., Zastrow, J.C. 2002. The Potential Influence of Climate Change on Offshore Primary Production in Lake Michigan. Journal of Great Lakes Research 28, 597-607.

Canale, R.P., DePalma, L.M., Vogel, A.H., 1976. A plankton-based food web model for Lake Michigan. Modeling biochemical processes in aquatic ecosystems 3374.

Chen, C., Ji, R., Schwab, D.J., Beletsky, D., Fahnenstiel, G.L., Jiang, M., Johengen, T.H., Vanderploeg, H., Eadie, B., Budd, J.W. 2002. A model study of the coupled biological and physical dynamics in Lake Michigan. Ecological Modelling 152, $145-168$.

Cotner, J.B., Biddanda, B.A., Makino, W., Stets, E. 2004. Organic carbon biogeochemistry of Lake Superior. Aquatic Ecosystem Health \& Management 7, $451-464$.

DePinto, J.V., Bierman Jr, V.J., Feist, T.J., Kaur, J. 2000. Conceptualization of an aquatic ecosystem model for integrated management of Lake Erie. Ann Arbor $1001,48108$.

Di Toro, D.M., O’Connor, D.J., Thomann, R.V., 1971. A dynamic model of the phytoplankton population in the Sacramento San Joaquin Delta. Adv. Chem. Ser $106,131-180$.

Edsall, T.A., Charlton, M.N., 1997. Nearshore waters of the Great Lakes. Environment Canada.

EPA, The Lake Superior Work Group 2009. Lake Superior Aquatic Invasive Species Complete Prevention Plan (Draft). Binational Program.

Gamble, A.E., Hrabik, T.R., Yule, D.L., Stockwell, J.D., 2011. Trophic connections in Lake Superior Part II: the nearshore fish community. Journal of Great Lakes Research 37, 550-560.

GLFC 2000. SEA LAMPREY A Great Lakes Invader; fact sheet 3.

Ji, R., Chen, C., Budd, J.W., Schwab, D.J., Beletsky, D., Fahnenstiel, G.L., Johengen, T.H., Vanderploeg, H., Eadie, B., Cotner, J. 2002. Influences of suspended sediments on the ecosystem in Lake Michigan: a 3-D coupled bio-physical modeling experiment. Ecological modelling 152, 169-190.

Lehman, J.T. 2002. Mixing patterns and plankton biomass of the St. Lawrence Great Lakes under climate change scenarios. Journal of Great Lakes Research 28, $583-$ 596. 
Leon, L.F., Smith, R.E.H., Hipsey, M.R., Bocaniov, S.A., Higgins, S.N., Hecky, R.E., Antenucci, J.P., Imberger, J.A., Guildford, S.J. 2011. Application of a 3D hydrodynamic-biological model for seasonal and spatial dynamics of water quality and phytoplankton in Lake Erie. Journal of Great Lakes Research 37, 4153.

Nalepa, T.F., Fanslow, D.L., Lang, G.A. 2009. Transformation of the offshore benthic community in Lake Michigan: recent shift from the native amphipod Diporeia spp. to the invasive mussel Dreissena rostriformis bugensis. Freshwater Biology 54, 466-479.

Quere, C.L. 2006. Reply to Horizons Article "Plankton functional type modelling: running before we can walk"Anderson (2005): I. Abrupt changes in marine ecosystems? Journal of Plankton Research 28, 871-872.

Smith, D.R., King, K.W., Williams, M.R., 2015. What is causing the harmful algal blooms in Lake Erie? Journal of Soil and Water Conservation 70, 27A-29A.

Sterner, R.W. 2010. In situ-measured primary production in Lake Superior. Journal of Great Lakes Research 36, 139-149.

Sterner, R.W. 2011. C: N: P stoichiometry in Lake Superior: Freshwater sea as end member. Inland Waters 1, 29-46.

Sterner, R.W., Anagnostou, E., Brovold, S., Bullerjahn, G.S., Finlay, J.C., Kumar, S., McKay, R.M.L., Sherrell, R.M. 2007. Increasing stoichiometric imbalance in North America's largest lake: Nitrification in Lake Superior. Geophysical research letters 34, L10406.

Tian, R.C. 2006. Toward standard parameterizations in marine biological modeling. Ecological Modelling 193, 363-386. doi:10.1016/j.ecolmodel.2005.09.003

Urban, N.R., Auer, M.T., Green, S.A., Lu, X., Apul, D.S., Powell, K.D., Bub, L. 2005. Carbon cycling in Lake Superior. J. Geophys. Res. 110, 17 PP.

Urban, Noel R., Jeong, J., Chai, Y. 2004a. The Benthic Nepheloid Layer (BNL) North of the Keweenaw Peninsula in Lake Superior: Composition, Dynamics, and Role in Sediment Transport. Journal of Great Lakes Research 30, 133-146.

Urban, N. R., Lu, X., Chai, Y., Apul, D.S. 2004b. Sediment trap studies in Lake Superior: Insights into resuspension, cross-margin transport, and carbon cycling. Journal of Great Lakes Research 30, 147-161. 
Urban, N.R., Munawar, M., Munawar, I.F. 2009. Nutrient cycling in Lake Superior: a retrospective and update. State of Lake Superior. New Delhi (India): Goodword Books 83-115.

White, B., Austin, J., Matsumoto, K. 2012. A three-dimensional model of Lake Superior with ice and biogeochemistry. Journal of Great Lakes Research 38, 6171.

Yurista, P.M., Kelly, J.R., Miller, S.E. 2009. Lake Superior zooplankton biomass: Alternate estimates from a probability-based net survey and spatially extensive LOPC surveys. Journal of Great Lakes Research 35, 337-346. 


\section{Chapter 2}

\section{Development and application of site- specific kinetics supporting primary production modeling in Lake Superior}

The man who moves a mountain begins by carrying away small stones.

Confucius (551-479 BC)

In preparation for submission to the Journal of Ecological Modeling. 


\subsection{Abstract}

Primary production modeling is generally plagued by a lack of system specific kinetic parameters and algorithms necessitating the application of system foreign kinetics, reducing the ability to test the suitability of the applied conceptual framework. Here, based on lab experiments performed on the natural phytoplankton assemblage of Lake Superior, site-specific primary production kinetics are developed. These consist of normalized $(0 \rightarrow 1)$ attenuation functions for temperature, light and nutrient conditions and the maximum specific rate of primary production. The selected algorithms and parameter values are confirmed to an independent data set, replicating in-situ measured rates with a good correlation $\left(r^{2}=0.85\right.$, P-value $\left.<0.001\right)$.

Application of the model developed in this work to EPA measurements made at 19 Lake Superior stations in August of 1998 indicates that on average a subsurface production maximum is manifested at a depth of $\sim 20 \mathrm{~m}$ with production rates of $11.8 \mathrm{mg} \mathrm{C} \mathrm{m}^{-3} \cdot \mathrm{d}^{-1}$. Integration of calculated primary production in the water column for the individual stations yields a range of $130-468 \mathrm{mg} \mathrm{C} \mathrm{m}^{-2} \cdot \mathrm{d}^{-1}$, averaging $224 \pm 90 \mathrm{mg} \mathrm{C} \mathrm{m}^{-2} \cdot \mathrm{d}^{-1}$ and indicates that offshore production is not as homogeneous as is often assumed.

Keywords: Lake Superior, kinetics, primary production, model parameterization 


\subsection{Introduction}

The application of coupled 3D hydrodynamic-water quality models has greatly increased in the Great Lakes. These models have the advantage that they can, once they are developed, answer complex research and management questions. In practice, a generic model containing an elaborate conceptual framework is selected and adapted to the specific environmental system at hand. The absence of site-specific science in conjunction with the high cost associated with alterations to the program leaves the conceptual framework uncontested. Tailoring of the model to the local ecosystem remains therefore generally limited to the selection and tuning of its kinetic parameters. Selection of kinetic coefficients, however, can be challenging especially when site specific information regarding key parameters is not available.

The body of algorithms and kinetic coefficients, required for the determination of primary production, is not well developed for Lake Superior. This forces modelers, working in this system, to apply kinetics that are unconfirmed for the studied system. For example, one-third of the 20 ecosystem model parameters applied by McDonald et al. (2012) were adopted from Bowie et al. (1985), a collection of freshwater kinetics of varying pedigree.

The lack of site-specific model kinetics is not new, but rather echoes through the ages. For example, the maximum phytoplankton growth rate used by White and Matsumoto (2012) in their Lake Superior model was adopted from that applied in the Lake Michigan model developed by Chen et al. (2002). This (single) value was derived from a range of maximum specific rates of primary production developed by Scavia et al. (1988) and others referenced to Bierman and Dolan (1981). The ranges established by Scavia et al. (1988) 
(three phytoplankton classes: diatoms, flagellates and cyanobacteria) for their Lake Michigan model are, in turn, based on rates of maximum specific primary production experimentally derived by Reynolds et al. (1982; flagellates, Blelham Tarn, England), Tilman et al. (1982 references therein; diatoms and cyanobacteria, Lake Michigan, Lake Norrviken, Sweden, Lake Windermere, England and Lake Ohrid, Macedonia-Albania), Reynolds (1984a 1984b; diatoms, flagellates and cyanobacteria, wide selection of temperate lakes) and Sommer (1983; diatoms and flagellates, Lake Constance, GermanySwitzerland-Austria). This cultivation of a model coefficient, proceeding through four generations, results in a value lying far distant from its basis in science and may lead to adaptation of kinetics uncharacteristic of the studied system.

Once kinetic coefficients are selected they are adjusted (tuned) to optimize model fit to field observations. Guidance is available for performing such optimizations (Fennel et al. 2001; McDonald et al. 2012; Jarabi 2013) and a satisfactory fit is often obtained at which point the applied kinetics are deemed suitable. However, a good fit to data does not necessarily mean that the model is correctly conceptualized and/or parameterized, i.e. models can yield a good fit for the wrong reasons (Oreskes et al. 1994). That is, discrepancies between field observations and model predictions may stem from inadequacy in conceptualization or from poor coefficient selection (Kawamiya 2002).

Incorporation of site-specific kinetics limits the need for coefficient tuning, making manifest the suitability of the conceptual framework. For example, a zero-degree of freedom phosphorus model (Auer et al. 1997), developed solely with site-specific coefficient values, performed well with tuning limited to the statistical uncertainty associated with coefficient determination. Site-specific treatment of kinetics thus supports 
confirmation of the conceptual framework and improves confidence in model performance.

Here, we present algorithms and kinetic coefficients pertaining to primary production (i.e. temperature, light and nutrient limitation and the maximum growth rate), derived from lab experiments on the natural phytoplankton assemblage of Lake Superior. Resulting kinetics are then confirmed to an independent data set of $i n$-situ measured rates of primary production. This work concludes with an application of the developed sitespecific information to evaluate spatial heterogeneity in summer offshore primary production in Lake Superior. 


\subsection{Methods}

The derivation of site-specific kinetics for Lake Superior is based on monitoring and experimentation conducted during the NSF-sponsored KITES project (Bub 2001, Siew 2003 and Auer and Bub 2004). Their sampling was performed along three transects extending lakeward from Michigan's Keweenaw Peninsula at Ontonagon, Houghton and Eagle Harbor. Methods for sample collection, analysis for soluble reactive and particulate phosphorus and particulate organic carbon and characterization of drivers for production (light, temperature and nutrients) are described below.

Temperature response - chlorophyll-a specific rates of primary production were measured by $\mathrm{C}^{14}$ uptake experiments (Wetzel and Likens 1991) on samples collected at HN210 (Houghton North transect 21 km offshore) on 4 April, 22 June, 30 July, 1 and 25 August, 27 Sep and 20 October 2000. Measurements were made at four to eight temperatures ranging from $2-20{ }^{\circ} \mathrm{C}$ and under saturating light conditions $(600 \mu \mathrm{mol}$ $\mathrm{m}^{-2} \cdot \mathrm{s}^{-1)}$.

Light response - light, in this application, refers to photosynthetically active solar radiation $\left(\mathrm{PAR}, \mu \mathrm{mol} \mathrm{m} \mathrm{m}^{-2} \cdot \mathrm{s}^{-1}\right)$. Chlorophyll-a specific rates of carbon assimilation were measured at 20-25 light levels ranging from 0 to $1200 \mu \mathrm{mol} \mathrm{m}{ }^{-2} \cdot \mathrm{s}^{-1}$ using the $\mathrm{C}^{14}$ uptake method (Wetzel and Likens 1991). The short incubation period (8 hrs) applied here measures net primary production (Peterson 1980); references to primary production in the remainder of this work therefore represent net rates. Experiments were conducted at ambient temperatures on samples obtained from a location considered representative of offshore conditions (Houghton transect, $21 \mathrm{~km}$ offshore, depth of $157 \mathrm{~m}$; Auer et al. 2010a). Samples were collected on 30 July, 25 August and 27 September of 2000 at the 
surface $(0 \mathrm{~m})$ and at a depth $(30 \mathrm{~m})$ approximating the $1 \%$ light level. Sample holding times were minimized to insure that cell physiology (e.g. C:P ratios) were representative of those at collection.

Nutrient response - variation in primary production, measured by $\mathrm{C}^{14}$ uptake (Wetzel and Likens 1991), with changes in nutrient status (phosphorus, Sterner et al. 2004) was quantified for a range of algal C:P ratios. Surface water samples were collected (by Bub, 2001) from May 1999 to September 2000 at stations located 9 to $21 \mathrm{~km}$ offshore (station depth $>140 \mathrm{~m}$ ) along all three transects. Paired measurements of particulate organic carbon and particulate phosphorus and chlorophyll-a were made to determine algal nutrient status (as seston C:P ratio) and carbon to chlorophyll-a ratios (as seston C:Chl), respectively. Samples for carbon analysis were filtered immediately on board on precombusted $0.7 \mu \mathrm{m}$ Binder-Free Glass Microfiber GF/F type filters and measured following the procedure described in Urban et al. (2005). Samples for particulate phosphorus were immediately filtered on board on $0.45 \mu \mathrm{m}$ cellulose acetate filters and analyzed according to the GLNPO standard operating procedure LG209 (EPA 2010). 


\subsection{Results}

\subsubsection{Algorithm Selection and Parameterization}

Mathematical models incorporating calculation of primary production commonly adopt a framework where primary production is calculated as the product of algal standing crop and a maximum specific rate of primary production attenuated by the rate-mediating effects of light, temperature and nutrient availability (Chapra 2008),

$$
P=\quad \mu_{\max } \cdot f(T) \cdot f(I) \cdot f(N) \cdot P O C \quad \text { Equation } 1 .
$$

where:

$$
\begin{array}{lll}
P= & \text { rate of primary production } & \mathrm{mg} \mathrm{C} \mathrm{m}^{-3} \mathrm{~d}^{-1} \\
\mu_{\text {max }}= & \text { maximum specific rate of primary production } & \mathrm{d}^{-1} \\
f(T)= & \text { attenuation function for temperature } & \text { dimensionless (0 to 1) } \\
f(I)= & \text { attenuation function for light }(\mathrm{PAR}) & \text { dimensionless }(0 \text { to } 1) \\
f(N)=\text { attenuation function for nutrient conditions } & \text { dimensionless (0 to } 1) \\
P O C=\text { particulate organic carbon concentration } & \mathrm{mg} \mathrm{C} \mathrm{m}^{-3}
\end{array}
$$

This calculation includes a state variable which may be directly measured (POC), a biokinetic coefficient for which widely-varying values have been reported $\left.\mu_{\max }\right)$ and three algorithms or functions ( $f$, with attendant biokinetic coefficients) describing the relationship between environmental forcing conditions and production. A variety of options are available for each of the functions, often making comparison of models and the exchange of kinetic coefficients difficult (Tian 2006). Here, an effort is made to assemble a select set of functions for application to Lake Superior which includes those that are commonly applied in modeling exercises and that are parsimonious in their demand for biokinetic coefficients. No co-variance is assumed to occur among the temperature, light and nutrient functions and each is given an equal weight by normalizing them over a range 
of zero to one with zero representing complete limitation and one representing no limitation. Development of the temperature, nutrient and light functions, and subsequent estimation of the maximum specific rate of primary production, are presented below.

\subsubsection{Temperature}

Temperature effects on primary production may be described by a concave function passing through a maximum rate at an optimum temperature. Such behavior is well described by a function developed by Cerco and Cole (1994).

$$
\begin{gathered}
f(T)=\quad \text { Equation } 2 . \\
e_{T}^{-\gamma_{T}\left(T-T_{o p t}\right)^{2}} \text { where } \\
\gamma_{T 1} \text { if } T \leq T_{o p t} \text { or } \gamma_{T}=\gamma_{T 2} \text { if } T>T_{o p t}
\end{gathered}
$$

where:

$\begin{array}{lll}\gamma_{T 1}= & \text { fitting parameter }\left(\text { below } \mathrm{T}_{\mathrm{opt}}\right) & \text { dimensionless } \\ \gamma_{T 2}= & \text { fitting parameter }\left(\text { above } \mathrm{T}_{\mathrm{opt}}\right) & \text { dimensionless } \\ T= & \text { temperature at depth } \mathrm{z} & { }^{\circ} \mathrm{C} \\ T_{\text {opt }}= & \text { optimum production temperature } & { }^{\circ} \mathrm{C}\end{array}$

This equation is similar to the function developed by Lancelot et al. (2002) as recommended by Tian (2006) but is able to accommodate differences in the temperature response above and below the optimum, i.e. here $\gamma_{T 1}$ governs the slope of the ascending limb and $\gamma_{T 2}$ that of the descending limb.

Chlorophyll-a specific primary production was measured over a range of temperatures on surface water samples collected in early and late spring, summer and fall 2000. These results were normalized by dividing by the maximum rate measured in each sampling period to obtain dimensionless coefficients ranging between $0 \rightarrow 1$. No significant 
difference in the temperature responses was noted between summer and fall assemblages or between early and late spring assemblages $(p>0.05)$. Observations were therefore pooled to obtain two temperature response functions, one representing phytoplankton adapted to cold water, i.e. spring conditions, and one for those adapted to warm temperatures, i.e. summer and fall conditions. Normalized, pooled data were fit to the function of Cerco and Cole (1994; Equation 2) to yield values for: $\gamma_{T_{1}}, \gamma_{T_{2}}$ and $\mathrm{T}_{\mathrm{opt}}$ (Fig. 2-1a and b; Table 1).

Temperatures in the hypolimnion during summer are similar to those observed at the surface in spring. Here we assume that the temperature response of the summer hypolimnetic assemblage is equivalent to that of surface waters in spring, i.e. the phytoplankton communities are similarly cold-water adapted. The cold water assemblage manifests a stronger response to changes in temperature below the optimum than above (larger $\gamma_{T 1, \text { cold }}$ ) while the community adapted to warmer temperatures manifests a more balanced response to departures from the optimum in either direction (Fig. 2-1a and 2-1b).

A winter temperature function was developed by direct model calibration (as discussed in the model confirmation section) to Sterner's (2010) April data set. The resulting winter temperature function (Fig. 2-1c) has a steep ascending limb similar to the cold water function and, as expected, a lower optimum temperature $\left(4.1^{\circ} \mathrm{C}\right.$; Table $\left.2-1\right)$. This function falls within expected ranges and coincides with three experimentally derived rates measured at 2,10 and $15^{\circ} \mathrm{C}$ on an assemblage adapted to winter temperatures $\left(\sim 2.5^{\circ} \mathrm{C}\right)$ 


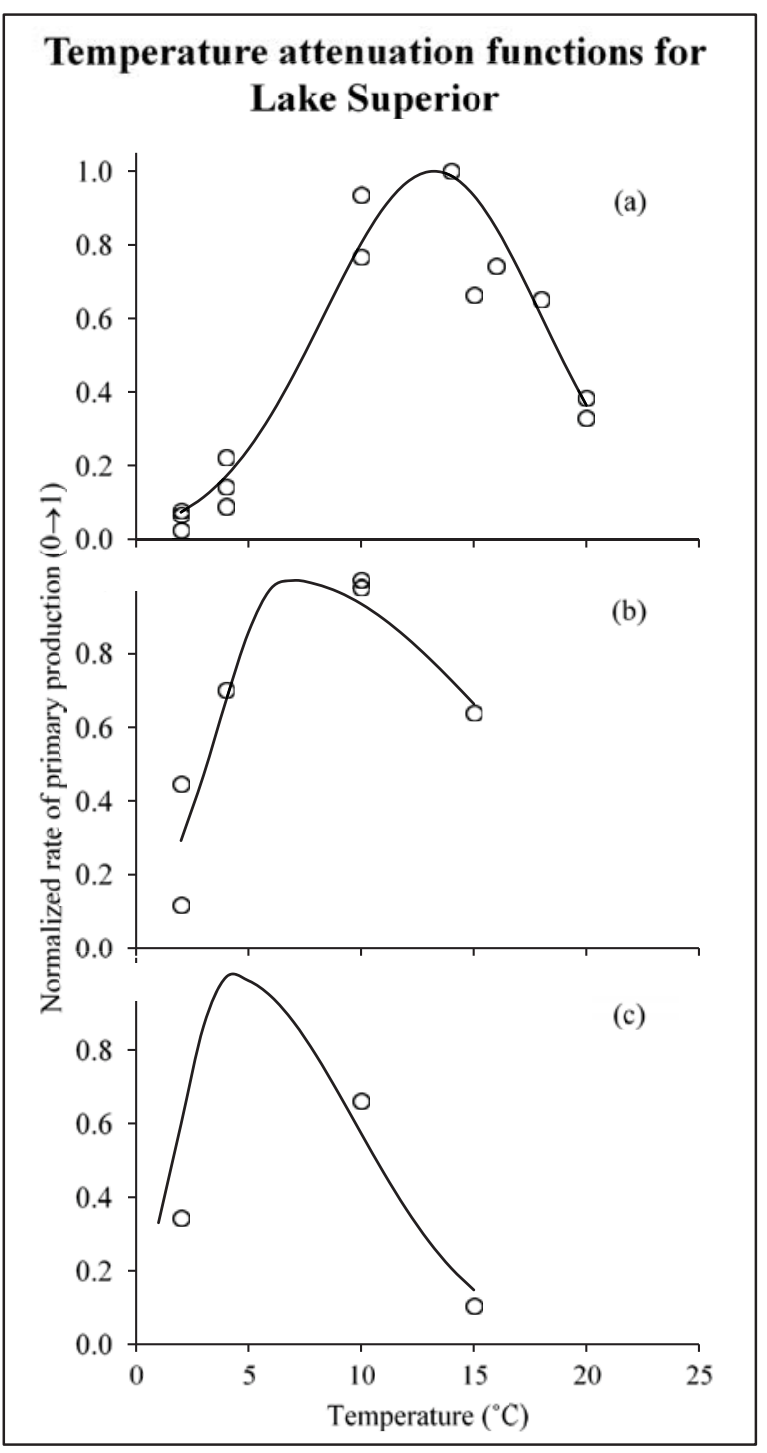

Figure 2-1 Temperature attenuation functions.

These functions are normalized to range between zero and one for algal assemblages adapted to different temperature conditions as represented by the solid line. The open circles represent the observed normalized specific rates of primary production measured under various temperatures. Panel a represents the assemblage adapted to warm water conditions, panel $b$ the cold water adapted assemblage and panel $c$ the assemblage adapted to winter temperatures. The winter temperature function was derived through direct calibration to in-situ measured rates (April; Sterner 2010). 


\subsubsection{Light (PAR)}

The relationship between phytoplankton production and light intensity is well described by the function of Platt et al. (1980) and this function has been recommended for use in biokinetic modeling by Tian (2006) based on its functionality, flexibility and reliability.

$$
P^{B}=\quad P_{S}^{B} \cdot\left(1-e^{\frac{-\alpha \cdot I}{P_{S}^{B}}}\right) \cdot e^{\frac{-\beta \cdot I}{P_{S}^{B}}} \quad \text { Equation 3a. }
$$

where:

$$
\begin{array}{lll}
P^{B}= & \begin{array}{l}
\text { Chlorophyll-a specific rate of primary } \\
\text { production }
\end{array} & \mathrm{mg} \mathrm{C} \mathrm{\mu gChl} l^{-1} \cdot \mathrm{d}^{-1} \\
P_{S}^{B}= & \begin{array}{l}
\text { maximum chlorophyll-a specific rate } \\
\text { of primary production }
\end{array} & \mathrm{mg} \mathrm{C} \mu \mathrm{gChl}^{-1} \cdot \mathrm{d}^{-1} \\
\alpha= & \text { fitting parameter }- \text { ascending limb } & \mathrm{mg} \mathrm{C} \mathrm{mg} \mathrm{Chl} l^{-1} \cdot \mathrm{d}^{-1} \cdot\left(\mu \mathrm{mol} \mathrm{m} \mathrm{m}^{-2} \cdot \mathrm{s}^{-1}\right)^{-1} \\
\beta= & \text { fitting parameter }- \text { descending limb } & \mathrm{mg} \mathrm{C} \mathrm{mg} \mathrm{Chl} l^{-1} \cdot \mathrm{d}^{-1} \cdot\left(\mu \mathrm{mol} \mathrm{m} \mathrm{m}^{-2} \cdot \mathrm{s}^{-1}\right)^{-1} \\
I= & \text { light (PAR) } & \mu \mathrm{mol} \mathrm{m}^{-2} \cdot \mathrm{s}^{-1}
\end{array}
$$

This function takes the form of a rectangular hyperbola characterized by a scaling parameter $\left(P_{s}^{B}\right)$ determining the maximum specific rate of primary production and ascending $(\alpha)$ and descending $(\beta)$ limbs with slopes reflecting the production rate response for $\mathrm{I}<\mathrm{I}_{\mathrm{opt}}$ and $\mathrm{I}>\mathrm{I}_{\mathrm{opt}}$, respectively.

In this study, light response curves were developed for three dates over the JulySeptember interval of 2000 (by Bub, 2001) using samples collected at the surface and compensation depth. Fitting coefficients were derived through a two-step process. First, measured chlorophyll-a specific primary production rates were fit to the Platt function 
(Equation 3a) and then normalized to the curve maximum. Normalization transforms these rates to dimensionless coefficients ranging from $0 \rightarrow 1$. This permits comparison of the light response for experiments having different rate maxima due to differences in nutrient condition and/or ambient temperature. Next, the normalized results were fit to Equation $3 b$ (as derived from the previously described Platt function where normalization has changed dimensions for the parameters as indicated by an $\sim$ ).

$$
\begin{aligned}
& f(I)=\quad P_{s}^{\tilde{B}} \cdot\left(1-e^{\frac{-\widetilde{\alpha} \cdot I}{P_{S}^{\tilde{B}}}}\right) \cdot e^{\frac{-\widetilde{\widetilde{\beta}} \cdot I}{P_{S}^{\tilde{B}}}} \quad \text { Equation } 3 \mathrm{~b} . \\
& \text { where: } \quad \text { : Indicates a normalized parameter } \\
& P_{S}^{\tilde{B}}=\quad \text { fitting parameter dimensionless } \\
& \tilde{\alpha}_{\text {surf }}=\quad \text { fitting parameter }- \text { ascending limb }(0 \mathrm{~m}) \quad\left(\mu \mathrm{mol} \mathrm{m} \mathrm{m}^{-2} \cdot \mathrm{s}^{-1}\right)^{-1} \\
& \tilde{\beta}_{\text {surf }}=\quad \text { fitting parameter }- \text { descending limb }(0 \mathrm{~m}) \quad\left(\mu \mathrm{mol} \mathrm{m} \mathrm{m}^{-2} \cdot \mathrm{s}^{-1}\right)^{-1} \\
& \tilde{\alpha}_{\text {comp }}=\text { fitting parameter }- \text { ascending limb }(30 \mathrm{~m}) \quad\left(\mu \mathrm{mol} \mathrm{m} \mathrm{m}^{-2} \cdot \mathrm{s}^{-1}\right)^{-1} \\
& \tilde{\beta}_{\text {comp }}=\text { fitting parameter }- \text { descending limb }(30 \mathrm{~m}) \quad\left(\mu \mathrm{mol} \mathrm{m} \mathrm{m}^{-2} \cdot \mathrm{s}^{-1}\right)^{-1} \\
& I=\quad \operatorname{light}(\mathrm{PAR}) \quad \mu \mathrm{mol} \mathrm{m}^{-2} \cdot \mathrm{s}^{-1}
\end{aligned}
$$

Derived $P_{s}^{\tilde{B}}$ values (in Equation 3b) for the surface and deep assemblage were not significantly different $(p>0.05)$, permitting the application of a single (average) $P_{s}^{\tilde{B}}$ value to all light response functions. Parameter values for $\tilde{\alpha}$ and $\tilde{\beta}$ were also determined, differences in which resulted in two distinctly different families of light response curves, one representing the surface and one the deep assemblage (Fig. 2-2a, b and c). Averaging $\tilde{\alpha}$ and $\tilde{\beta}$ values within these families yielded only a small $(<4 \%)$ increase in the coefficient 
of variation of the RMSE (CV[RMSE]) as compared with those derived on an experimentspecific basis. This analysis thus results in a single value of $P_{S}^{\tilde{B}}$ and ass emblage-specific (surface and deep) values for $\alpha \sim$ and $\beta$, a total of five coefficients characterizing the light response at the boundaries of the photic zone (Fig. 2-2d; Table 1). 


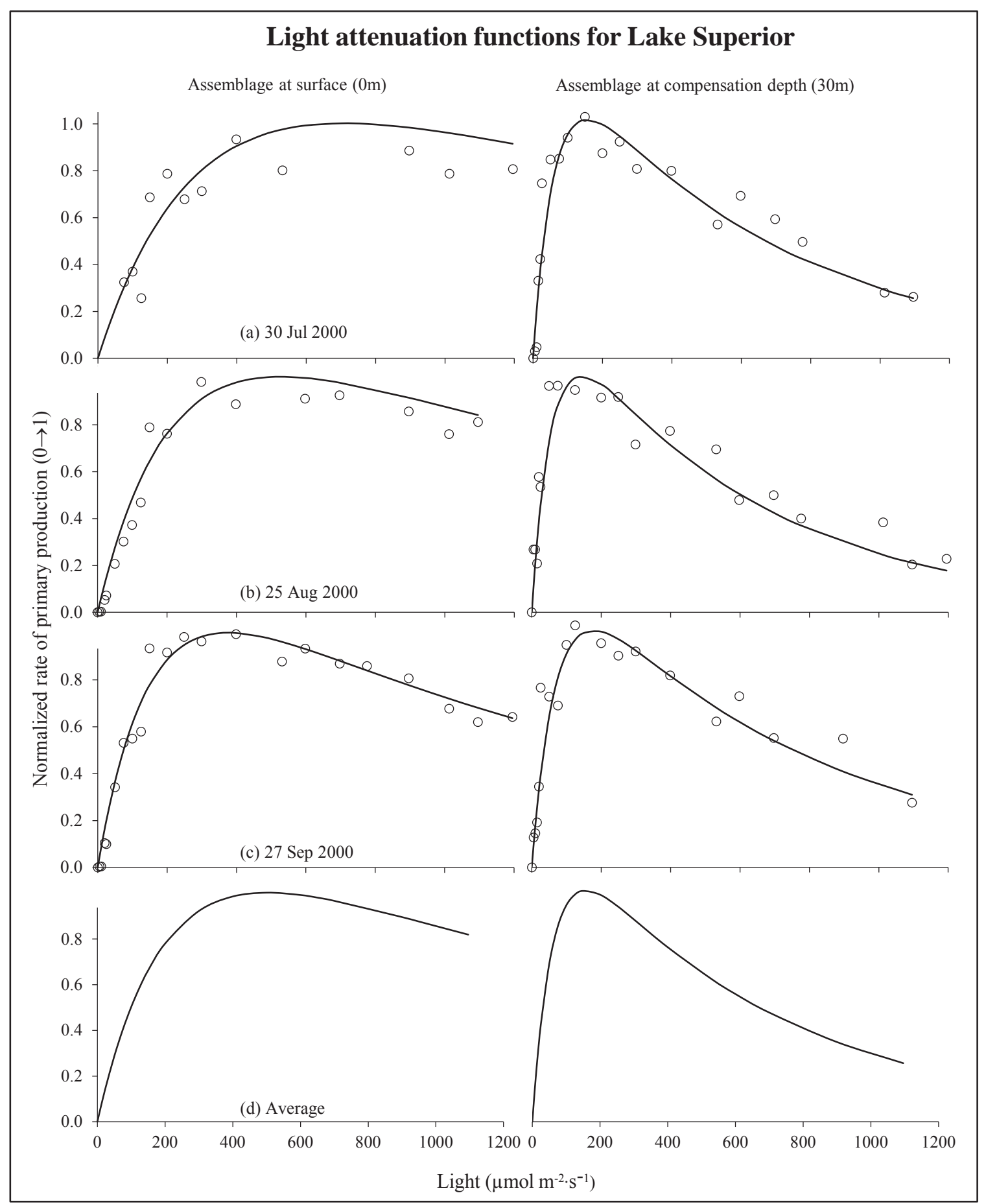

Figure 2-2 Light attenuation functions for Lake Superior.

Panels $a, b$ and $c$ display the relationship between photosynthetically available radiation and phytoplankton growth rate at the surface $(0 \mathrm{~m}$, shown on left side) and for a depth of 30 (shown on right side). Panel d depict the average functions for the assemblages at $0 \mathrm{~m}$ and $30 \mathrm{~m}$ depth. 


\subsubsection{Nutrients}

Traditionally attenuation of algal production due to sub-optimal nutrient conditions is simulated by application of Monod-based functions where the specific rate of primary production varies with the dissolved concentration of the limiting nutrient. These functions have been applied for decades in marine and fresh water models including those recently developed for Lake Superior (Bennington et al. 2012; McDonald et al. 2012 and White et al. 2012). Application of Monod kinetics to oligotrophic, freshwater systems such as Lake Superior is problematic. The concentration of phosphorus (the limiting nutrient; Sterner et al. 2004), represents environmental forcing in the Monod function and is largely invariant, regularly falling below the detection limit. Yet, the nutrient status of the assemblage (C:P ratio) varies dramatically in Lake Superior (Sterner 2011). Flynn (2010) recognized the inability of Monod-type functions to accommodate variable stoichiometry and recommended that modelers update their frameworks to include this important concept.

An expression describing the effects of nutrient limitation, based on variable stoichiometry, was developed by Droop (1974). A comparison of this model to Monod kinetics was made by Sommer (1991) and more recently by Cerucci et al. (2010) and in both cases Droop kinetics captured observed phytoplankton dynamics better. Although not (yet) commonly used, Droop kinetics have been successfully applied in a variety of ecosystem models (e.g. Bierman and Dolan 1981; those referenced by Tian 2006 and Auer et al. 2010b) and are applied here using the molar C:P ratio to represent the algal nutrient status: 


$$
\begin{aligned}
& f(N)=\quad 1-\left(\frac{C: P}{C: P_{\max }}\right) \quad \text { Equation } 4 . \\
& C: P_{\text {max }}=\text { maximum } \mathrm{C}: \mathrm{P} \text { ratio }(\mathrm{P} \text { starved }) \quad \text { mole } \mathrm{C} \text { mole } \mathrm{P}^{-1} \\
& C: P=\quad \text { algal nutrient condition mole } \mathrm{C} \text { mole } \mathrm{P}^{-1}
\end{aligned}
$$

In the spirit of the Droop model, production is zero at $\mathrm{C}: \mathrm{P}_{\max }$ and increases as nutrient status improves (C:P declines) and asymptotically approaches the maximum rate with further improvement in nutrient status.

Chlorophyll-a specific primary production rates, measured at ambient temperature and nutrient conditions, were standardized for temperature and normalized to the highest observed specific rate of primary production transforming these rates into dimensionless coefficients ranging from $0 \rightarrow 1$. The data were then fit to the Droop function to yield the minimum molar based cell quota (Fig 3; Table 1). The observed scatter in data may have been caused by differences in species composition and/or antecedent (light) conditions for individual samples as these were taken at multiple offshore locations off the Keweenaw Peninsula over a two year period thus spanning multiple seasons and mixing conditions. More sophisticated models have been developed since the introduction of the Droop model in the early seventies and have shown their merit especially in nitrogen limited systems (see Flynn 2008b and 2010). Application of the more complex ${ }^{\mathrm{n}} \mathrm{Quota}$ model developed by Flynn (2008 a, b) in this phosphorus limited system resulted in a small (4\%) reduction in CV(RMSE), thus not justifying the introduction of two additional fitting parameters. 


\section{Nutrient attenuation function for Lake Superior}

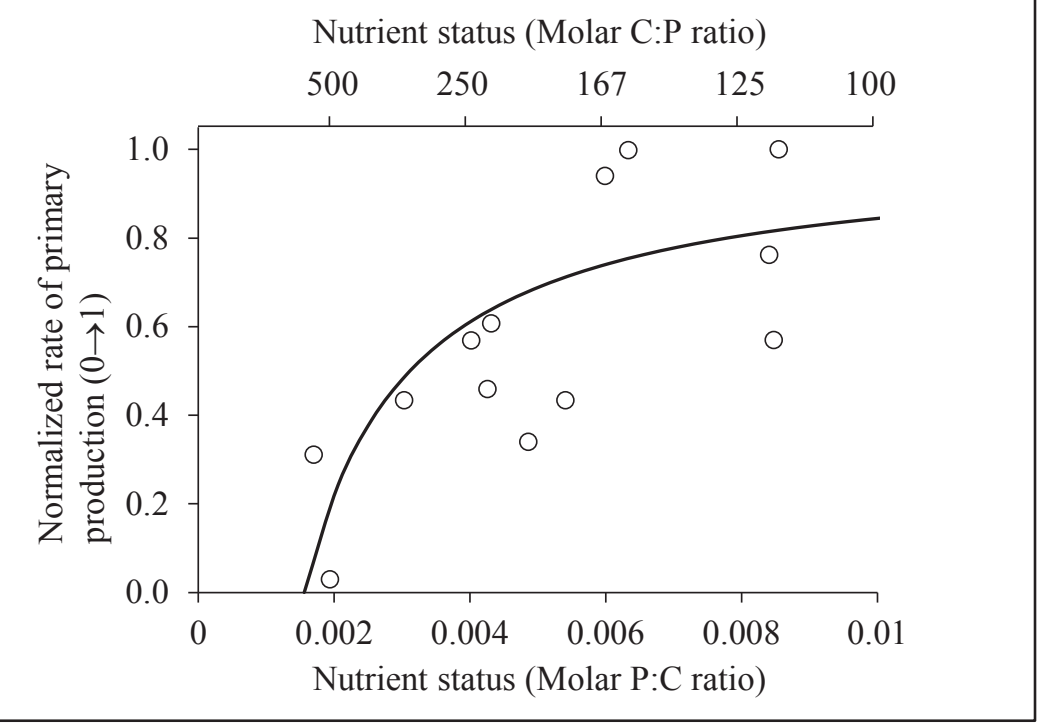

Figure 2-3. Nutrient attenuation function for Lake Superior.

Temperature corrected and normalized specific rates of primary production (open circles) measured in 1999 and 2000 at multiple offshore locations off the Keweenaw Peninsula and the model derived nutrient attenuation function (solid line) following Droop 1974. 


\subsubsection{Maximum specific rate of primary production}

The maximum specific rate of primary production $\left(\mu_{\max }\right)$ was derived from rates of chlorophyll-a specific primary production measured under a wide range of light, temperature and nutrient conditions by Bub (2001). These rates were converted to a specific $\left(\mathrm{d}^{-1}\right)$ basis by multiplying by the Chl:C ratio (MacIntyre et al. 2002). Both sides of Equation 1 were then divided by $\mathrm{POC}$ and rearranged to yield:

$$
\mu_{\max }=\frac{\mu}{f(T, I, N)} \quad \text { Equation } 5 .
$$

The value of $\mu_{\max }$ in the hypolimnion was significantly greater than in the epilimnion $\left(\right.$ mean \pm S.D. $=0.25 \pm 0.08 \mathrm{~d}^{-1}$ vs. $0.15 \pm 0.06 \mathrm{~d}^{-1}, \mathrm{p}<0.0001$; Fig. 2-4a and b; Table 1), a difference that may be due to photoadaptation by the hypolimnetic assemblage effectively doubling the photosynthetic capacity $(\mathrm{C}: \mathrm{Chl}$ ratio $\sim$ double that of the epilimnion; Barbiero and Tuchman 2004). Based on a $95 \%$ confidence interval rates could range from $0.09 \mathrm{~d}^{-1}$ to $0.41 \mathrm{~d}^{-1}$; a range that is for example three times smaller than that applied to Lake Michigan by Scavia et al. (1988).

Kinetic coefficients (Table 1) were derived here based on a suite of primary production measurements made at various conditions of light, temperature and nutrient status. Application of those coefficients, for the same set of environmental conditions, yields model-calculated rates of specific primary production that are well correlated with the measurements $\left(r^{2}=0.78, n=102\right)$. We interpret this as indicating that the algorithms and coefficient values employed here effectively represent the physiological response of the assemblage to environmental conditions. All of the coefficients are not, however, of equal importance thus meriting performance of sensitivity analyses. 


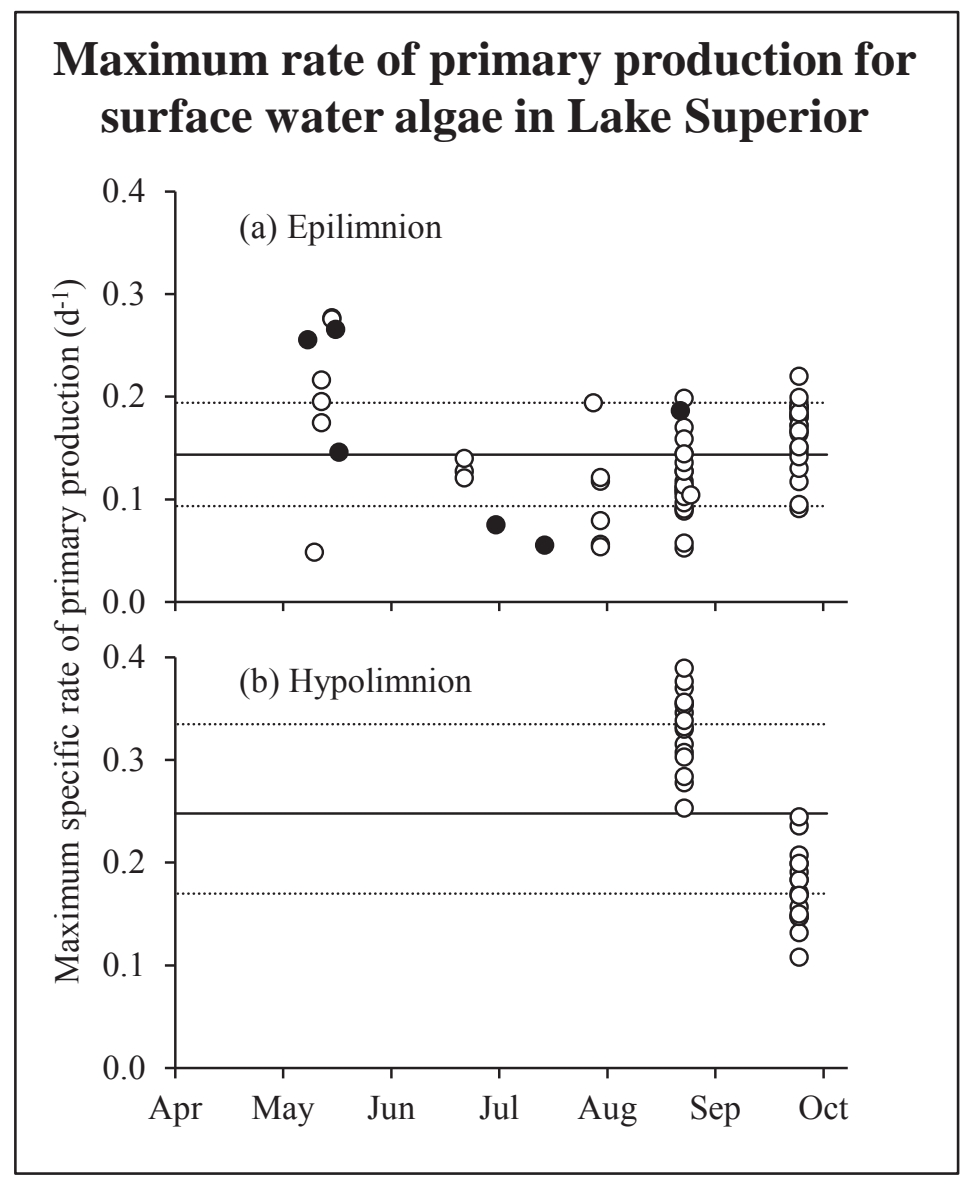

Figure 2-4 Maximum specific rate of primary production.

Panel a shows the maximum specific rate of primary production for the assemblage from the epilimnion with the solid line representing the average and the dotted upper and lower lines representing one standard deviation from average $(n=68$ and contains 20 offshore data sets collected off the Keweenaw Peninsula). Panel b shows the maximum specific rate of primary production for the assemblage from the hypolimnion $(n=34,2$ data sets). The filled circles represent 1999 data and open circles those of 2000. 
Table 1. Derived site-specific model kinetics.

\begin{tabular}{|c|c|c|c|c|}
\hline Parameter & Description & Value & SDV & Units \\
\hline$\alpha_{T 1, \text { cold }}=$ & $\begin{array}{l}\text { fitting parameter (below } \mathrm{T}_{\mathrm{opt}} \text { ) cold } \\
\text { assemblage }\end{array}$ & 0.0575 & n.a. & ${ }^{\circ} \mathrm{C}^{-2}$ \\
\hline$\alpha_{T 2, \text { cold }}=$ & $\begin{array}{l}\text { fitting parameter (above } \mathrm{T}_{\mathrm{opt}} \text { ) cold } \\
\text { assemblage }\end{array}$ & 0.0058 & n.a. & ${ }^{\circ} \mathrm{C}^{-2}$ \\
\hline$T_{o p t, \text { cold }}=$ & $\begin{array}{l}\text { optimum growth temperature cold } \\
\text { assemblage }\end{array}$ & 6.6 & n.a. & ${ }^{\circ} \mathrm{C}$ \\
\hline$\alpha_{T 1, \text { warm }}=$ & $\begin{array}{l}\text { fitting parameter (below } \mathrm{T}_{\mathrm{opt}} \text { ) warm } \\
\text { assemblage }\end{array}$ & 0.0207 & n.a. & ${ }^{\circ} \mathrm{C}^{-2}$ \\
\hline$\alpha_{T 2, \text { warm }}=$ & $\begin{array}{l}\text { fitting parameter (above } \mathrm{T}_{\mathrm{opt}} \text { ) warm } \\
\text { assemblage }\end{array}$ & 0.0222 & n.a. & ${ }^{\circ} \mathrm{C}^{-2}$ \\
\hline$T_{\text {opt }, \text { warm }}=$ & $\begin{array}{l}\text { optimum growth temp. warm } \\
\text { assemblage }\end{array}$ & 13.3 & n.a. & ${ }^{\circ} \mathrm{C}$ \\
\hline$\alpha_{T 1, \text { winter }}=$ & $\begin{array}{l}\text { fitting parameter (below } \mathrm{T}_{\mathrm{opt}} \text { ) winter } \\
\text { assemblage }\end{array}$ & 0.1240 & n.a. & ${ }^{\circ} \mathrm{C}^{-2}$ \\
\hline$\alpha_{T 2, \text { winter }}=$ & $\begin{array}{l}\text { fitting parameter (above } \mathrm{T}_{\mathrm{opt}} \text { ) winter } \\
\text { assemblage }\end{array}$ & 0.0162 & n.a. & ${ }^{\circ} \mathrm{C}^{-2}$ \\
\hline$T_{\text {opt }, \text { winter }}=$ & $\begin{array}{l}\text { optimum growth temperature winter } \\
\text { assemblage }\end{array}$ & 4.14 & n.a. & ${ }^{\circ} \mathrm{C}$ \\
\hline$P_{S}^{B *}=$ & fitting parameter & 1.44 & 0 & dimensionless \\
\hline$\alpha_{\text {surf }}^{*}=$ & fitting parameter - ascending limb $(0 \mathrm{~m})$ & 0.0066 & 0.0021 & $\left(\mu \mathrm{mol} \mathrm{m} \mathrm{m}^{-2} \cdot \mathrm{s}^{-1}\right)^{-1}$ \\
\hline$\beta_{\text {surf }}^{*}=$ & fitting parameter - descending limb $(0 \mathrm{~m})$ & 0.00073 & 0.00023 & $\left(\mu \mathrm{mol} \mathrm{m}{ }^{-2} \cdot \mathrm{s}^{-1}\right)^{-1}$ \\
\hline$\alpha_{\text {comp }}^{*}=$ & fitting parameter - ascending limb $(30 \mathrm{~m})$ & 0.021 & 0.0022 & $\left(\mu \mathrm{mol} \mathrm{m}{ }^{-2} \cdot \mathrm{s}^{-1}\right)^{-1}$ \\
\hline$\beta_{\text {comp }}^{*}=$ & $\begin{array}{l}\text { fitting parameter - descending limb } \\
(30 \mathrm{~m})\end{array}$ & 0.0023 & 0.00025 & $\left(\mu \mathrm{mol} \mathrm{m}{ }^{-2} \cdot \mathrm{s}^{-1}\right)^{-1}$ \\
\hline$C: P_{\max }=$ & maximum $\mathrm{C}: \mathrm{P}$ ratio (P starved) & 610 & n.a. & $\mathrm{mol} \mathrm{C} \mathrm{mol} \mathrm{P} \mathrm{P}^{-1}$ \\
\hline$\mu_{\text {max,epilimnion }}=$ & $\begin{array}{l}\text { net maximu } \mathrm{m} \text { specific growth rate } \\
\text { surface assemblage }(0 \mathrm{~m})\end{array}$ & 0.15 & 0.06 & $\mathrm{~d}^{-1}$ \\
\hline$\mu_{\text {max, hypolimnion }}=$ & $\begin{array}{l}\text { net maximu } \mathrm{m} \text { specific growth rate deep } \\
\text { assemblage }(30 \mathrm{~m})\end{array}$ & 0.25 & 0.08 & $\mathrm{~d}^{-1}$ \\
\hline
\end{tabular}




\subsubsection{Sensitivity analysis}

Once the algorithms and coefficients constituting the primary production model have been derived and their suitability tested against the data base from which they are developed, it is desirable to evaluate their suitability in application to an independent data base, i.e. model confirmation. This task will necessarily and appropriately involve some 'tuning' of model coefficients, to achieve a best fit. Sensitivity analysis seeks to identify those coefficients whose adjustment imparts the greatest effect on model predictions and are thus the best candidates for tuning. Bounds are established, over which coefficients may be adjusted consistent with their analytical and experimental uncertainty.

Here, model sensitivity is quantified as the change in RMSE between observed and predicted specific rates of primary production corresponding to a $\pm 25 \%$ change in a coefficient (Fig. 2-5). The analysis indicates that the model is most sensitive to changes in the temperature optima ( $\mathrm{T}_{\mathrm{opt}, \mathrm{cold}}, \mathrm{T}_{\mathrm{opt}, \mathrm{warm}}$; at $48 \%$ and $32 \%$ ), the maximum specific rates of primary production ( $\mu_{\text {max,epilimnion, }} \mu_{\text {max,hypolimnion; at }} 18 \%$ and $16 \%$ ) and the maximum cell quota (C: $\mathrm{P}_{\max } ;$ at $\left.8 \%\right)$. The remaining coefficients engender a response on the order of $5 \%$, an uncertainty comparable to that accepted for analytical measurements. These five coefficients are thus the most significant contributors to model uncertainty and thus would be adjusted within their 95\% confidence intervals (Table 1) in model confirmation and application. These are also appropriate candidates for further experimental study to reduce model uncertainty. 


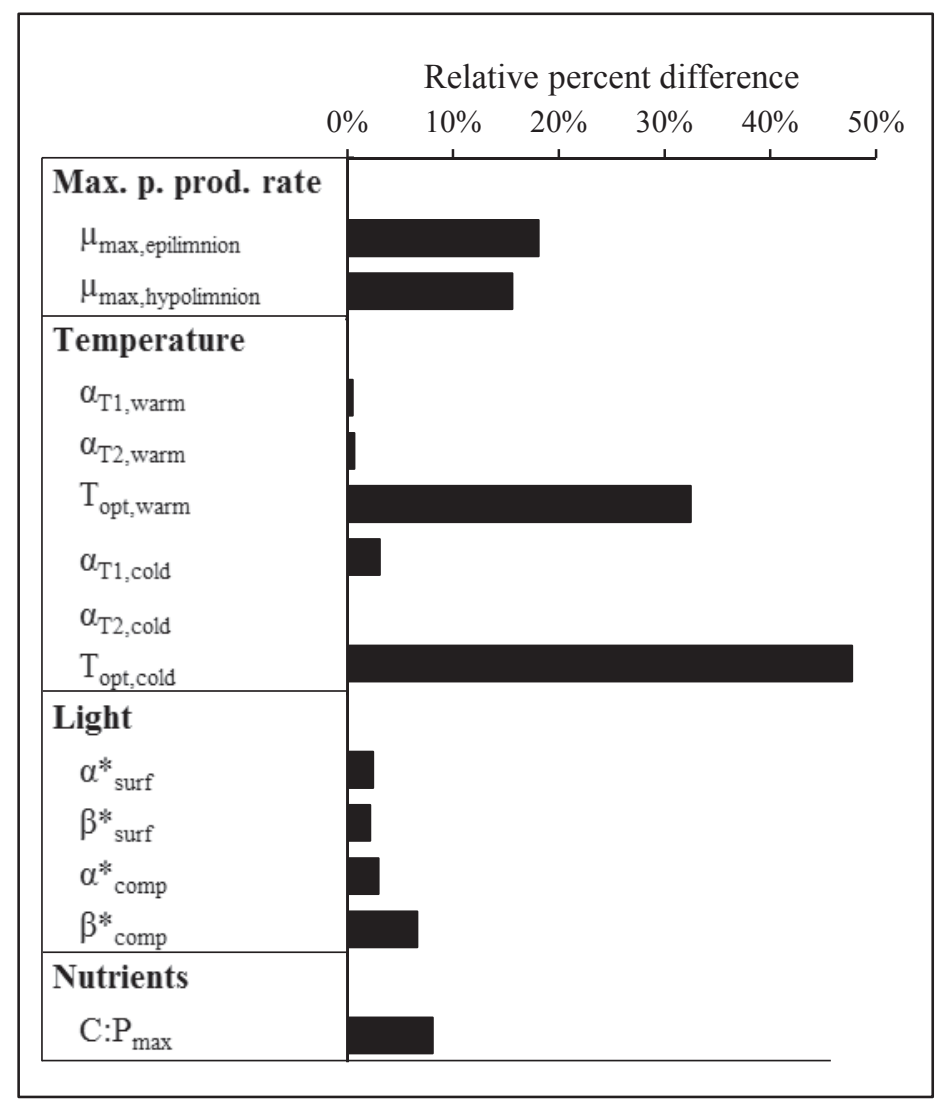

Figure 2-5. Model sensitivity.

Response to variations in applied kinetics expressed by the relative change in RSME between observed and model derived rates of primary production in Lake Superior. 


\subsubsection{Model confirmation}

Confirmation of algorithms selected for use in the primary production model and attendant site-specific coefficients derived from field measurements and laboratory experimentation was sought by comparison to rates measured in-situ by Sterner (2010). Surface measurements (2 m, see Sterner 2010) and two outliers (mean relative error > $150 \%)$ were excluded as were measurements reported for April as these were used to determine the winter temperature function. Model results for April presented here are thus only for indicative purposes.

\subsubsection{Model inputs, algorithms and coefficients}

Model calculations of the specific rate of primary production were made on an hourly basis in one meter increments over a depth range of 80 meters and summed for a 24 hour period to obtain daily rates. Model coefficients were as described above. During stratification the water column was segmented into an epilimnion, metalimnion and hypolimnion. The upper and lower boundaries of the metalimnion were extended outward from the thermocline (determined by averaging the depth of the two bins spanning the greatest change in density) until changes in density fell below $0.03 \mathrm{~kg} \cdot \mathrm{m}^{-3}$.

Maximum specific rate of primary production - the value of $\mu_{\text {max,hypolimnion was }}$ applied over the entire water column under isothermal conditions. During stratification, the

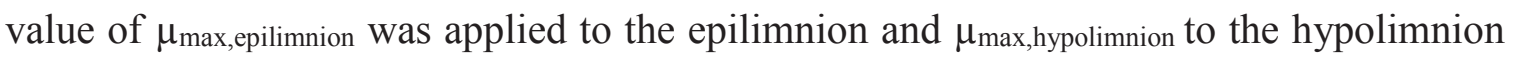
with those values interpolated for application within the metalimnion.

Temperature - during thermal stratification the cold water temperature function and coefficients were applied to the hypolimnion and the warm water temperature function and coefficients to the epilimnion. These functions and coefficients where then interpolated 
across the metalimnion to obtain a gradual transition between the epilimnion and hypolimnion.

Light - calculation of light at depth was done according to Beer's Law with an hourly incident light (PAR, $\mu \mathrm{mol} \mathrm{m}^{-2} \cdot \mathrm{s}^{-1}$ ) derived as described in Sterner (2010) and datespecific vertical extinction coefficients reported by Sterner (2010). Assignment (epilimnion and hypolimnion) and interpolation (metalimnion) were applied here as for the temperature functions.

Nutrients and POC biomass - nutrient status and biomass were interpolated for depth for which measurements were not available. Ambient temperature and nutrient status (C:P ratio) for Lake Superior measured from 2006-2008 (supplementing the measurements reported in Sterner 2010) were provided by Sterner (unpublished data).

\subsubsection{Confirmation results}

Confirmation of model performance to the independent data set is tested in three ways. First, overall model performance is described by the correlation of observed specific rates of primary production with those calculated by the model. Confirmation to the total data set may, however, preclude a lack of model performance in the temporal or vertical dimension (i.e. the model does not capture seasonal or water column dynamics). To test temporal model performance, areal primary production rates were compared to those calculated by the model. Finally, confirmation of model performance in the vertical dimension was sought by comparison of observed and model calculated vertical profiles of specific rates of primary production.

Overall model performance - application of the model, parameterized with the sitespecific kinetics derived here, resulted in a strong correlation with specific rates of primary 
production measured by Sterner $\left(2010, r^{2}=0.81, n=40, \mathrm{p}<0.001\right)$, but resulted in a systematic $47 \%$ underestimation of measured values. An improved fit was sought by adjusting model coefficients within the bounds of their $95 \%$ confidence limits. Increasing the maximum specific rate of primary production applied in the epilimnion from $0.15 \mathrm{~d}^{-1}$ to $0.25 \mathrm{~d}^{-1}$ and that applied in the hypolimnion from $0.25 \mathrm{~d}^{-1}$ to $0.39 \mathrm{~d}^{-1}$ (both remaining within the $95 \%$ C.I.) eliminated underestimation of model predictions and resulted in a correlation of $r^{2}=0.84$ (Fig. 2-6).

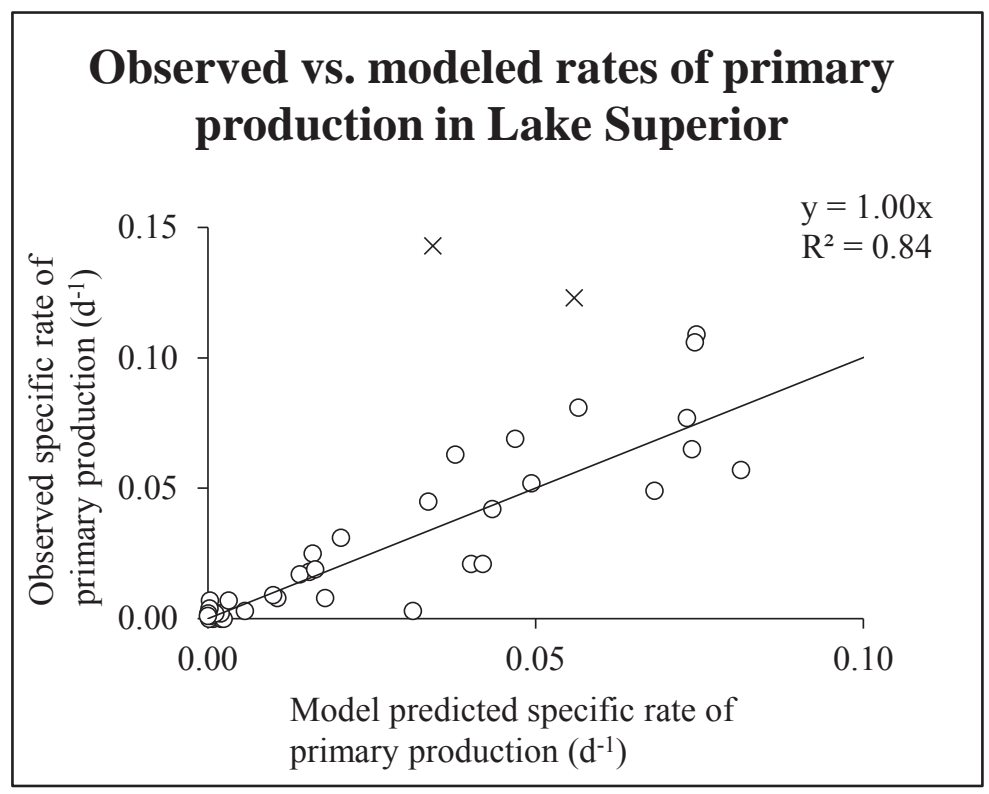

Figure 2-6. Observed versus model derived specific rates of primary production.

Applied model kinetics as shown in Table 1 with the exception of; $\mu_{\text {max.surf }}$ which was increased to $0.25 d^{-1}$ and $\mu_{\max , \text { hypo }}$ which was increased to $0.39 d^{-1}$, both remaining within the $95 \%$ C.I of these parameters. Outlies are shown by a cross. Observed rates of primary production $(n=43)$ were measured from 2006 to 2008 in Lake Superior at multiple depth, described in more detail in Sterner (2010). 
Temporal model performance - was tested by comparing model-predicted estimates of areal primary production to those reported by Sterner (2010) Table 4 for several dates over the April - November interval. Areal rates are derived by integrating primary production over the photic zone, i.e. multiplying biomass (as seston POC) at each depth by the attendant model-derived specific rate of primary production and summing the result. The correlation between model-predicted and in-situ based estimates of areal primary production was good $\left(r^{2}=0.79\right.$, two-tailed $\mathrm{P}<0.035$, Fig. $\left.2-7\right)$, confirming that the model captures temporal fluctuations in production as well. Deviations were largest in fall possibly due to the effects of entrainment of hypolimnetic algae (with a higher $\mu_{\max }$ ) in the epilimnion.

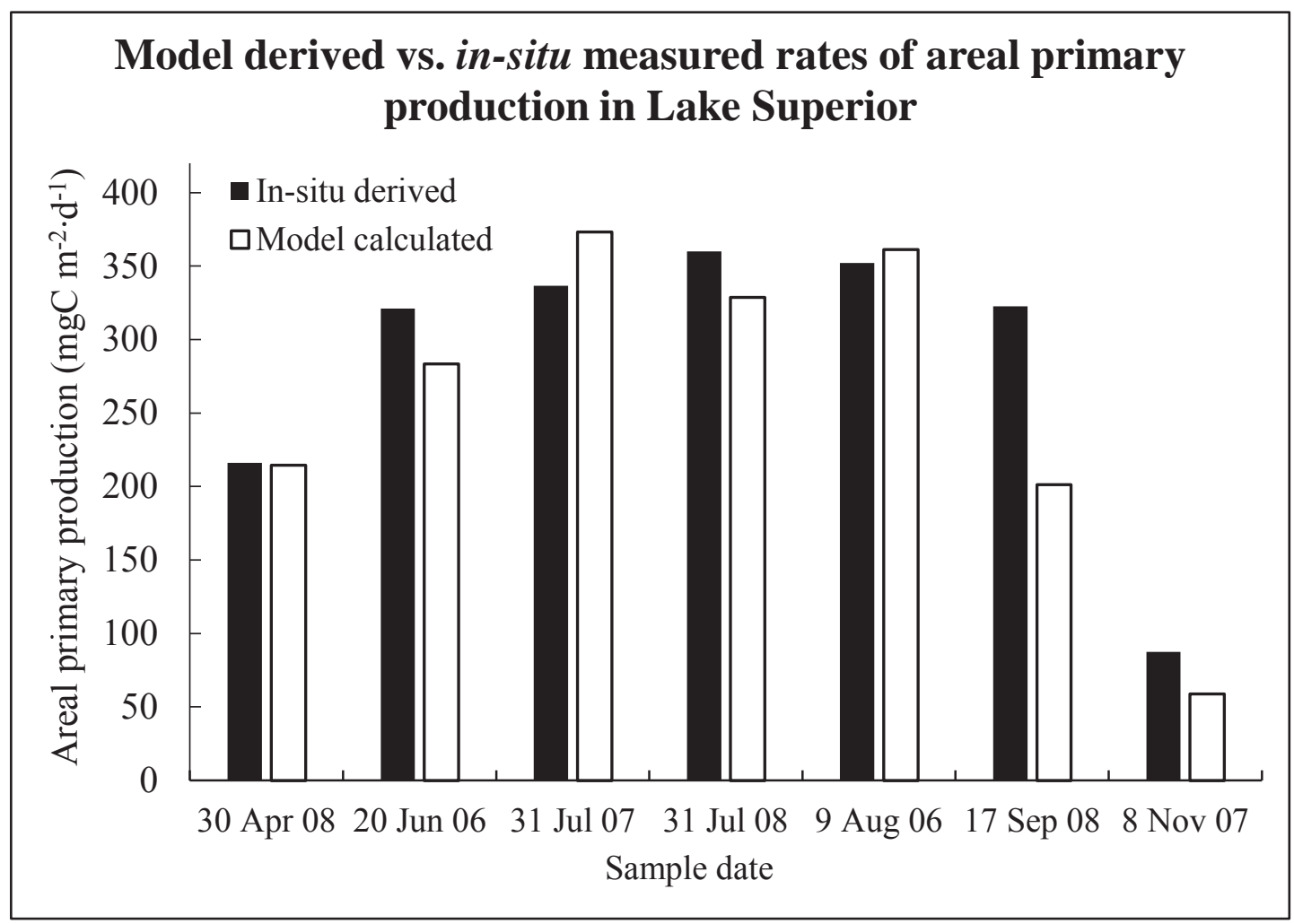

Figure 2-7. Comparison of in-situ measured rates of areal primary production (Sterner 2010) shown in black to model derived rates for the same dates, shown in white. 
Vertical model performance - expressing the model-results over the photic zone shows that the model is able to predict specific rate of primary production accurately in the vertical dimension with a slight underestimation in the surface waters (Fig. 2-8). The large reduction of specific rates of primary production in the surface waters in August is caused by elevated water temperatures $\left(>5^{\circ} \mathrm{C}\right.$ above optimum) and limiting nutrient conditions. The utility of the developed model will be demonstrated in the next section. 


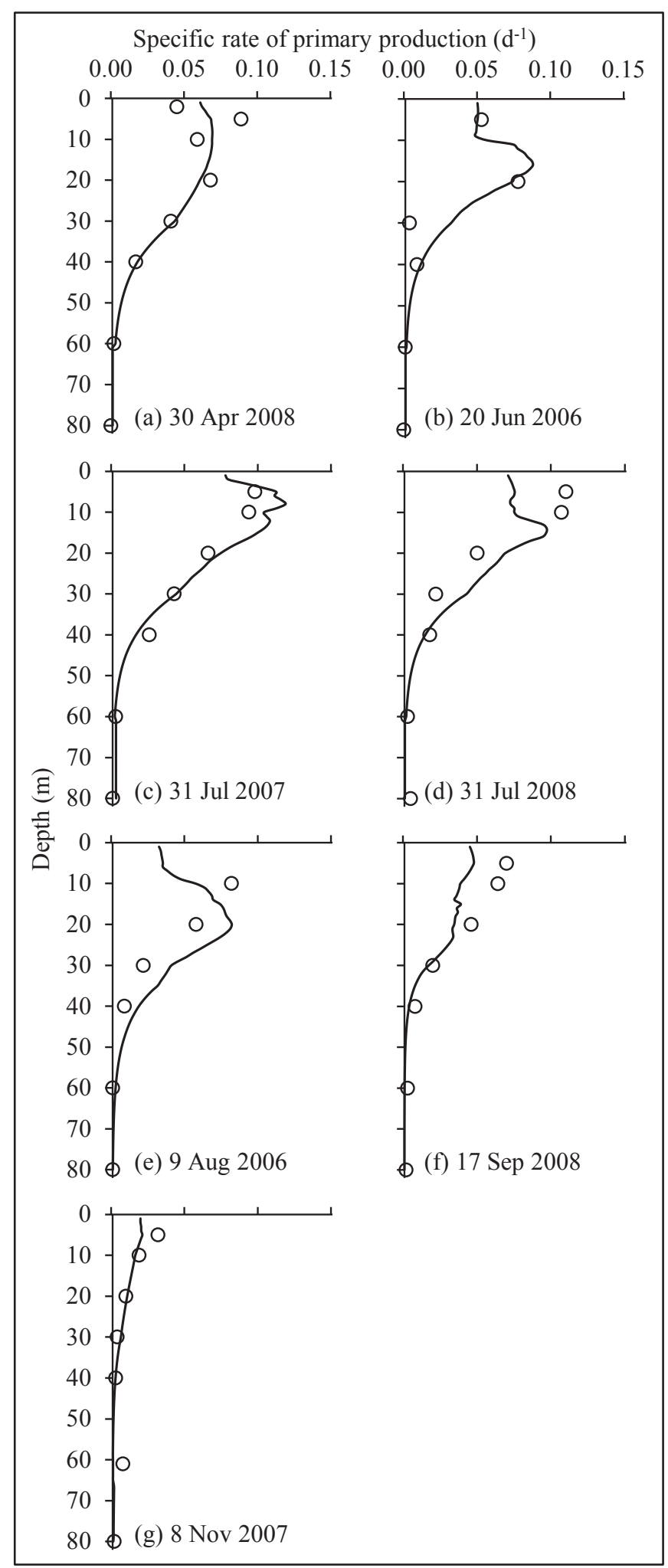

Figure 2-8 Comparison of in-situ measured rates of specific primary production (as reported by Sterner 2010) to model calculated rates for Lake Superior. 


\subsection{Discussion}

Spatial gradients in algal standing crop (chlorophyll-a) and environmental forcing conditions (e.g. water temperature) are commonly observed in Lake Superior in both the horizontal (e.g. thermal bar formation, Auer and Gatzke 2004; Shuchman et al. 2013) and vertical (e.g. Barbiero and Tuchman 2004) dimensions. It remains unclear, however, if primary production manifests spatial heterogeneity as well and is therefore considered to be a single homogeneous system in lake wide estimates of primary production (e.g. Sterner 2010). Here, application of the developed primary production model to field data from a suite of stations selected by U.S. EPA to represent offshore conditions in Lake Superior, will serve to evaluate the degree of spatial variability in primary production.

\subsubsection{Model inputs, algorithms and coefficients}

The primary production model (Eq. 1) is parameterized with the sitespecific kinetic coefficients developed here for Lake Superior (Table 1) and application thereof is similar to that described in the model confirmation section. Secondary data (water temperature, light extinction coefficients, chlorophyll-a, particulate organic carbon and phosphorus concentrations) collected at 19 stations by the EPA in August 1998 as part of GLNPO's long term monitoring of Lake Superior are unpublished data of R.P. Barbiero (see also Barbiero and Tuchman 2001, 2004).

Temperature - water column temperature profiles, taken at $0.5 \mathrm{~m}$ intervals, were divided into an epilimnion, a metalimnion and a hypolimnion. The position of the upper and lower boundaries of the metalimnion was determined as described in the model confirmation section. 
Light - incident light data were taken at the Trout Lake / Woodruff, Wisconsin airport, located at a latitude similar to the Lake Superior sampling sites. Light measurements were taken at hourly intervals and averaged over the 12-day period when lake sampling was conducted. Site-specific light extinction coefficients were applied for EPA stations SU 2, 3, 4, 6, 9, 11, 13, 15, 16, and 17 and an average extinction coefficient $\left(0.14 \pm 0.2 \mathrm{~m}^{-1}\right)$ was used for the remaining stations. The effects of light limitation across the photic zone were determined as described in the model confirmation section.

Nutrients - Algal nutrient status, quantified as the C:P ratio, was determined at the surface, mid-depth and bottom of the epilimnion and averaged to yield a value representative of the epilimnion. Measurements taken below the metalimnion at an average depth of $31 \mathrm{~m}$ were assumed to be representative for the entire hypolimnion. C:P ratios for the metalimnion were derived through a linear interpolation between the C:P ratio of the epilimnion and that applied for the hypolimnion. No hypolimnetic C:P ratio was available for station SU19 and the hypolimnetic average was applied there.

Biomass - chlorophyll-a profiles, taken with a CTD, were calibrated to lab derived chlorophyll-a measurements and converted to a carbon specific basis by dividing by the C:Chl ratio. The epilimnetic C:Chl ratio was applied over the epilimnion and interpolated across the metalimnion using an exponential function yielding a maximum value at the compensation depth.

\subsubsection{Vertical heterogeneity in primary production}

Average water column conditions, at the 19 sampling sites in the summer of 1998, manifested in temperature, light and nutrient status are shown in Fig. 2-9a. The interplay 
between these environmental forcing conditions results in attenuation profiles shown individually (Fig. 2-9b) and acting in concert (Fig. 2-9c). Conversion of potential productivity by the biomass at depth (Fig. 2-9d) results in a vertical production profile with peak values (11.8 $\left.\mathrm{mg} \mathrm{C} \mathrm{m}^{-3} \cdot \mathrm{d}^{-1}\right)$ located within the metalimnion ( $20 \mathrm{~m}$, Fig.2-9e). This rate is close to the maximum rate observed in August 72006 a by Sterner ( $\sim 13 \mathrm{mg} \mathrm{C}$ $\mathrm{m}^{-3} \cdot \mathrm{d}^{-1}$ at a depth of $\left.\sim 10 \mathrm{~m} ; 2010\right)$. Total water column primary production at the 19 sampling sites was partitioned $14 \%$ in the epilimnion, $60 \%$ in the metalimnion and $26 \%$ immediately below the metalimnion (at and directly above the deep chlorophyll maximum, DCM). Maximum biomass (expressed as POC and chlorophyll-a) was observed at a depth of $\sim 30 \mathrm{~m}$, directly below the metalimnion (Fig. 2-9d). Environmental conditions supporting primary production, however, are most favorable within the metalimnion, i.e. at a depth of $\sim 20 \mathrm{~m}$ (Fig.2- 9). Above this depth, temperature and nutrient conditions increasingly restrict production while below this depth light becomes limiting. We note that this depth of maximum production is coincident with that where the highest densities of zooplankton are observed in Lake Superior (Yurista et al. 2009). Localization of maximum rates of primary production within the metalimnion is consistent with results reported by Fahnenstiel and Glime (1983) for Lake Superior. Similar results have been reported for Lake Michigan, with $60 \%$ of areal primary production in early summer taking place below the epilimnion (Moll et al. 1984) and peaks in primary production just above the DCM (Moll and Stoermer 1982) and $~ 30 \%$ of production within the DCM itself (Fahnenstiel and Sc avia 1987). 


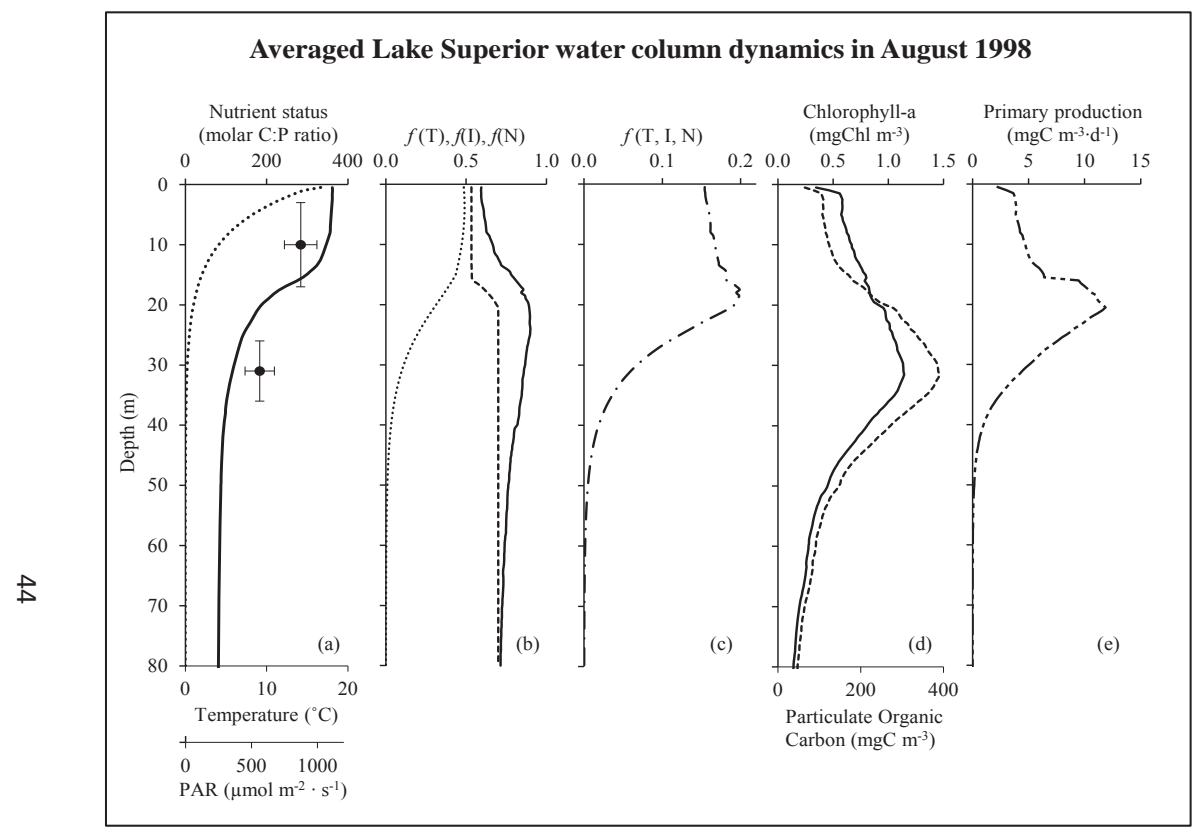

Figure 2-9 Water column dynamics in forcing conditions, biomass and primary production

Panel a shows average water temperature (solid line), noon light extinction (dotted line) and algal nutrient status with error bars representing one standard deviation. Panel $b$ shows the derived attenuation functions for temperature (solid line), light (dotted line) and nutrient status (dashed line). Panel c shows the resulting attenuation due to temperature, light and nutrient status. Panel $d$ shows the distribution of biomass as chlorophyll-a (dashed line) and POC (solid line) in the water column. Panel e shows the resulting rate of primary production at depth. 


\subsubsection{Horizontal heterogeneity in areal primary production}

Summer areal primary production, calculated for the 19 sites in 1998 by integration of calculated primary production in the water column, ranged from $130-$

$468 \mathrm{mg} \mathrm{C} \mathrm{m}^{-2} \cdot \mathrm{d}^{-1}$ and averaged 224 with a S.D. of $90 \mathrm{mg} \mathrm{C} \mathrm{m}^{-2} \cdot \mathrm{d}^{-1}$ (Fig. 2-10a). The variation in production was comparable to the inter-annual summer range reported for Lake Superior by others: $\sim 100 \mathrm{mg} \mathrm{C} \mathrm{m}^{-2} \cdot \mathrm{d}^{-1}$, in 1999 and 2000 at a location $21 \mathrm{~km}$ of off the Keweenaw Peninsula (Urban et al. 2005) and $\sim 300 \mathrm{mg} \mathrm{C} \mathrm{m} \mathrm{m}^{-2} \cdot \mathrm{d}^{-1}$ for 2006-2008 at multiple sites on the lake (Sterner 2010). Areal production is significantly higher $(\mathrm{t}$-test; $\mathrm{p}<0.05)$ for stations along the North coast of the lake (EPA stations SU6, 9, 11, 13, 15, 16, 18 19; Fig.9b), primarily due to higher biomass (76\%) at the depth of greatest specific production. Based on the large variation in areal primary production between sampling stations, offshore production should not be considered to be homogeneous. 


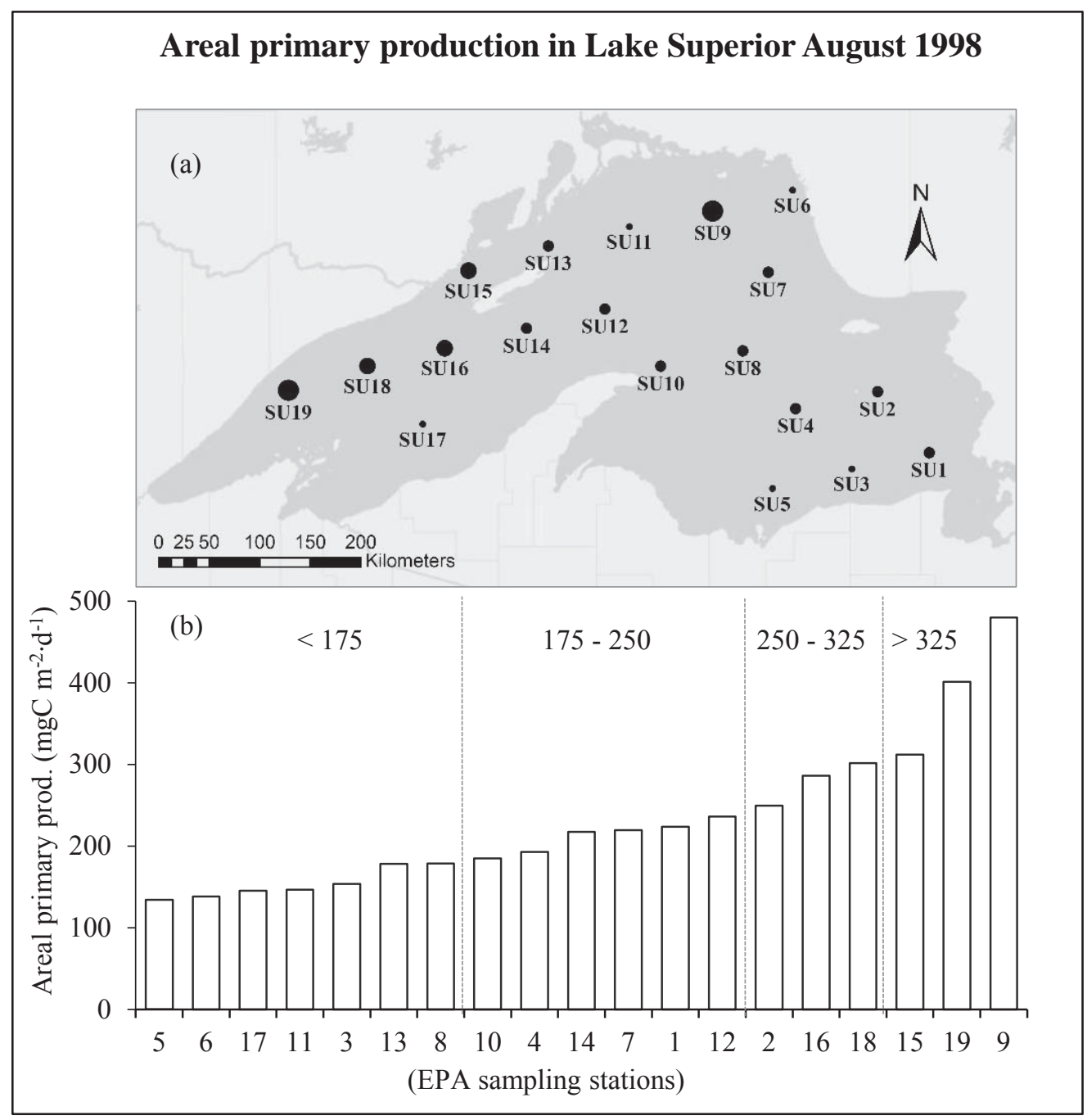

Figure 2-10 Areal primary production at EPA's offshore stations in August 1998

Panel a describes the spatial distribution of calculated areal primary production at EPA's off shore sampling stations in August 1998 where the dot size indicates rates of production (bin ranges are shown in panel $b$ ). Panel $b$ shows the areal primary production at all sampling stations ordered from low to high production. 


\subsection{Conclusions}

In this work we have shown that site specific kinetic coefficients derived from lab experiments on the natural phytoplankton assemblage in conjunction with the chosen algorithms can determine rates of primary production in Lake Superior with great confidence. Excellent model fit to in-situ measured rates of primary production obtained with these site specific coefficients is interpreted as confirmation that the conceptual model (i.e. the chosen algorithms) must be suitable and captures the system's biological dynamics. Other (oligotrophic) phosphorus-limited ecosystems may also benefit from the kinetics and selected algorithms presented here either through their direct application or as a reference in model development.

Application of the developed model to calculate primary production for average water column conditions measured at 19 offshore stations in August of 1998 manifested a subsurface production maximum at a depth of $\sim 20 \mathrm{~m}$. Primary production at this depth was $11.8 \mathrm{mg} \mathrm{C} \mathrm{m} \mathrm{m}^{-3} \cdot \mathrm{d}^{-1}$ and is similar to the average of the maximum rates measured by Sterner (2010) in July and August. Integration of calculated primary production in the water column yields a range from $130-468 \mathrm{mg} \mathrm{C} \mathrm{m}{ }^{-2} \cdot \mathrm{d}^{-1}$ with an average of $224 \pm 90 \mathrm{mg} \mathrm{C} \mathrm{m}^{-}$ ${ }^{2} \cdot \mathrm{d}^{-1}$. The variation between stations is similar to the inter-annual summer range reported for 1999 and $2000\left(\sim 100 \mathrm{mg} \mathrm{C} \mathrm{m} \mathrm{m}^{-2} \cdot \mathrm{d}^{-1}\right.$, Urban et al. 2005) and 2006-2008 ( 300 $\mathrm{mg} \mathrm{C}$ $\mathrm{m}^{-2} \cdot \mathrm{d}^{-1}$ for at multiple sites on the lake, Sterner 2010). 


\subsection{Acknowledgements}

We thank R.W. Sterner and R.P. Barbiero for providing us with additional field data, in addition we thank L.A. Bub and P. Siew for the experimental and field data obtained as part of the NSF-KITES project and the anonymous reviewers who provided constructive comments that improved this work. This research was supported by EPAGLRI grant (\#GL-00E00560/0) and benefitted from a NSF funded GK-12 fellowship. 


\subsection{References}

Auer, M.T., Auer, N.A., Urban, N.R., Bub, L.A. 2010a. Primary production, carbonflux and the distribution of the amphipod Diporeia in Lake Superior. Verh. Internat. Verein. Limnol. 30: 1499-1504.

Auer, M.T., Bub, L.A. 2004. Selected features of the distribution of chlorophyll along the southern shore of Lake Superior. Journal of Great Lakes Research 30: 269284.

Auer, M.T., Doerr, S.M., Effler, S.W., Owens, E.M., 1997. A zero degree of freedom total phosphorus model: 1. Development for Onondaga Lake, New York. Lake and Reservoir Management 13: 118-130.

Auer, M.T., Gatzke, T.L. 2004. The Spring Runoff Event, Thermal Bar Formation, and Cross Margin Transport in Lake Superior. Journal of Great Lakes Research 30: 64-81, doi:10.1016/S0380-1330(04)70378-0

Auer, M.T., Tomlinson, L.M., Higgins, S.N., Malkin, S.Y., Howell, E.T., Bootsma, H.A. 2010b. Great Lakes Cladophora in the 21st century: same algae-different ecosystem. Journal of Great Lakes Research 36: 248-255.

Barbiero, R.P., Tuchman, M.L. 2001. Results from the U.S. EPA's Biological Open Water Surveillance Program of the Laurentian Great Lakes: I. Introduction and Phytoplankton Results. Journal of Great Lakes Research 27: 134-154, doi:10.1016/S0380-1330(01)70628-4

Barbiero, R.P., Tuchman, M.L. 2004. The deep chlorophyll maximum in Lake Superior. Journal of Great Lakes Research 30: 256-268.

Bennington, V., McKinley, G.A., Urban, N.R., McDonald, C.P. 2012. Can spatial heterogeneity explain the perceived imbalance in Lake Superior's carbon budget? A model study. Journal of Geophysical Research 117: G03020.

Bierman Jr, V.J., Dolan, D.M., 1981. Modeling of phytoplankton-nutrient dynamics in Saginaw Bay, Lake Huron. Journal of Great Lakes Research 7: 409-439.

Bowie, G. L., Mills, W. B., Porcella, D. B., Campbell, C. L., Pagenkopf, J. R., Rupp, G. L., Johnson, K. M., Chan, P. W., Gherini, S. A., and Chamberlain, C. E. (1985). Rates, constants, and kinetics formulations in surface water quality modeling (second edition). United States Environmental Protection Agency, Athens, GA. EPA/600/3-85/040.

Bub LA. 2001. Spatial and temporal distribution of phytoplankton in Lake Superior. M.S. Thesis. Michigan Technological University, Houghton, MI. 
Cerco, C.F., Cole, T.M., 1994. Three-Dimensional Eutrophication Model of Chesapeake Bay. Volume 1: Main Report, DTIC Document.

Cerucci, M., Jaligama, G.K., Ambrose Jr, R.B. 2010. Comparison of the Monod and Droop Methods for Dynamic Water Quality Simulations. Journal of Environmental Engineering 136: 1009-1019.

Chapra, S.C. 2008. Surface water-quality modeling, Waveland press.

Chen, C., Ji, R., Schwab, D.J., Beletsky, D., Fahnenstiel, G.L., Jiang, M., Johengen, T.H., Vanderploeg, H., Eadie, B., Budd, J.W. 2002. A model study of the coupled biological and physical dynamics in Lake Michigan. Ecological Modelling 152: $145-168$.

Droop, M.R., 1974. The nutrient status of algal cells in continuous culture. Journal of the Marine Biological Association of the United Kingdom 54: 825-855.

EPA 2010. Sampling and Analytical Procedures for GLNPO's Open Lake Water Quality Survey of the Great Lakes [WWW Document]. URL http://www.epa.gov/glnpo/monitoring/sop/ (accessed 8.21.13).

Fahnenstiel, G.L., Glime, J., 1983. Subsurface chlorophyll maximum and associated Cyclotella pulse in Lake Superior. Internationale Revue der gesamten Hydrobiologie und Hydrographie 68: 605-616.

Fahnenstiel, G.L., Scavia, D., 1987. Dynamics of Lake Michigan phytoplankton: the deep chlorophyll layer. Journal of Great Lakes Research 13: 285-295.

Fennel, K., Losch, M., Schröter, J., Wenzel, M. 2001. Testing a marine ecosystem model: sensitivity analysis and parameter optimization. Journal of Marine Systems 28: 45-63.

Flynn, K.J. 2008a. The importance of the form of the quota curve and control of nonlimiting nutrient transport in phytoplankton models. Journal of plankton research 30: $423-438$.

Flynn, K.J. 2008b. Use, abuse, misconceptions and insights from quota models - the Droop cell quota model 40 years on. Oceanography and Marine Biology: An Annual Review 46: 1-23.

Flynn, K.J. 2010. Ecological modelling in a sea of variable stoichiometry: Dysfunctionality and the legacy of Redfield and Monod. Progress in Oceanography, Special Issue: Parameterisation of Trophic Interactions in Ecosystem Modelling 84: 52-65, doi:10.1016/j.pocean.2009.09.006 
Jarbi, M.E., Rückelt, J., Slawig, T., Oschlies, A. 2013. Reducing the model-data misfit in a marine ecosystem model using periodic parameters and linear quadratic optimal control. Biogeosciences 10: 1169-1182.

Kawamiya, M. 2002. Numerical Model Approaches to Address Recent Problems on Pelagic Ecosystems. Journal of Oceanography 58: 365-378, doi:10.1023/A:1015822011358

Lancelot, C., Staneva, J., Van Eeckhout, D., Beckers, J.-M., Stanev, E. 2002. Modelling the Danube-influenced north-western continental shelf of the Black Sea. II: Ecosystem response to changes in nutrient delivery by the Danube River after its damming in 1972. Estuarine, Coastal and Shelf Science 54: 473-499.

MacIntyre, H.L., Kana, T.M., Anning, T., Geider, R.J. 2002. Photoacclimation of Photosynthesis Irradiance Response Curves and Photosynthetic Pigments in Microalgae and Cyanobacteria1. Journal of Phycology 38: 17-38.

McDonald, C.P., Bennington, V., Urban, N.R., McKinley, G.A. 2012. 1-D test-bed calibration of a 3-D Lake Superior biogeochemical model. Ecological Modelling 225: $115-126$.

Moll, R.A., Brache, M.Z., Peterson, T.P., 1984. Phytoplankton dynamics within the subsurface chlorophyll maximum of Lake Michigan. J. Plankton Res. 6: 751766, doi:10.1093/plankt/6.5.751

Moll, R.A., Stoermer, E.F., 1982. Hypothesis Relating Trophic Status and Subsurface Chlorophyll Maxima of Lakes. Archiv fur Hydrobiologie 94: 425-440.

Oreskes, N., Shrader-Frechette, K., Belitz, K., 1994. Verification, Validation, and Confirmation of Numerical Models in the Earth Sciences. Science 263: 641-646.

Peterson, B.J., 1980. Aquatic Primary Productivity and the 14C-CO2 Method: A History of the Productivity Problem. Annual Review of Ecology and Systematics 11: $359-385$.

Platt, T., Gallegos, C.L., Harrison, W.G., 1980. Photoinhibition of photosynthesis in natural assemblages of marine phytoplankton. Journal of marine research 38 .

Reynolds, C.S., 1984a. Phytoplankton periodicity: the interactions: form, function and environmental variability. Freshwater Biol. 14: 111-142. 
Reynolds, C.S., 1984b. The Ecology of Freshwater Phytoplankton, Cambridge University Press.

Reynolds, C.S., Thompson, J.M., Ferguson, A.J.D., Wiseman, S.W., 1982. Loss processes in the population dynamics of phytoplankton maintained in closed systems. J. Plankton Res. 4: 561-600, doi:10.1093/plankt/4.3.561

Scavia, D., Lang, G.A., Kitchell, J.F., 1988. Dynamics of Lake Michigan plankton: a model evaluation of nutrient loading, competition, and predation. Canadian Journal of Fisheries and Aquatic Sciences 45: 165-177.

Shuchman, R.A., Leshkevich, G., Sayers, M.J., Johengen, T.H., Brooks, C.N., Pozdnyakov, D. 2013. An algorithm to retrieve chlorophyll, dissolved organic carbon, and suspended minerals from Great Lakes satellite data. Journal of Great Lakes Research 39: 14-33.

Siew, P.F. 2003. Phosphorus distribution and cycling in the Keweenaw Peninsula region of Lake Superior. M.S. thesis, Mich. Technol. Univ., Houghton.

Sommer, U., 1983. Nutrient competition between phytoplankton species in multispecies chemostat experiments. Archiv für hydrobiologie 96: 399-416.

Sommer, U., 1991. A comparison of the Droop and the Monod models of nutrient limited growth applied to natural populations of phytoplankton. Functional Ecology, British Ecological Society: 535-544, DOI: 10.2307/2389636

Sterner, R.W. 2010. In situ-measured primary production in Lake Superior. Journal of Great Lakes Research 36: 139-149.

Sterner, R.W. 2011. C: N: P stoichiometry in Lake Superior: Freshwater sea as end member. Inland Waters 1: 29-46.

Sterner, R.W., Smutka, T.M., McKay, R.M.L., Xiaoming, Q., Brown, E.T., Sherrell, R.M. 2004. Phosphorus and Trace Metal Limitation of Algae and Bacteria in Lake Superior. Limnology and Oceanography 49: 495-507.

Tian, R.C. 2006. Toward standard parameterizations in marine biological modeling. Ecological Modelling 193: 363-386, doi:10.1016/j.ecolmodel.2005.09.003

Tilman, D., Kilham, S.S., Kilham, P., 1982. Phytoplankton Community Ecology: The Role of Limiting Nutrients. Annual Review of Ecology and Systematics 13:349372. 
Urban, N.R., Auer, M.T., Green, S.A., Lu, X., Apul, D.S., Powell, K.D., Bub, L. 2005. Carbon cycling in Lake Superior. J. Geophys. Res. 110: 17 PP, doi: 10.1029/2003JC002230

Urban, N.R., Munawar, M., Munawar, I.F. 2009. Nutrient cycling in Lake Superior: a retrospective and update. State of Lake Superior, New Delhi (India): Goodword Books: 83-115.

Wetzel, R.G., Likens, G.E., 1991. Limnological analyses, Springer Verlag. New York 391.

White, B., Austin, J., Matsumoto, K. 2012. A three-dimensional model of Lake Superior with ice and biogeochemistry. Journal of Great Lakes Research 38: 6171, doi:10.1016/j.jglr.2011.12.006

White, B., Matsumoto, K. 2012. Causal mechanisms of the deep chlorophyll maximum in Lake Superior: A numerical modeling investigation. Journal of Great Lakes Research 38: 504-513, doi:10.1016/j.jglr.2012.05.001

Yurista, P.M., Kelly, J.R., Miller, S.E. 2009. Lake Superior zooplankton biomass: Alternate estimates from a probability-based net survey and spatially extensive LOPC surveys. Journal of Great Lakes Research 35: 337-346, doi:10.1016/j.jglr.2009.03.004 


\section{Chapter 3}

\section{Spatiotemporal dynamics in environmental forcing conditions, standing crop and primary production of Lake Superior}

"What is now proved was once only imagined."

William Blake (1757-1827)

In preparation for submission to the Journal of Great Lakes Research. 


\subsection{Abstract}

A suite of measurements supporting calculation of rates of primary production for Lake Superior was made over the April to October interval of 2011, a period which was broadly representative of the decadal-scale climatology and thermal regime of the lake. Measurements were made along a $26 \mathrm{~km}$ transect extending lakeward from Michigan's Keweenaw Peninsula. Measurements included: temperature, solar radiation, transparency, beam attenuation, chlorophyll-a fluorescence, colored dissolved organic matter, suspended solids and phosphorus and carbon constituents. Primary production was calculated with a multiplicative model incorporating site-specific algorithms and kinetics and confirmed using published in-situ measurements for Lake Superior. This program of measurements and modeling represents a particularly well defined spatiotemporal treatment of patterns in forcing conditions and primary production for Lake Superior. The signal feature in the surface waters was the development of a mid-summer "desert"; a period of suboptimal temperatures coincident with a high degree of phosphorus limitation. The absence of a nearshore spring algal bloom in 2011 was ascribed to low levels of nutrient input during the time of the thermal bar. The dominant feature in the offshore was the occurrence of elevated levels of primary production within the metalimnion: $<1.5 \mathrm{mg} \mathrm{C} \mathrm{m}^{-3} \mathrm{~d}^{-1}$ in the epilimnion, $\sim 20 \mathrm{mg}$ $\mathrm{C} \mathrm{m}^{-3} \mathrm{~d}^{-1}$ at the top of the metalimnion $(\sim 17 \mathrm{~m})$ and $\sim 5 \mathrm{mg} \mathrm{C} \mathrm{m}^{-3} \mathrm{~d}^{-1}$ at the bottom of the metalimnion $(29 \mathrm{~m})$. Areal rates of primary production ranged from $19-104 \mathrm{mg} \mathrm{C}$ $\mathrm{m}^{-2} \mathrm{~d}^{-1}$ in the nearshore and $38-253 \mathrm{mg} \mathrm{C} \mathrm{m}^{-2} \mathrm{~d}^{-1}$ in the offshore, with maxima in May and July, respectively.

Key words: Lake Superior, primary production, C:P ratios, DCM, Thermal bar, nearshore offshore gradient 


\subsection{Introduction}

Lake Superior has been of interest to the research community since the first known measurement of water transparency was made by Louis Agassiz in 1848 (Agassiz and Cabot, 1850). A notable body of work has since been accumulated, one that continues to expand through application of new technologies, e.g. gene sequence analysis, flow cytometry, hydroacoustics and satellite remote sensing. From this a picture emerges of an endmember ecosystem characterized by its large surface area and great depth, by its clear and cold waters and by a degree of nutrient limitation that supports only modest levels of primary production.

Lake Superior is dimictic, mixing completely in spring and fall and maintains an average temperature of $3.6^{\circ} \mathrm{C}$ (Bennett 1978). Spring warming leads to formation of a thermal bar which is typically present by early May (Auer and Gatzke 2004). This front migrates lakeward as the season progresses and dissipates as the lake becomes thermally stratified, usually in mid-July (Bennett 1978). The duration of stratification in offshore waters averages 170 days (Austin and Colman 2008). Levels of phosphorus, the limiting nutrient (Sterner et al. 2004), are low (soluble reactive phosphorus, SRP averaged $\sim 0.2 \mu \mathrm{g}$ $\mathrm{L}^{-1}$ for all stations, at all depths, May - July 1998; Urban et al. 2009 and Siew 2003) and exhibit no vertical structure (Baehr and McManus 2003). Phosphorus loads to Lake Superior are the lowest of all the Great Lakes. This, in conjunction with the magnitude of the organic phosphorus pool ( $>90 \%$ of the phosphorus in Lake Superior is organic; Sterner 2011) and the short phosphorus residence time (1-6 years; Urban et al. 2009) signals the importance of phosphorus cycling in mediating nutrient availability. Extensive crossmargin transport of particulate matter has, however, been documented and indicates that 
$10-30 \%$ of the solids deposited in the offshore originate in the nearshore (sediment trap measurements; Urban et al. 2004).

Primary producer biomass in offshore waters, measured as carbon and as chlorophyll-a, ranges from 36-160 $\mu \mathrm{g} \mathrm{C} \mathrm{L}^{-1}$ (Sterner 2011) and from $0.6 \pm 0.08$ (spring) to $1.3 \pm 0.06 \mu \mathrm{g} \mathrm{Chl-a} \mathrm{L}{ }^{-1}$ (summer) (Munawar and Munawar 2009). The average epilimnetic molar C:P ratio in summer is 298 (Sterner 2011) and is indicative of severe nutrient limitation (starvation; Healey and Hendzel 1980). Nearshore to offshore gradients in biomass are irregular in their occurrence and were, for example, not observed in 1973 (Munawar and Munawar 1978) but were reported for 1999 and 2000 (Auer and Bub 2004).

The diverse phytoplankton community ( $>231$ species; Munawar and Munawar 2009) is dominated by diatoms and cryptomonads and shows little seasonality in structure other than an increase in diatom abundance in summer (Reavie et al. 2014; Munawar et al. 2009). The community structure near the compensation depth remains similar to that of the surface with the exception of Cyclotella biomass which at times is lower (C. comta; Barbiero and Tuchman 2004) and at other times higher than that of the surface $(C$. stelligera; Fahnenstiel and Glime 1983).

The phytoplankton assemblage is dominated by small forms that contribute significantly to primary production ( $\sim 50 \%$ from cells $<3 \mu \mathrm{m}$; Fahnenstiel et al. 1986,31 $55 \%<2 \mu \mathrm{m}$; Munawar and Munawar 2009). Areal rates of primary production in offshore waters average $\sim 300 \mathrm{mg} \mathrm{C} \mathrm{m}^{-2} \mathrm{~d}^{-1}$ and exhibit a seasonal pattern characterized by low winter production, increasing in spring, reaching a maximum in early summer and then decreasing towards winter (Sterner 2010). Seasonally-averaged rates of primary production at nearshore stations (depth $<125 \mathrm{~m}$ ) were $>60 \%$ higher than those of offshore waters 
(depth $>125 \mathrm{~m}$ ) in 2000 (Auer et al. 2010).

It is in this context that we present the results of an intensive field sampling program capturing spatiotemporal dynamics in factors governing primary production (i.e. temperature, light, phosphorus and primary producer biomass) and supporting calculation of rates of primary production using a confirmed, site-specific model. 


\subsection{Methods}

Sampling was conducted bi-weekly from 25 April through 25 October 2011 (15 cruises) at 11 stations along a shore-perpendicular transect extending lakeward for $26 \mathrm{~km}$ from Michigan's Keweenaw Peninsula (HN transect; Auer and Bub 2004). The transect was divided into regions as proposed by Auer et al. (2009): the shelf ( $<30 \mathrm{~m})$, the slope $(30-125 \mathrm{~m})$ and the profundal (depth $>125 \mathrm{~m})$. Here, nearshore equates with the shelf, slope with a transitional region and offshore with the profundal. Offshore habitat represents $56 \%$, the slope $24 \%$ and the shelf $20 \%$ of the lake's area (Auer et al. 2013). For each cruise, discrete samples representative of shelf, slope and profundal habitats were taken 3, 4 and $26 \mathrm{~km}$ offshore and had station depths of $22 \mathrm{~m}, 50 \mathrm{~m}$ and $>185 \mathrm{~m}$, respectively. During periods of thermal stratification the slope and profundal station were also sampled at a depth of $25 \mathrm{~m}$ and at $5 \mathrm{~m}$ from the bottom.

Vertical profiles of temperature, chlorophyll-a fluorescence, transmissivity and photosynthetically available radiation (PAR) were taken with a Seabird Electronics (SBE25). Light extinction coefficients were derived from the log linearized PAR data, excluding non-log linear near surface values. The fluorescence probe was calibrated according to the Great Lakes National Program Office procedure LG405 (GLNPO, EPA 2010); the depth, temperature and PAR sensors were calibrated by the manufacturer. Surface water samples were collected with a pre-rinsed acid washed PE bucket and samples from the metalimnion and hypolimnion were taken with a 20-liter Niskin bottle. Samples were transferred to acidwashed PE carboys and transported to onshore facilities for further processing.

Aliquots of water were filtered through $0.4 \mu \mathrm{m}$ Polycarbonate Track-Etched Membrane filters with the retentate used for particulate phosphorus (PP) analysis and the 
filtrate reserved for determination of soluble reactive phosphorus (SRP), total dissolved phosphorus (TDP) and colored dissolved organic matter (CDOM). Filtration for chlorophyll-a and particulate organic carbon (POC) was done using $0.7 \mu \mathrm{m}$ Binder-Free Glass Microfiber GF/F type filters (GLNPO procedures LG404, LG210 and LG206; EPA 2010). The filtrate was reserved for determination of dissolved organic carbon (DOC). After the initial sample processing the filtrate and retentate were preserved following GLNPO procedures (LG204, LG209, LG405, LG210 and LG211; EPA 2010).

CDOM light absorption was measured at $440 \mathrm{~nm}$ on a Perkin Elmer Lambda-2 spectrophotometer using a path length of $10 \mathrm{~cm}$ and converted to a partial light extinction coefficient following Miller et al. (2002). Measurements of chlorophylla were made using a Shimatzu RF-1501 spectrofluorometer according to procedures outlined by APHA (2005; Method 10200H). Regression of CTD casts taken at mid-day against night casts indicated that quenching of surface water algae decreased chlorophyll-a fluorescence by $6.9 \%$ to a depth of 8 meters; data were adjusted accordingly. Phosphorus was measured using a Perkin Elmer Lambda-2 spectrophotometer according to the ascorbic acid method (APHA 2005; Method 4500P E). PP and TDP samples were first digested with acid-persulfate (APHA 2005; Method 4500-P H). The detection limit for phosphorus analysis was $0.3 \mu \mathrm{g} \mathrm{P} \mathrm{L} \mathrm{L}^{-1}, 4.6$

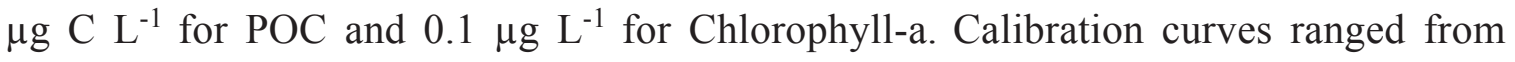
$0.3 \mu \mathrm{g} \mathrm{P} \mathrm{L}{ }^{-1}$ to $5 \mu \mathrm{g} \mathrm{P} \mathrm{L}{ }^{-1}$ and maintained an $\mathrm{r}^{2}$ of 0.99 . The DOC samples were analyzed on a Fisons NA 1500 Elemental Analyzer with a detection limit $<0.1 \mathrm{mg} \mathrm{C} \mathrm{L}^{-1}$. 
Primary production is calculated by the product of phytoplankton biomass and a maximum specific growth rate attenuated by the rate-mediating conditions of temperature, light and nutrients (Chapra 2008),

$$
P=\quad \mu_{\max } \cdot f_{(T)} \cdot f_{(I)} \cdot f_{(N)} \cdot P O C \quad \text { Equation } 1 .
$$

where:

$P=\quad$ rate of primary production $\quad \mathrm{mg} \mathrm{C} \mathrm{m}^{-3} \mathrm{~d}^{-1}$

$\mu_{\max }=$ maximum specific rate of primary production $\mathrm{d}^{-1}$

$f_{(T)}=$ attenuation function for temperature dimensionless ( 0 to 1$)$

$f_{(I)}=\quad$ attenuation function for light (PAR) dimensionless ( 0 to 1$)$

$f_{(N)}=\quad$ attenuation function for nutrient conditions dimensionless ( 0 to 1$)$

$P O C=$ particulate organic carbon concentration $\quad \mathrm{mg} \mathrm{C} \mathrm{m}^{-3}$

Phytoplankton biomass, expressed as carbon, was derived by correlating beam attenuation with measurements of POC $\left(\mathrm{r}^{2} 0.75\right)$ as described by Behrenfeld and Boss (2006). The product of temperature $\left(f_{(\mathrm{T})}\right)$, light $\left(f_{(\mathrm{I})}\right)$ and nutrient $\left(f_{(\mathrm{N})}\right)$ limitation may also be represented by one parameter, $f_{\text {(TIN) }}$ representing the combined effect of environmental forcing conditions in a multiplicative model. The model (Eq. 1) was parameterized with site specific kinetic coefficients derived from a series of experiments on the natural phytoplankton assemblage of Lake Superior more fully described in Dijkstra and Auer (in review); examples of normalized response functions are shown in Fig. 3-1. 


\section{Functions describing temperature, light and nutrient attenuation of primary production in Lake Superior}

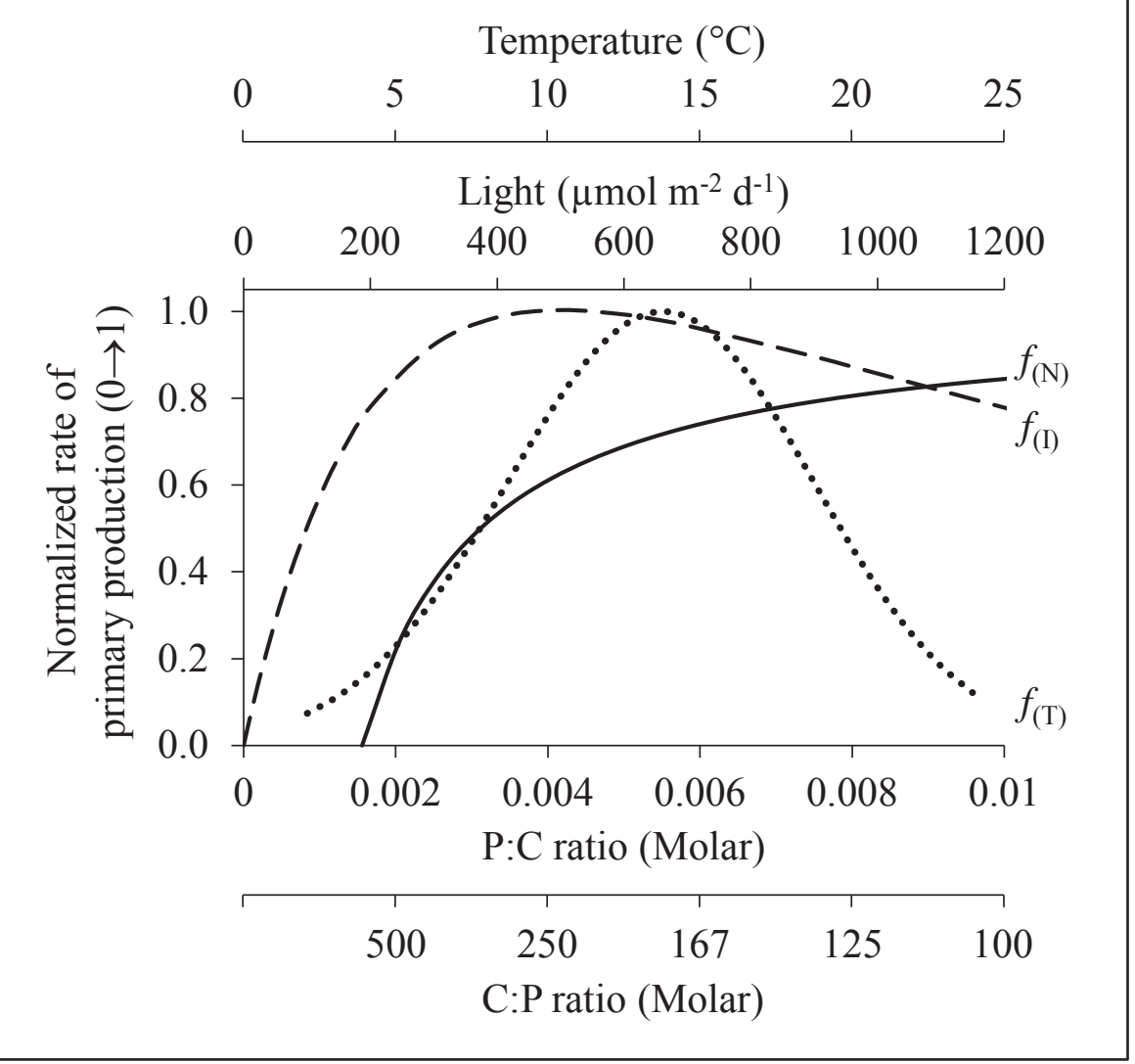

Figure 3-1. Normalized dimensionless attenuation functions

Functions represent the growth limiting effect on phytoplankton due to temperature $(f(T)$, dotted line), light $(f(I)$, dashed line) and nutrients $(f(N)$, solid line; axis expressed in the molar C:P and $P: C$ ratio). Values range from 0 to 1 and represent complete limitation and no limitation, respectively. Functions are based on field measurements and lab experiments made by Bub (2001) and Siew (2003) in 1998-2000 on the natural phytoplankton assemblage of Lake Superior as described in Dijkstra and Auer(inreview). 


\subsection{Results and Discussion}

\subsubsection{Temporal dynamics}

Primary production is driven by temperature, light and nutrient conditions (Cloern 1977; Dijkstra and Auer, in review), with spatiotemporal differences in these factors resulting in points in space and in time where conditions for production are better than at others. Patterns in phytoplankton biomass and forcing conditions, including nutrient stoichiometry, are compared here for the nearshore and offshore surface waters of Lake Superior off the Keweenaw Peninsula.

\subsubsection{Seasonal dynamics in temperature}

In 2011, water temperatures, driven by meteorological conditions (e.g. solar radiation, air temperature and wind speed), followed the annual bell-shaped pattern described by Bennett (1978). Lakewide, average surface water temperatures as low as $\sim 1^{\circ} \mathrm{C}$ (NOAA CoastWatch data) were observed by mid-March, a response to antecedent winter conditions. During spring, water temperature rose faster in the nearshore $\left(0.11{ }^{\circ} \mathrm{C} \mathrm{d}^{-1}\right.$; reaching $3.6{ }^{\circ} \mathrm{C}$ by early May) than in the offshore $\left(0.05{ }^{\circ} \mathrm{C} \mathrm{d}^{-1}\right.$; reaching $\sim 2{ }^{\circ} \mathrm{C}$ by early May, Fig. 3-2a). Completely mixed in spring, nearshore waters were positively stratified by mid-June and warmed at a rate of $0.19{ }^{\circ} \mathrm{C} \mathrm{d}^{-1}$ until late August. This period of warming was interrupted by a rapid decline in temperature in mid-July following a week in which air temperatures were $\sim 3{ }^{\circ} \mathrm{C}$ lower than antecedent conditions (NOAA Nowcast data). In early August the nearshore became isothermal, then re-stratified in late August reaching a peak temperature of $20^{\circ} \mathrm{C}$. The nearshore then cooled at a rate of $-0.18{ }^{\circ} \mathrm{C} \mathrm{d}^{-1}$, becoming completely mixed at $9^{\circ} \mathrm{C}$ by late September.

A different pattern was observed in the offshore. The well mixed water column of 
spring became strongly stratified in mid-July with temperatures increasing by $0.23{ }^{\circ} \mathrm{C} \mathrm{d}^{-1}$ and peaking in late August at $17.5^{\circ} \mathrm{C}$. Temperatures started to decline in late August and fell at a rate of $-0.15^{\circ} \mathrm{C} \mathrm{d}^{-1}$ over the September - November interval, reaching $5^{\circ} \mathrm{C}$ in early December. The pattern in lake averaged surface water temperatures for 2011 was similar to that of the decadal average (Fig. 3-2b). Therefore, dynamics described here for 2011 represent a useful benchmark condition for comparison to recently-observed extremes in warm (2012) and cold (2014) conditions (Fig. 3-2b).

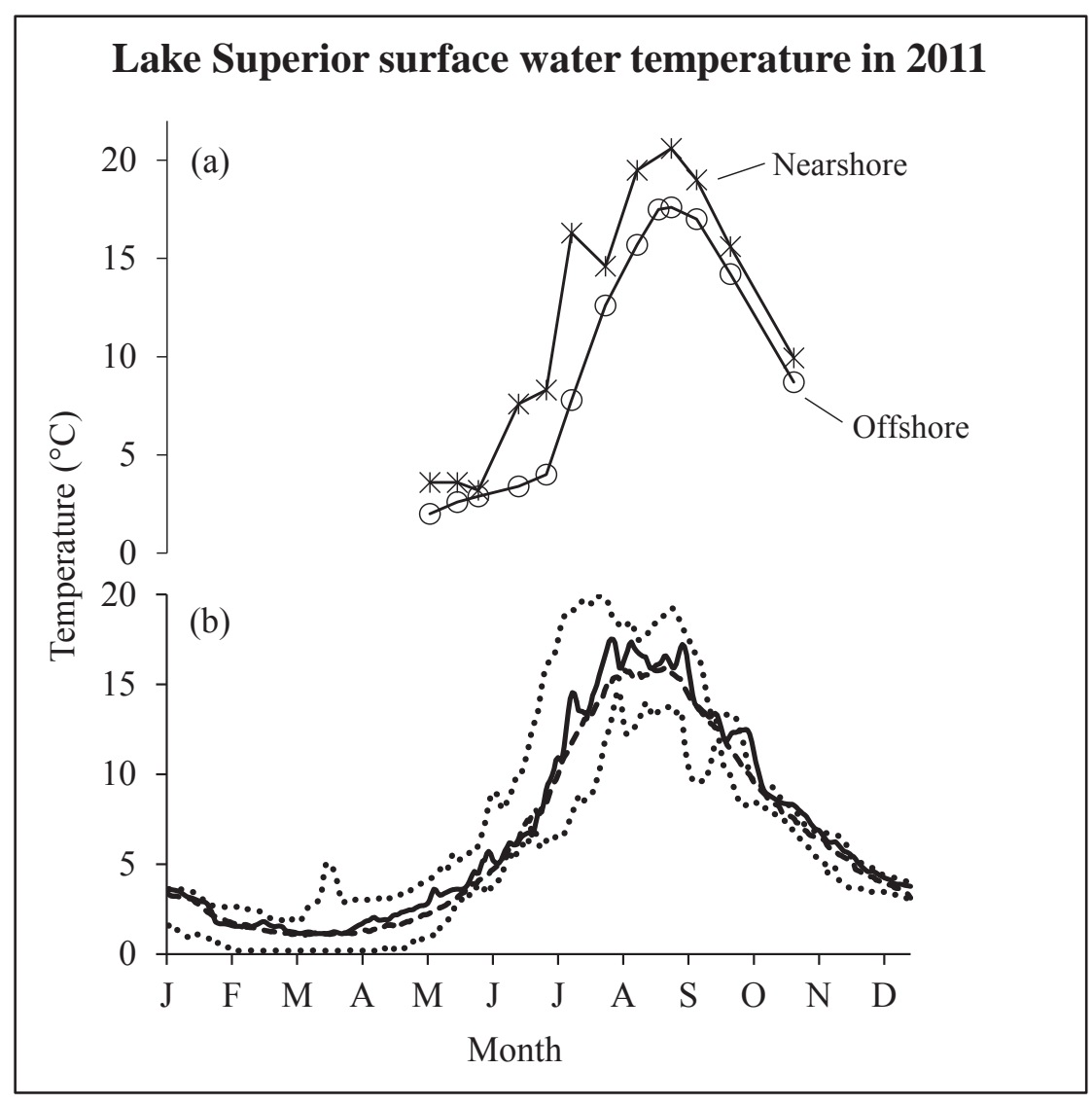

Figure 3-2 Dynamics in surface water temperature

Panel a described dynamics in the nearshore (indicated by stars) and offshore (indicated by open circles) and panel $b$ the lake averaged surface water temperatures for 2011: solid line 2012: upper dotted line 2014: lowerdotted line and the average for the 1992 -2014 interval: dashed line. 


\subsubsection{Seasonal dynamics in phytoplankton biomass}

Average spring chlorophyll-a concentrations (serving as a proxy for phytoplankton biomass) were initially similar in the nearshore and offshore $\left(0.7 \mu \mathrm{g} \mathrm{Chl} \mathrm{L} \mathrm{L}^{-1}\right)$ and remained so until early August (Fig. 3-3a). At that point, nearshore concentrations increased, peaking at $0.9 \mu \mathrm{g} \mathrm{Chl} \mathrm{L} \mathrm{L}^{-1}$ by mid-August. This increase in nearshore chlorophyll-a concentrations may have been aided by resuspension of sedimented phytoplankton as the water column was completely mixed at that time. Concentrations decreased again during a short second period of stratification (settling with no resuspension) and then increased once more in fall when the water column became completely mixed again. A similar dynamic was seen in the offshore albeit delayed by $\sim 2$ weeks (peaking in late August at $1.1 \mu \mathrm{g} \mathrm{Chl} \mathrm{L}{ }^{-1}$ ). During this period, however, the offshore water column remained stratified and the peak there is likely a sole result of fluctuations in biomass standing stock. Over the May to November interval, chlorophyll-a concentrations in both the nearshore and offshore increased by approximately $30 \%$.

In spring the pool of particulate organic carbon (POC, seston-based) was substantially higher in the nearshore than in the offshore, at $95 \mu \mathrm{g} \mathrm{C} \mathrm{L}-1$ and $60 \mu \mathrm{g} \mathrm{C} \mathrm{L}{ }^{-1}$, respectively (Fig. 3-3b). No difference was observed, however, between nearshore and offshore chlorophyll-a concentrations at this time indicating that the difference is likely due to detrital matter kept in suspension in the completely mixed nearshore water column. Nearshore POC dynamics are strongly impacted by sedimentation and resuspension of detrital matter. This is seen when complete mixing in late August increased concentrations from $99 \mu \mathrm{g} \mathrm{C} \mathrm{L}^{-1}$ to $170 \mu \mathrm{g} \mathrm{C} \mathrm{L}{ }^{-1}$. Concentrations then decreased to $99 \mu \mathrm{g} \mathrm{C} \mathrm{L}^{-1}$ by late September; this, during a period in which the water column was stratified allowing 
sedimentation of detrital matter. POC increased to $175 \mu \mathrm{g} \mathrm{C} \mathrm{L}^{-1}$ in late October when the water column again became well mixed. Sedimentation-resuspension effects were not evident in the deeper offshore waters where POC concentrations remained stable until the onset of stratification. At this point, concentrations in the offshore increased from the 60 $\mu \mathrm{g} \mathrm{C} \mathrm{L}{ }^{-1}$ characteristic of spring to $147 \mu \mathrm{g} \mathrm{C} \mathrm{L}^{-1}$ by late August. Concentrations fell to 102 $\mu \mathrm{g} \mathrm{C} \mathrm{L}{ }^{-1}$ by mid-September, similar to the pattern seen in chlorophyll-a, and then increased markedly in late October when fall mixing entrained biomass from the DCM.

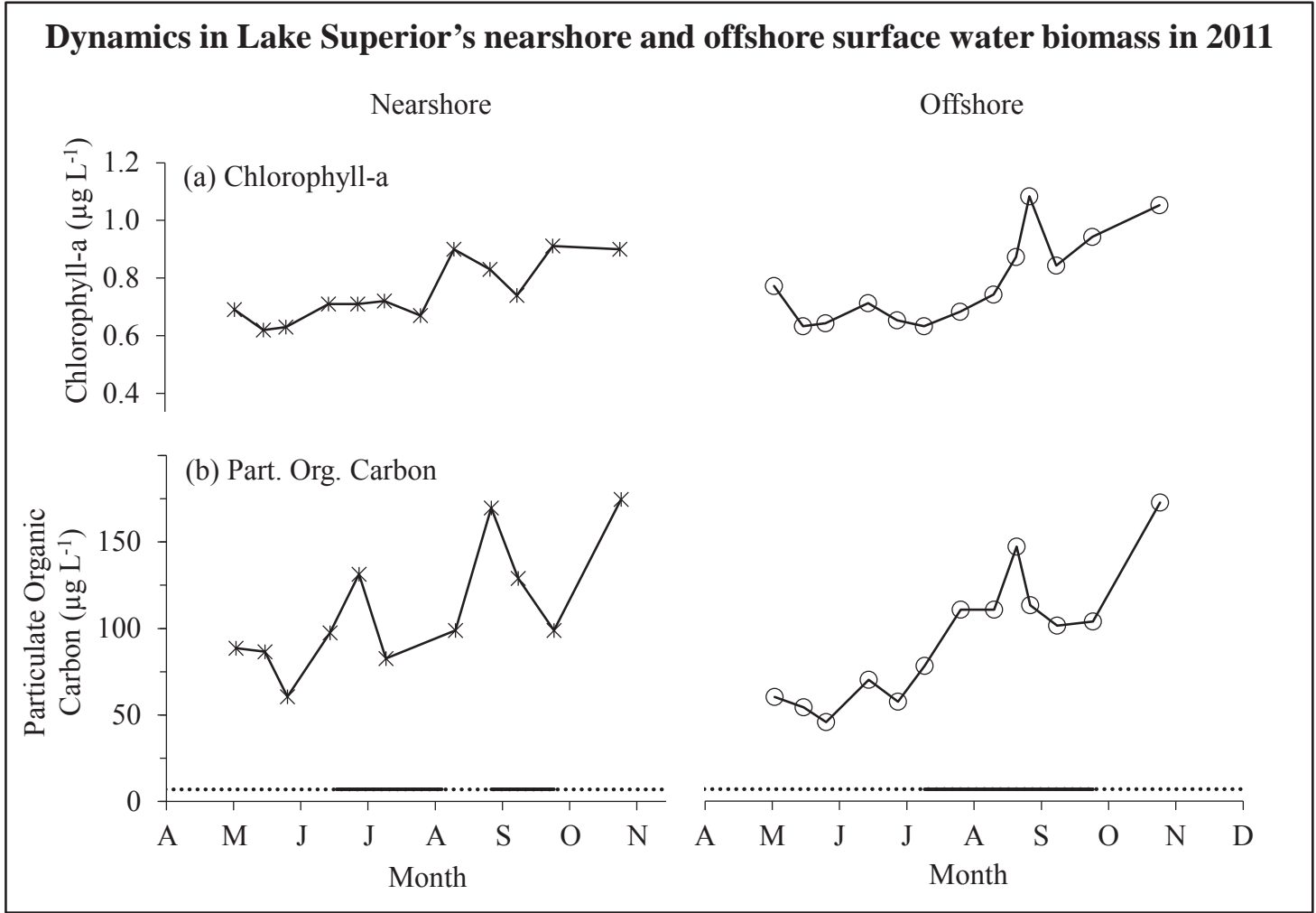

Figure 3-3. Description of nearshore and offshore dynamics in surface water biomass.

Panel: (a) chlorophyll-a, and (b) particulate organic carbon.

\subsubsection{Seasonal dynamics in the light regime}

Apart from water itself, surface radiation is attenuated by colored dissolved organic matter (CDOM), non-algal particles and phytoplankton. The latter three are known to vary 
not only seasonally but also spatially, e.g. with distance offshore (Effler et al. 2010). Differences in these constituents thus impart variability to the light extinction coefficient $\left(\mathrm{K}_{\mathrm{e}}\right)$ and the underwater light field as measured by Secchi-disk (SD). Light extinction coefficients manifested the expected inverse correlation with $\mathrm{Z}_{\mathrm{SD}}$ but the relationship was not particularly strong statistically $r^{2}=0.63(n=7)$ and $r^{2}=0.57(n=7)$ in the nearshore and offshore, respectively.

Nearshore waters were, on average, significantly (t-test: $\mathrm{P}<0.1)$ less transparent than those in the offshore (mean \pm S.D. for $Z_{S D, \text { near }}=10.5 \pm 2.8 \mathrm{~m}$ and $Z_{\mathrm{SD}, \text { off }}=13.3 \pm 3.9$ $\mathrm{m} ; \mathrm{K}_{\mathrm{e}, \text { near }}=0.16 \pm 0.04 \mathrm{~m}^{-1}$ and $\mathrm{K}_{\mathrm{e}, \text { off }}=0.13 \pm 0.03 \mathrm{~m}^{-1}$, Fig. 3-4a and $\mathrm{b}$ ), reflecting differences in the concentration of particulate matter $\left(\mathrm{TSS}_{\text {near }}=0.45 \mathrm{mg} \mathrm{L}^{-1}\right.$ and $\mathrm{TSS}_{\text {off }}=$ $0.35 \mathrm{mg} \mathrm{L}^{-1}$, Fig. 3-4c and d) and colored dissolved organic matter $\left(\mathrm{K}_{\mathrm{e}, \mathrm{CDOM} \text {, near }}=0.12 \mathrm{~m}^{-1}\right.$ and $\mathrm{K}_{\mathrm{e}, \mathrm{CDOM} \text {,off }}=0.09 \mathrm{~m}^{-1}$ ). Temporally, transparency in both nearshore and offshore waters generally tracked the seasonal increase in plankton biomass (Chl and POC, Fig. 3-3, respectively) while deviations from this pattern were associated with fluctuations in TSS and CDOM (Fig. 3-4a and b).

In the nearshore, periods of complete mixing led to resuspension, elevating TSS and reducing transparency (e.g. late October). An exception to this occurred on 12 August when the magnitude of the light extinction coefficient did not respond to the observed elevation in TSS (grey diamond in Fig. 3-4b). No $Z_{S D}$ measurements were made on that date due to high seas. In a similar manner, episodes of stratification (July and late August - early September) led to reduced mixing, facilitating sedimentation of TSS and resulting in increased transparency. Several periods of increased turbidity were observed (early May and late July) where TSS and CDOM increased simultaneously, likely not the result of 
resuspension but of terrestrial loadings from the adjoining Ontonagon River (major runoff event 7 days prior to sampling, date).

Seasonality in transparency in the offshore was less dynamic than in the nearshore, with CDOM imparting little variance and patterns generally tracking TSS. Transparency was greatest in spring, gradually declining over summer and reaching its lowest level in fall. Degraded transparency in fall occurs when the mixing depth increases to $25 \mathrm{~m}$, entraining constituents (CDOM and particulate matter) from the deep chlorophyll-a maximum (DCM). 


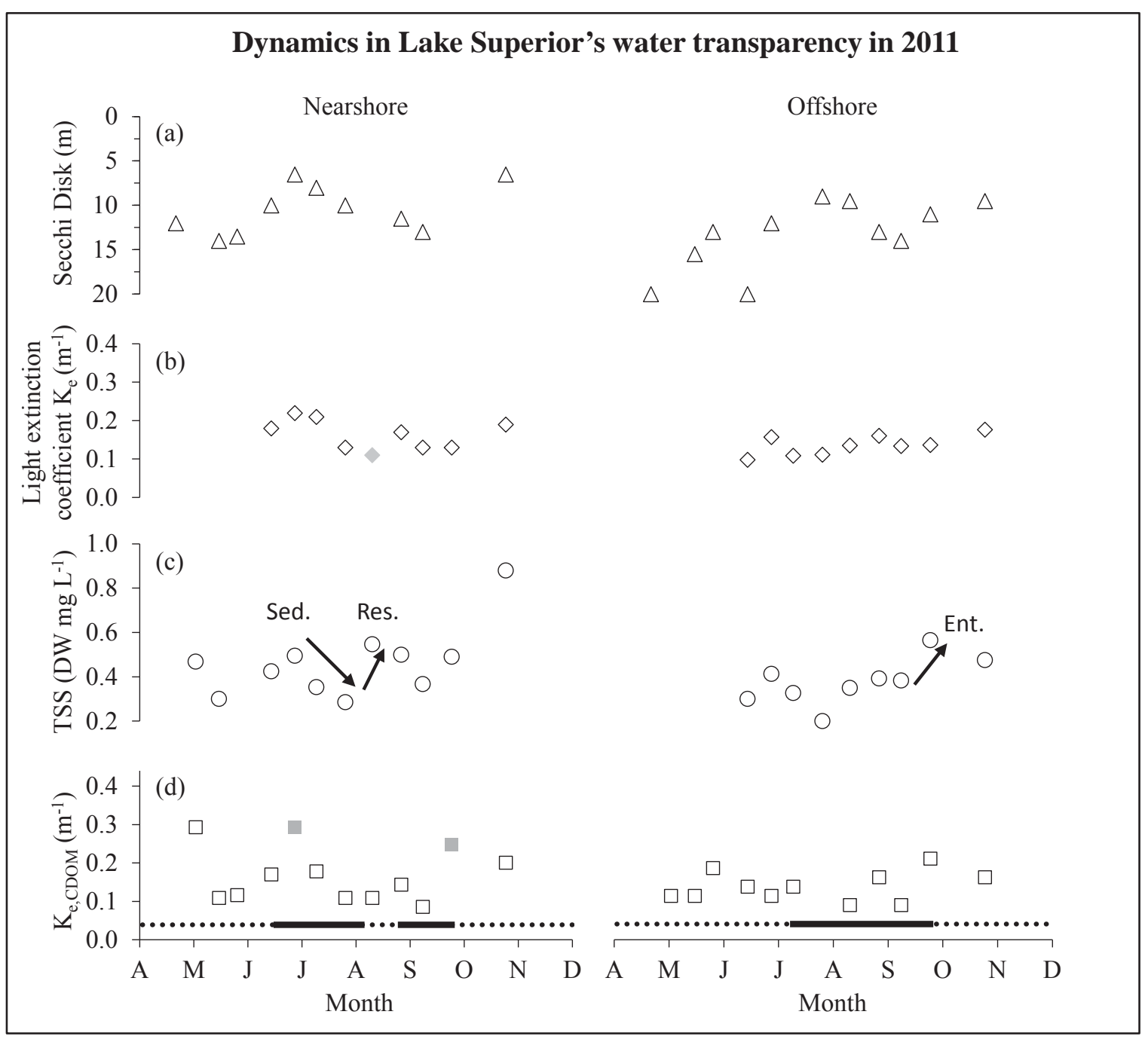

Figure 3-4. Dynamics in nearshore and offshore water transparency.

Expressed as: (a) Secchi Disk depth, (b) light extinction coefficient and constituents impacting transparency, including: (c) Total Suspended Solids and (d) partial light extinction coefficient due to Colored Dissolved Organic Matter. Abbreviations in figure (c) are as follows: Sed. refers to sedimentation, Res. to resuspension and Ent. to entrainment. Outliers are identified in grey. 


\subsubsection{Seasonal dynamics in phosphorus}

In Lake Superior, where terrestrial inputs are small relative to lake volume, phosphorus dynamics are primarily driven by internal cycling. Two phenomena stand out in mediating seasonal patterns in phosphorus constituents; one dominated by sedimentation/resuspension (the particulate fraction) and the other by biogeochemical cycling (the dissolved fraction). These phenomena can be conceptualized through a mass balance on the three components that make up the total phosphorus analyte in the surface waters: particulate (PP), dissolved organic (DOP) and soluble reactive phosphorus (SRP). The mass balance on PP includes SRP uptake by phytoplankton and losses to respiration and settling. For DOP, the source is respiratory losses from the PP pool and the sink is remineralization to SRP. The mass balance on SRP includes losses to the PP pool (uptake by phytoplankton) and gains through remineralization of DOP. In addition all three forms may be reintroduced to the surface waters through episodic mixing of the water column.

Changes in the particulate phosphorus pool generally tracked seasonality in vertical mixing and attendant sedimentation and resuspension. Nearshore PP concentrations were highest in spring $\left(1.5 \mu \mathrm{g} \mathrm{P} \mathrm{L}^{-1}\right)$ and remained relatively constant until the onset of thermal stratification when concentrations rapidly declined (losses to sedimentation > gains from

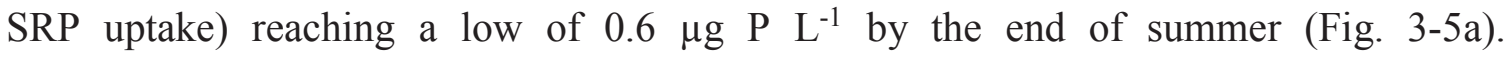
Concentrations increased during fall mixing, reaching levels observed in spring by late

October $\left(1.5 \mu \mathrm{g} \mathrm{P} \mathrm{L}^{-1}\right)$. A similar pattern was noted in the offshore waters where spring concentrations were relatively stable $\left(1.2 \mu \mathrm{g} \mathrm{P} \mathrm{L}^{-1}\right)$, decreased during thermal stratification and reached a minimum of $0.6 \mu \mathrm{g} \mathrm{P} \mathrm{L}{ }^{-1}$ by late-August (Fig. 3-5a). Concentrations then increased to1.4 $\mu \mathrm{g} \mathrm{P} \mathrm{L}^{-1}$ as fall mixing entrained particulate matter from the DCM. The 
seasonal average nearshore and offshore PP concentrations were not significantly different, $1.0 \pm 0.3 \mu \mathrm{g} \mathrm{P} \mathrm{L}{ }^{-1}$ and $1.0 \pm 0.2 \mu \mathrm{g} \mathrm{P} \mathrm{L}^{-1}$, respectively.

In contrast to $\mathrm{PP}$, total dissolved phosphorus concentrations $(\mathrm{TDP}=\mathrm{SRP}+\mathrm{DOP})$ in the nearshore and in the offshore did not manifest seasonality (Fig. 3-5b), but maintained generally similar concentrations over the sampling season $\left(1.1 \pm 0.3 \mu \mathrm{g} \mathrm{P} \mathrm{L}^{-1}\right)$. The TDP pool showed no response to seasonal dynamics in the mixing regime, suggesting that exchange with deeper waters is neither a significant source nor sink. Thus, TDP pool size is driven by biogeochemical cycling, i.e. the balance between SRP uptake and respiratory losses from the PP pool. Within the pool the relative abundance of the component constituents (SRP and DOP) is driven by the balance of DOP remineralization and uptake by phytoplankton.

Concentrations of dissolved phosphorus constituents were similar in nearshore and offshore waters: seasonal averages of $0.5 \pm 0.3 \mu \mathrm{g} \mathrm{P} \mathrm{L}{ }^{-1}$ for SRP (Fig. 3-5c) and $0.6 \pm 0.3$ $\mu g \mathrm{P} \mathrm{L}^{-1}$ for DOP (Fig. 3-5d). However, considerable differences in the relative abundance in SRP and DOP were observed over the sampling season. Concentrations of SRP were low in spring and increased towards summer, possibly due to elevated rates of DOP remineralization attending increases in water temperature and UV radiation (Ramin et al. 2012; Wetzel et al. 1995). Over the same interval, DOP concentrations fell, consistent with the remineralization concept proposed for SRP. As stratification persisted, SRP concentrations were reduced to non-detect levels (phytoplankton uptake exceeded remineralization) and remained low during summer and fall. Similar reductions were not noted in DOP over this interval, suggesting the accumulation of a recalcitrant DOP component (e.g. phosphate diesters; Sato et al. 2013). 
The total phosphorus (TP) analyte, routinely used as a metric of trophic status, consists of particulate and dissolved fractions. In Lake Superior, TP

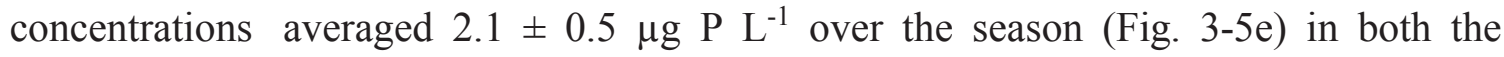
nearshore and offshore with dynamics driven by changes in the particulate phosphorus component. While average concentrations were similar in the nearshore and offshore, the timing of patterns differed. Nearshore TP concentrations in spring averaged 2.4 $\mu \mathrm{g} \mathrm{P} \mathrm{L}^{-1}$, decreased after thermal stratification reaching $1.6 \mu \mathrm{g} \mathrm{P} \mathrm{L}^{-1}$ by mid-July and increased again to $2.5 \mu \mathrm{g} \mathrm{P} \mathrm{L}{ }^{-1}$ by late October. TP concentrations in the offshore where relatively stable in spring at $2.5 \mu \mathrm{g} \mathrm{P} \mathrm{L}^{-1}$, decreased to $1.7 \mu \mathrm{g} \mathrm{P} \mathrm{L} \mathrm{L}^{-1}$ by mid-August and

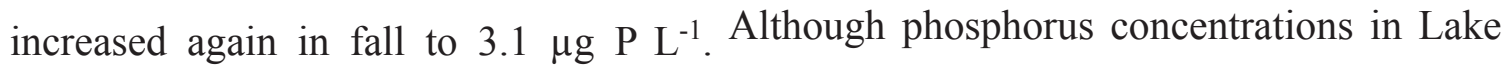
Superior are among the lowest for the Great Lakes, signals in TP and its components, e.g. sedimentation/resuspension of PP and transformations of TDP, were clearly evident. However, these same low concentrations and an absence of information regarding the lability of the DOP pool preclude further discernment of conditions driving seasonal patterns in phosphorus. 


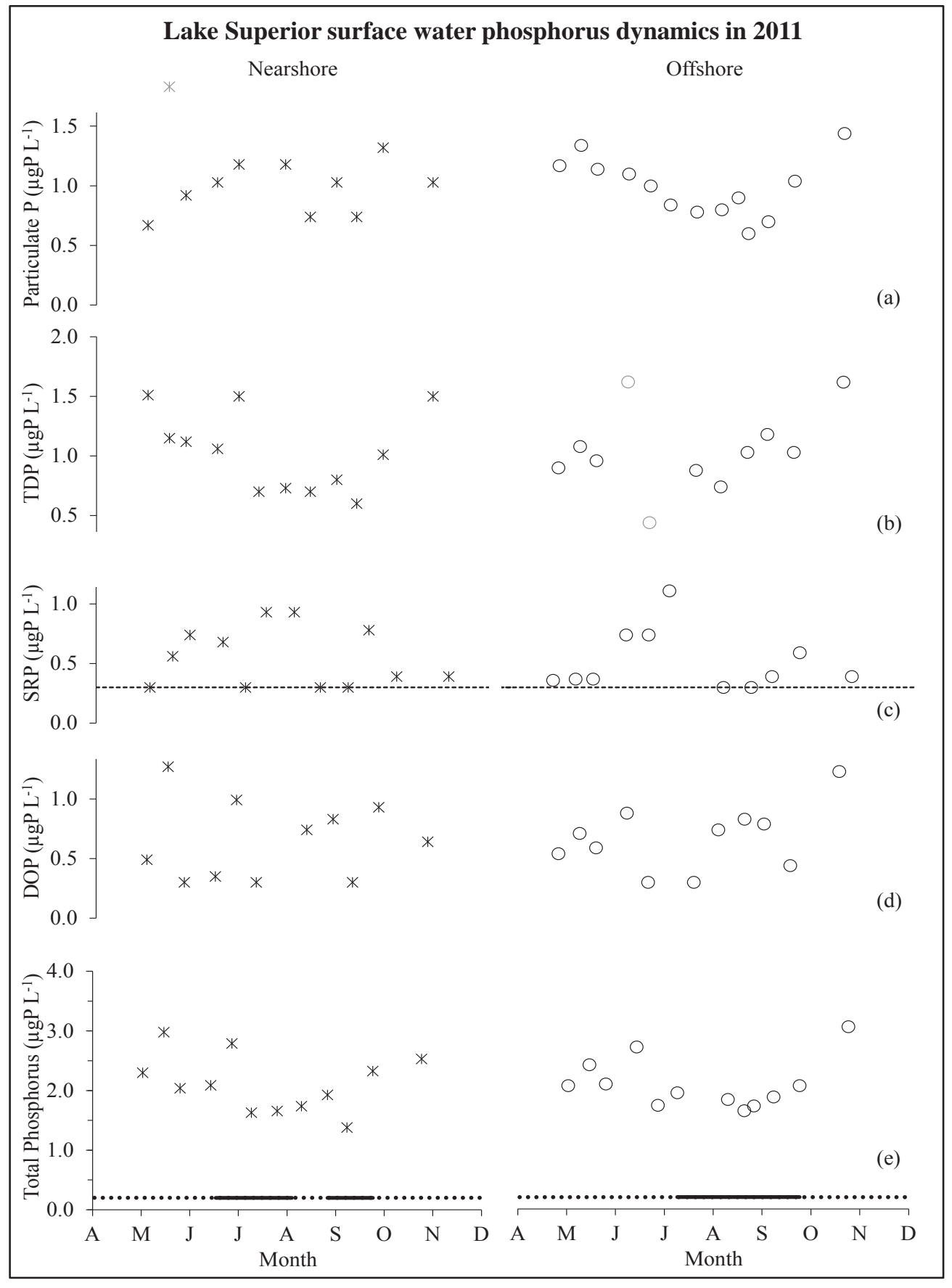

Figure 3-5. Surface water dynamics in phosphorus constituents.

Nearshore and offshore surface water concentrations of: (a) Particulate Phosphorus (outlier identified in grey), (b) Total Dissolved Phosphorus, (c) Soluble Reactive Phosphorus, (d) Dissolved Organic Phosphorus, (e) Total Phosphorus and the period of thermal stratification is indicated by the solid bar at the bottom of the figure. 


\subsubsection{Seasonal dynamics in phytoplankton stoichiometry}

The patterns in the ambient concentration of the growth limiting nutrient, SRP, described previously relate only indirectly to the level of nutrient stress experienced by the phytoplankton. These organisms are able to take up phosphorus beyond that required to meet immediate needs (i.e. luxury uptake; Droop 1974) and utilize those reserves during times when the nutrient is scarce. The competing effects of luxury uptake and dilution through growth results in a variable carbon to phosphorus $(\mathrm{C}: \mathrm{P})$ ratio. The $\mathrm{C}: \mathrm{P}$ metric serves to describe nutrient stress in a manner more reflective of organism physiology than that afforded by ambient nutrient concentrations (Flynn 2010). Phosphorus is considered non-limiting (or marginally so) at C:P ratios $<130$ while ratios ranging from 130-260 and $>260$ are reflective of moderate and severe limitation, respectively (Healey and Hendzel 1980).

C:P ratios in Lake Superior are not constant (fixed stoichiometry; Sterner 2011) but rather manifest a seasonal pattern where ratios are low during winter (non-limiting nutrient conditions) and then increase modestly during spring (pre-stratification) as increases in carbon content (growth) exceeds accumulation of phosphorus through uptake. Following stratification, $\mathrm{C}: \mathrm{P}$ ratios in the photic zone continue to increase (becoming more P-limited) as growth proceeds but SRP levels decline (Fig. 3-5c). Below the photic zone, phytoplankton maintain their pre-stratified ratios as light limitation restricts growth and physical conditions (temperature and UV-light availability) limit mineralization of DOP. In fall, as mixing intensifies, phytoplankton from below the photic zone (low C:P ratio) are entrained by the surface waters reducing the average $\mathrm{C}: \mathrm{P}$ ratio. 
Surface water C:P ratios in the nearshore remained close to levels indicative of moderate starvation (C:P ratio, 152; Fig. 3-6) during spring mixing. During summer stratification, the growth/mineralization dynamic drove C:P ratios higher, passing the boundary for severe starvation by mid-July $(\mathrm{C}: \mathrm{P}>260)$ and reaching levels indicative of extreme nutrient stress (C:P ratio; 550) by the end of summer. A period of complete mixing, lasting from early to late August, did not serve to improve nutrient status $(\mathrm{C}: \mathrm{P}$ ratio) because all phytoplankton remained in the photic zone $\left(Z_{\text {comp }}>Z_{\text {nearshore }}\right)$ where growth exceeded uptake. During fall mixing, however, nutrient stress was relaxed to some degree $(\mathrm{C}: \mathrm{P}$ ratio $550 \rightarrow 301)$ likely due to the entrainment of low C:P phytoplankton from the aphotic zone of the offshore waters.

In the offshore a similar, but less extreme, pattern was noted lagging, conditions in the nearshore by about two weeks. From spring until the onset of stratification in early July, C:P ratios in the offshore indicated a low degree of nutrient stress (C:P ratio $\sim 130$, Fig. 36). With the cessation of deep mixing (onset of stratification), nutrient stress increased, reaching levels indicative of severe starvation (C:P ratio >260) by mid-June. Phytoplankton became extremely nutrient stressed by late August (C:P ratio; 488) but to a lesser extent and for a shorter period than in the nearshore. C:P ratios dropped to 301 with fall mixing, a relaxation of phosphorus limitation but still a condition representing severe nutrient stress.

On average, the degree of phosphorus limitation was quite similar in nearshore and offshore waters (C:P ratio of 298 and 267, respectively) despite the fact that the nearshore receives an influx of phosphorus from the watershed. Terrestrial nutrient loading and its 
retention in the nearshore, especially associated with the spring runoff event, is impacted by the timing of the formation of the thermal bar (Auer and Gatzke 2004) as discussed subsequently.

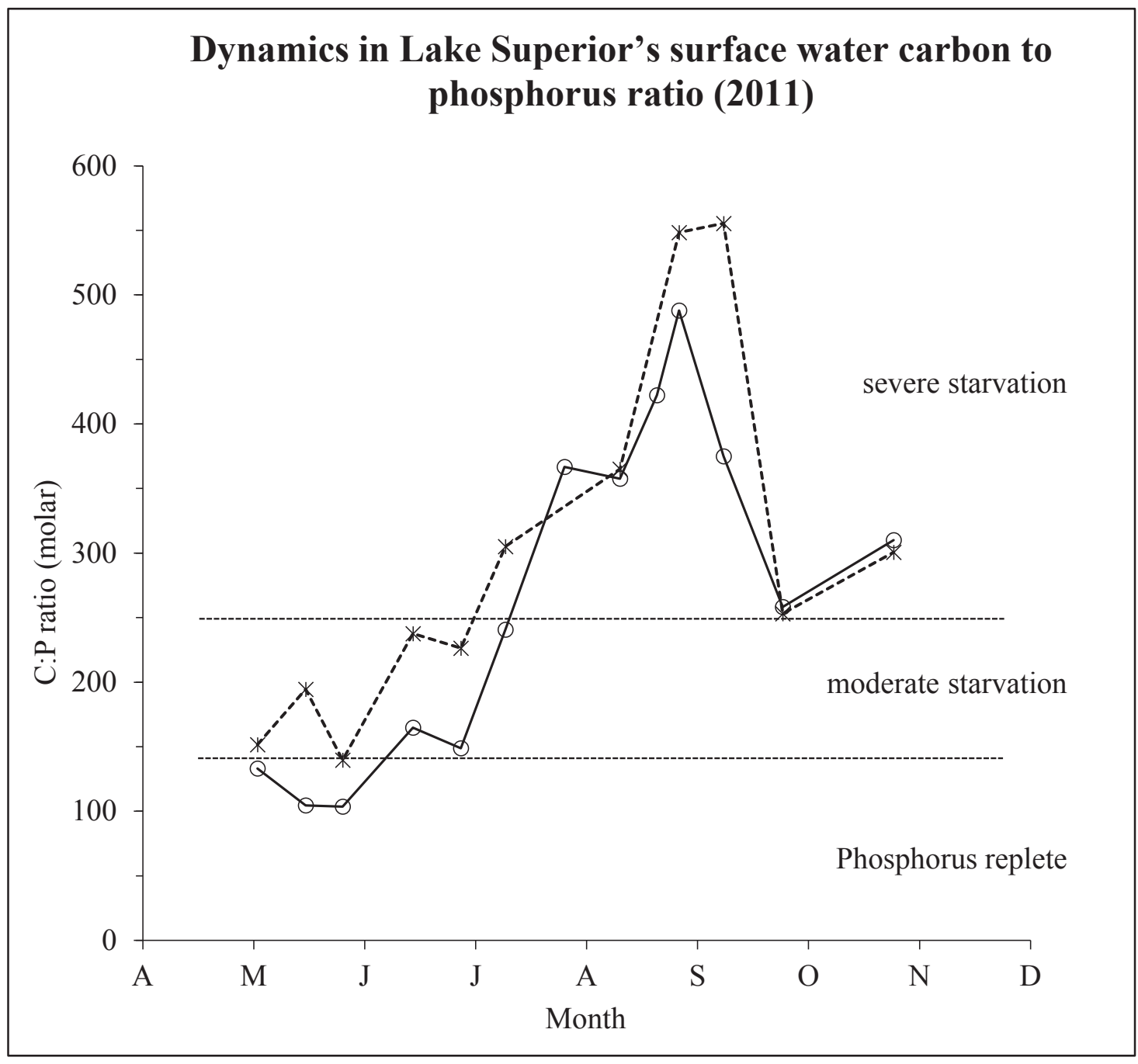

Figure 3-6. Seasonality in the surface water carbon to phosphorus ratio (molar).

Nearshore measurements indicated by stars and offshore measurements by circles, where C:P ratios $<130$ reflect phosphorus replete conditions, those ranging 130 to 260 moderate phosphorus starvation and rates $>260$ that of severe phosphorus starvation as described by Healey and Hendzel (1980). 


\subsubsection{Seasonal dynamics in growth mediation}

Mediation of the phytoplankton growth rate by environmental forcing conditions (i.e. temperature, light and phosphorus availability) may be captured in a multiplicative model using dimensionless multipliers (ranging from $0 \rightarrow 1$, complete $\rightarrow$ no limitation; Dijkstra and Auer, in review). The product of these multipliers yields a parameter $\left(f_{(\mathrm{TIN})}\right)$ that describes the combined effects of temperature, light and phosphorus limitation in mediating growth. Seasonal dynamics in each forcing condition are described here to examine the relative importance of each singly and in concert.

Temperature effects - the limiting effect of sub-optimal temperatures on phytoplankton productivity in Lake Superior is commonly represented by an exponential or Arrhenius function (e.g. Sterner 2011 and White et al. 2012). Temperature regulation in the phytoplankton assemblage of Lake Superior, however, was found to be better described byaconcavefunctionpassingthroughamaximumrateatanoptimumtemperature $\left(13^{\circ} \mathrm{C}\right.$

in summer, Dijkstra and Auer, in review). Based on this function a general pattern emerges where the temperature limitation characteristic of winter eases in spring, as water temperatures increase, and approaches an optimum (Fig. 1). Growth becomes less favorable in summer when surface water temperatures rise above the optimum and then eases again in fall as decreasing water temperatures approach the optimum once again. In 2011, $f_{(\mathrm{T})}$ increased in spring, more rapidly in the warmer nearshore waters and then followed the general pattern of spring and fall maxima (optimum conditions) and a mid-summer minimum (sub-optimum conditions; Fig. 3-7a). The mid-summer minimum was reached earlier (by $\sim 3$ weeks) and was more extreme $\left(f_{(\mathrm{T}) \text {, nearshore }} \sim 0.3\right.$ and $\left.f_{(\mathrm{T}) \text {, offshore }} \sim 0.7\right)$ in the nearshore due to greater warming of the surface waters. 
Light effects - phytoplankton response to changes in the light regime (seasonal and daily) may be described by a rectangular hyperbola function where the ascending and descending limb describe the effects of too little and too much light, respectively (Fig. 31). The observed pattern in light limitation at the surface was essentially identical for the nearshore and offshore, tracking the seasonal cycle of day length (Fig. 3-7b). The impact of depth on the light environment is treated subsequently in relation to calculation of areal primary production.

Phosphorus availability - limitation of growth due to phosphorus availability may be described by the Droop function with the C:P ratio representing the algal stored phosphorus content, a reasonable assumption for Lake Superior where terrestrial particulate matter is of lesser importance than that generated through in-lake processes (Fig. 3-1). Here, a low C:P ratio represents phosphorus replete conditions $\left(f_{(\mathrm{N})} \rightarrow 1\right)$ and a high $\mathrm{C}: \mathrm{P}$ ratio represents phosphorus starved conditions $\left(f_{\mathrm{N})} \rightarrow 0\right)$. Following the categories defined by Healey and Hendzel $(1980)$, an $f_{(\mathrm{N})}$ value of 0.7 represents moderate limitation and 0.6 severe nutrient limitation.

In early spring, prior to thermal stratification, phytoplankton in the nearshore were phosphorus replete, $f_{(\mathrm{N})} \sim 0.8$ (Fig. 3-7c). With the onset of stratification, phytoplankton resident within the epilimnion grew (Fig. 3-3a), diluting their phosphorus stores and increasing the degree of phosphorus limitation with the minimum $f_{(\mathbb{N})}$ value $(\sim 0.1)$ occurring in late August/early September. Conditions improved in mid-September as fall mixing in the nearshore entrained pelagic waters (with low C:P ratios) increasing the nearshore $f_{(\mathrm{N})}$ to $\sim 0.6$. Offshore limitation showed an identical, yet less extreme, pattern where phytoplankton were least phosphorus limited in spring $\left(f_{(\mathrm{N})} \sim 0.8\right)$ and became 
progressively more limited over the stratified season (Fig. 3-7c) with $f_{(\mathrm{N})}$ reaching a minimum of $\sim 0.3$ in late August. As in the nearshore, P-limitation eased through the fall, increasing to an $f_{(\mathrm{N})}$ of $\sim 0.6$.

Composite forcing conditions - the aggregate effect of temperature, light and phosphorus limitation in the surface waters is represented by $f_{\text {(TIN) }}($ Fig. 3-7d), the product of the component forcing condition functions $\left(f_{(\mathrm{T})}, f_{(\mathrm{I})}, f_{(\mathrm{n})}\right.$; Fig. 3-7a, $\mathrm{b}$ and $\mathrm{c}$ respectively). The signal feature of $f_{\text {(TIN) }}$ is the mid-summer minimum brought on by a combination of suboptimal temperatures and a high degree of phosphorus limitation (Fig. 3-7a and c.). This phenomenon, we termed the "summer desert", is governed by the thermal structure of the water column: directly by way of impacting temperature limitation and indirectly through the degree of phosphorus limitation. In the case of the latter, stratification of the water column greatly reduces vertical mixing allowing particulate matter to settle out of the epilimnion and thus reducing the size of the particulate phosphorus pool in the surface waters (Fig. 3-5a). This results in less material to be mineralized forming DOP and ultimately less SRP. The phytoplankton then must draw upon their internal P-reserves, the $\mathrm{C}: \mathrm{P}$ ratio increases and the degree of phosphorus limitation intensifies. Longer stratification in combination with a warmer and deeper epilimnion in the offshore and warmer nearshore waters, resulting from a warmer climate, will extend and intensify the "summer desert" and may result in a loss of primary production. This phenomenon may therefore have a significant impact on the timing and magnitude of energy transfer to the pelagic and benthic communities. 


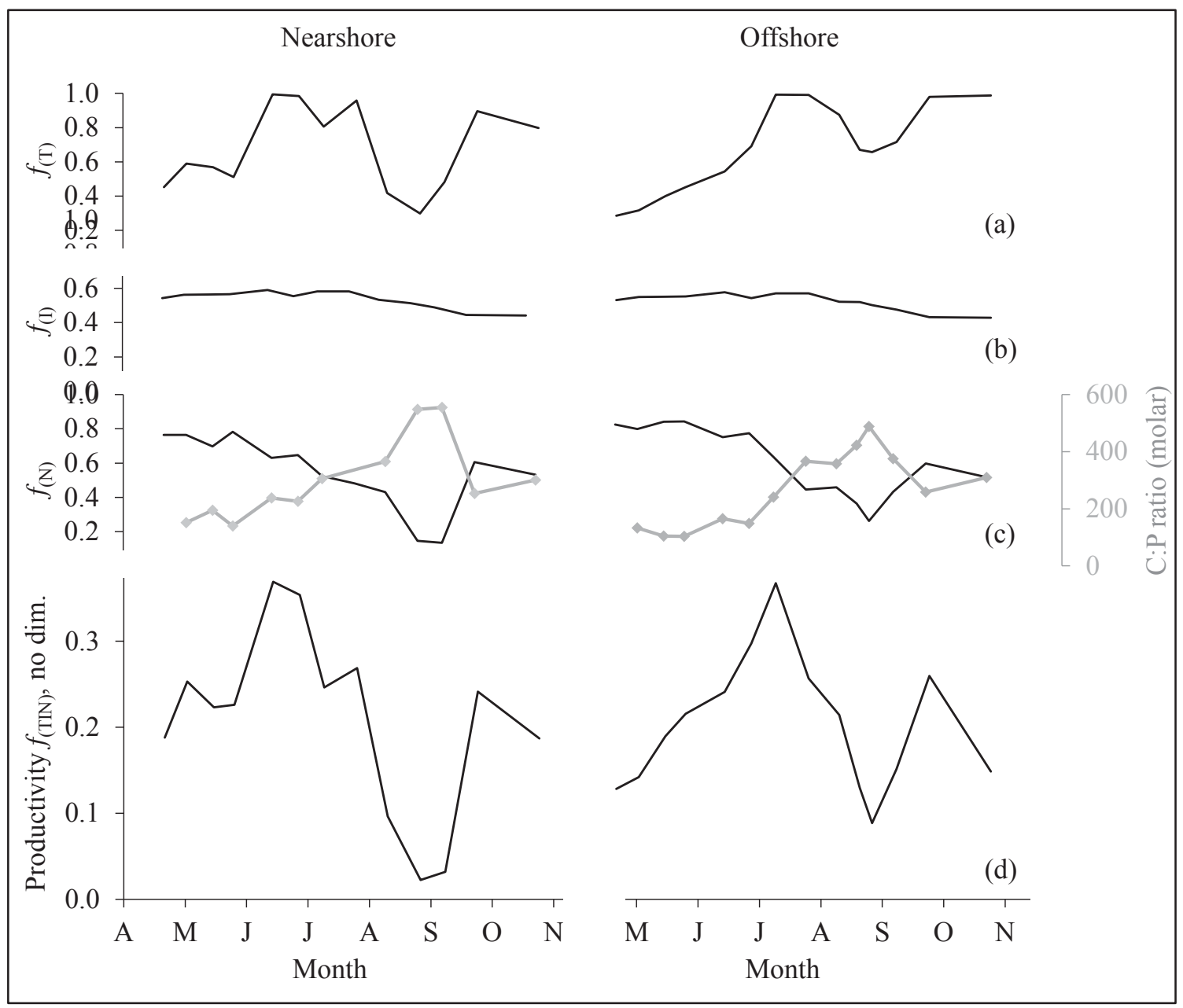

Figure 3-7. Surface water dynamics in growth limiting factors.

Dimensionless factors representing phytoplankton growth limitation in the surface water, ranging from complete to no limitation ( 0 and 1 , respectively) are displayed for: (a) temperature, (b) light, (c) phosphorus, (d) temperature, light and phosphorus limitation acting in concert. The molar C:P ratio is displayed by the grey line and axis on the right side offigure (c). 


\subsubsection{Spatial dynamics in phosphorus, algal biomass and production}

The previous section examined temporal structure in water temperature, attenuation factors of growth (i.e. temperature, light and nutrient status) and biomass for surface waters in the nearshore and offshore of Lake Superior. However, spatial phenomena evolving from horizontal and vertical heterogeneity represent key features in the ecosystem function of Lake Superior. Here we examine the impact of spatial phenomena in the horizontal, the role of the thermal bar in nearshore phosphorus retention, and in the vertical, the carbon biomass character of the DCM.

\subsubsection{Thermal bar mediated phosphorus retention in the nearshore}

The vast majority of the phosphorus loaded to the Great Lakes is received in the nearshore. For this reason, scientists, have long recognized differences between nearshore and offshore phosphorus concentrations and in attendant biology (e.g. Moll et al. 1993a 1993b; Keough et al. 1996). Lake Superior's relatively small and undeveloped watershed does not, however, provide loads of the magnitude observed in others of the Great Lakes. For example, the phosphorus load to Lake Ontario is six times that of Lake Superior (3.4 metric tonnes per annum (MTA) $\mathrm{km}^{-1}$ to Lake Ontario, $0.6 \mathrm{MTA} \mathrm{km}^{-1}$ to Lake Superior; Dolan and Chapra 2012).

Loading to the nearshore is not distributed evenly throughout the year, but is highest in spring when flow rates are elevated due to snowmelt. For example, in Lake Superior, $70 \%$ of the average annual TSS load is received during the spring runoff event (Auer and Gatzke 2004). In some years, a spring chlorophyll-a pulse suggests nearshore nutrient enrichment (Auer and Bub 2004; Depew et al. 2006 and references therein; Auer et al. 2010), while in other years no pulse is observed (Munawar and Munawar 1978; based on 
monthly sampling of 34 stations May - November 1973 and Urban et al. 2004; based on sediment trap measurements).

Differences in nearshore nutrient conditions may stem from variability in the magnitude of the spring runoff event and the duration of its retention in the nearshore prior to lakeward dispersal. Nearshore retention is impacted by the presence of a thermal bar (i.e. water with the greatest density $\left(\sim 4{ }^{\circ} \mathrm{C}\right)$ that forms the interface between less dense waters from the warmer nearshore and colder offshore), reducing transport across the coastal margin by establishing a density gradient (Spain et al. 1976) that separates warmer nearshore waters from the colder offshore. Model calculations show that nearshore entrainment of riverine constituents such as TSS may be transported to the open lake immediately or held close to shore for over 60 days (Auer and Gatzke 2004). Here we describe the formation and lakeward transition of the thermal bar for 1999 (significant entrainment potential) and 2011 (minimal entrainment potential) and discuss the significance of the phenomenon in retaining nutrients and impacting phytoplankton standing stock biomass (chl-a) in the nearshore.

Thermal bar dynamics and impacts - based on field sampling and satellite images, the thermal bar (further referred to as TB) became established on $\sim 8$ May 2011, remained close to shore $(<2 \mathrm{~km}$; depth $<13 \mathrm{~m})$ until the end of May and traversed the shelf-slope boundary by 16 June, extending to $>13 \mathrm{~km}$ offshore (Fig. 3-8). By 30 June nearshore temperatures approached $9^{\circ} \mathrm{C}$ and the TB was located over $26 \mathrm{~km}$ offshore. In 1999 , formation of the TB occurred around the same time ( $\sim 7$ May) and traversed the shelf-slope boundary one week earlier ( $\sim 8$ June), resulting in a shorter presence in the nearshore. Despite a modest difference in the duration of the TB (four weeks in 1999 and five weeks 
in 2011), a striking difference in the load available for trapping was predicted (58.5 MT in 1999 and 12.8 MT in 2011), based on USGS flows and the CQ relationship of Robertson et al. (personal communication).

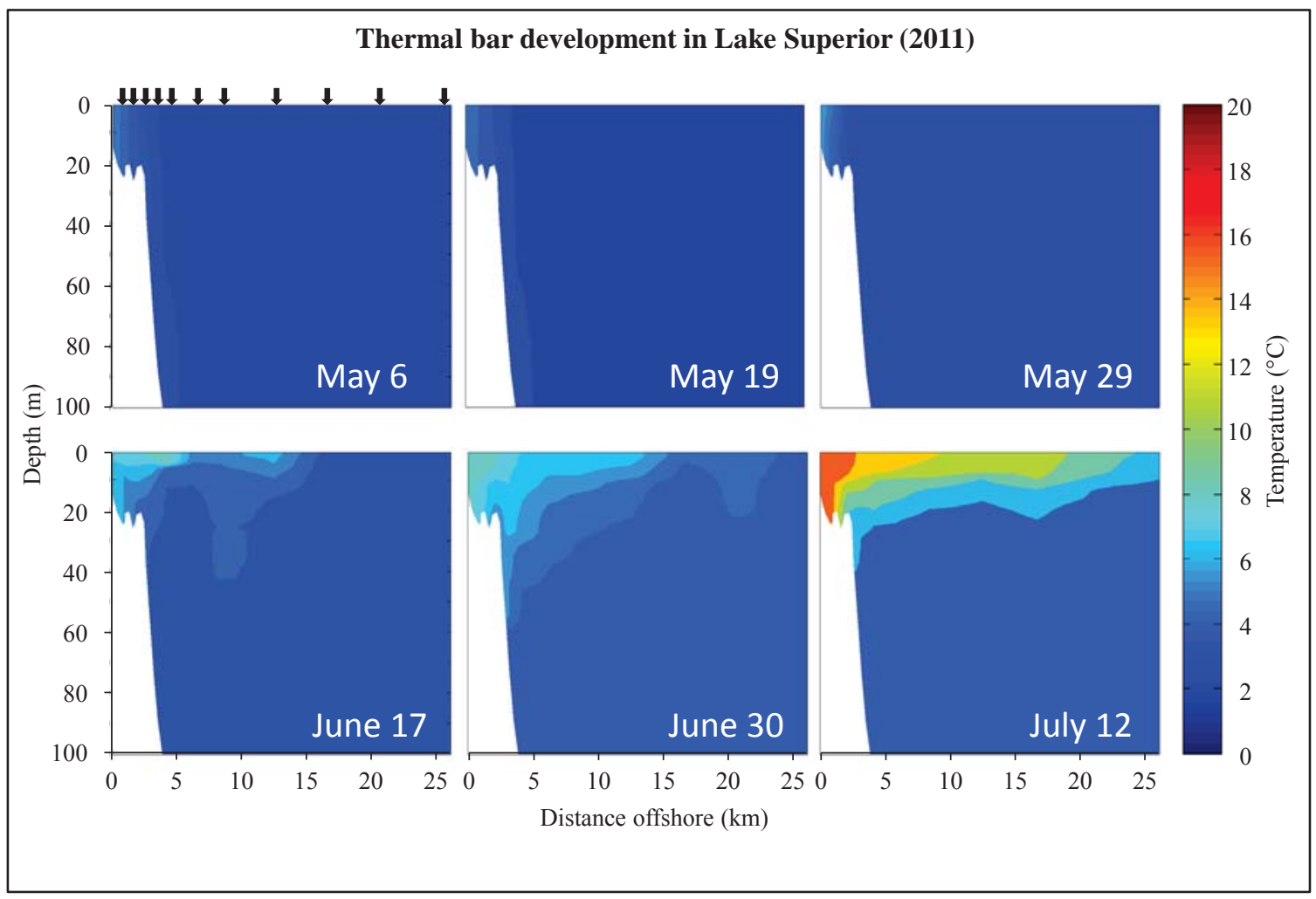

Figure 3-8. Dynamics in thermal bar development.

Lakeward progression of the thermal bar: first occurrence in the nearshore $>8$ May, remained close to shore until the end of May and rapidly traversed the shelf slope boundary by June 16, extending $>13 \mathrm{~km}$ offshore. Sampling stations are indicated by arrows in top left panel.

There were marked differences in phytoplankton biomass (chl-a) observed in the nearshore in May-June between 1999 and 2011 as well. Biomass increased in 1999, coincident with establishment of the TB and the bloom remained a prominent feature of the nearshore for over 8 weeks; lasting 4 weeks after the TB passed the shelf-slope boundary (Fig. 3-9a). The occurrence of elevated loads coincident with the presence of the 
TB 'trapping' apparently serves to support the spring phytoplankton bloom in the nearshore.

In May of 2011, a modest peak (1.2 $\mu \mathrm{g}$ Chl-a $\left.\mathrm{L}^{-1}\right)$ in phytoplankton biomass was observed shortly before the formation of the TB (Fig. 3-9b), coincident with elevated nutrient loadings to the nearshore. However, in the absence of a TB, nutrients and phytoplankton biomass were rapidly dispersed into the offshore and there was no sustained elevation in biomass in the nearshore. A second modest increase in biomass was observed in early July, but the TB had transitioned beyond the nearshore and again no sustained increase in biomass was observed.

In contrast, nutrient loads were substantially higher in 1999 and were coincident with the presence of the TB. This resulted in a striking increase in phytoplankton biomass, i.e. a spring bloom. Observations made in 1999 and 2011 illustrate that the timing and intensity of a spring phytoplankton bloom is mediated by the convergence of peaks in watershed runoff and formation of the TB. The attendant flux in biomass to higher trophic levels may cause cascading effects across the food web (e.g. to the benthos, Auer et al. 2013 and to zooplankton serving as prey for young-of-the-year fish; Keough et al. 1996). 


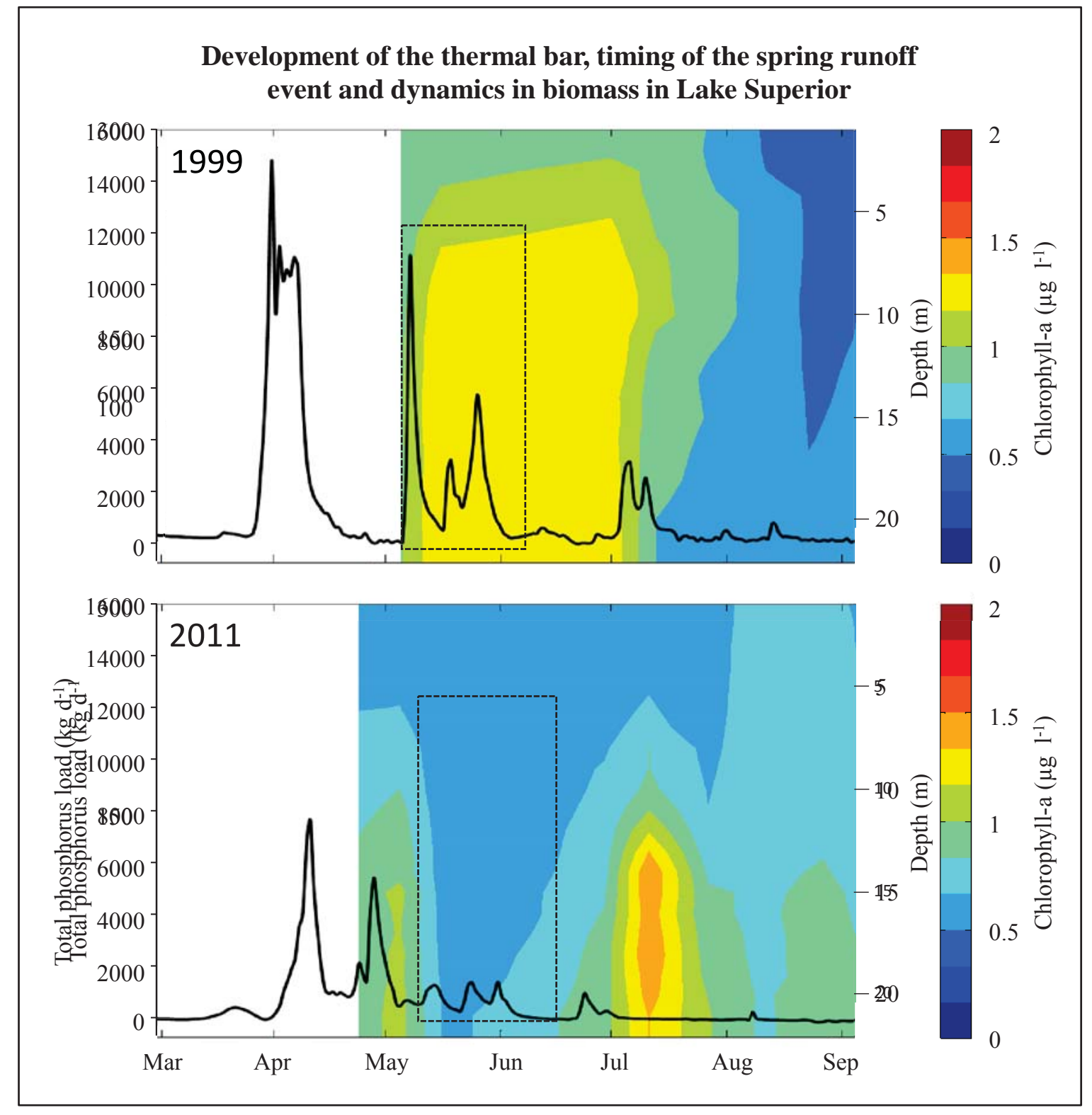

Figure 3-9. Timing of thermal bar formation in relation to the spring runoff event.

Intensity of the spring runoff event is indicated by TP loadings from the Ontonagon River, and nearshore chlorophyll-a concentrations; (a) in 1999 a high potential for nearshore entrainment of elevated nutrients loadings coincided with elevated chlorophyll-a concentrations, (b) in 2011 a low potential for nearshore entrainment of nearshore loadings from the spring runoff coincided with the absence of a spring phytoplankton bloom. 


\subsubsection{The Deep Chlorophyll-a Maximum}

The development of a sub-surface maximum in chlorophyll-a, also termed the deep chlorophyll-a maximum (DCM), has been observed for decades in clear, stratified systems including Lake Superior (e.g. Olson and Odlaug 1966 and Watson et al. 1975). Investigation of the DCM in Lake Superior through synoptic mid-summer sampling reveals that the DCM is resident within the metalimnion, generally at depths between $20 \mathrm{~m}$ and $40 \mathrm{~m}$, and close to the bottom of the photic zone (Barbiero and Tuchman 2001). Median maximum chlorophyll-a concentrations within the DCM ( $\sim .8$ ugChl-a

$\mathrm{L}^{-1}$ ) are double those of the surface waters (Barbiero and Tuchman 2004). Subsurface peaks are not only manifested in chlorophyll-a but in carbon as well (seston POC; Sterner 2011); these, however, seem to be of a smaller magnitude (Barbiero and Tuchman 2004).

Two distinct patterns in the vertical distribution of chlorophyll-a in offshore waters were observed in 2011: one during pre-stratification and one during the stratified period (Fig. 3-10). During pre-stratification, surface water chlorophyll-a levels $\left(<0.5 \mu \mathrm{g} \mathrm{L}^{-1}, 0-20\right.$ m) were lower than at depths $>20 \mathrm{~m}$, approaching $1 \mu \mathrm{g} \mathrm{L}-1$. With the onset of stratification in early July, the deep chlorophyll-a maximum began to form, first in waters with maximum depths as shallow as $50 \mathrm{~m}$, then extending to deeper waters. Lakeward progression of DCM formation continued, reaching $26 \mathrm{~km}$ offshore by the end of July. Highest concentrations were reached in July $(1.9 \mu \mathrm{g}$ Chl-a L-1, 2.7 times higher than surface concentrations). The thickness of the DCM remained constant $(\sim 22 \mathrm{~m})$ and the position of its centroid deepened ( $25 \mathrm{~m} \rightarrow 34 \mathrm{~m}$ ) as the season progressed. Deepening of 
the epilimnion during fall mixing entrained DCM waters dissipating the chlorophyll-a maximum and homogenizing chlorophyll-a concentrations to a depth of $60 \mathrm{~m}$. The DCM persisted longest in the offshore waters ( $\sim 3$ months) and dissipated in early October. 
Dynamics in the manifestation of the deep chlorophyll-a maximum in Lake Superior (2011)

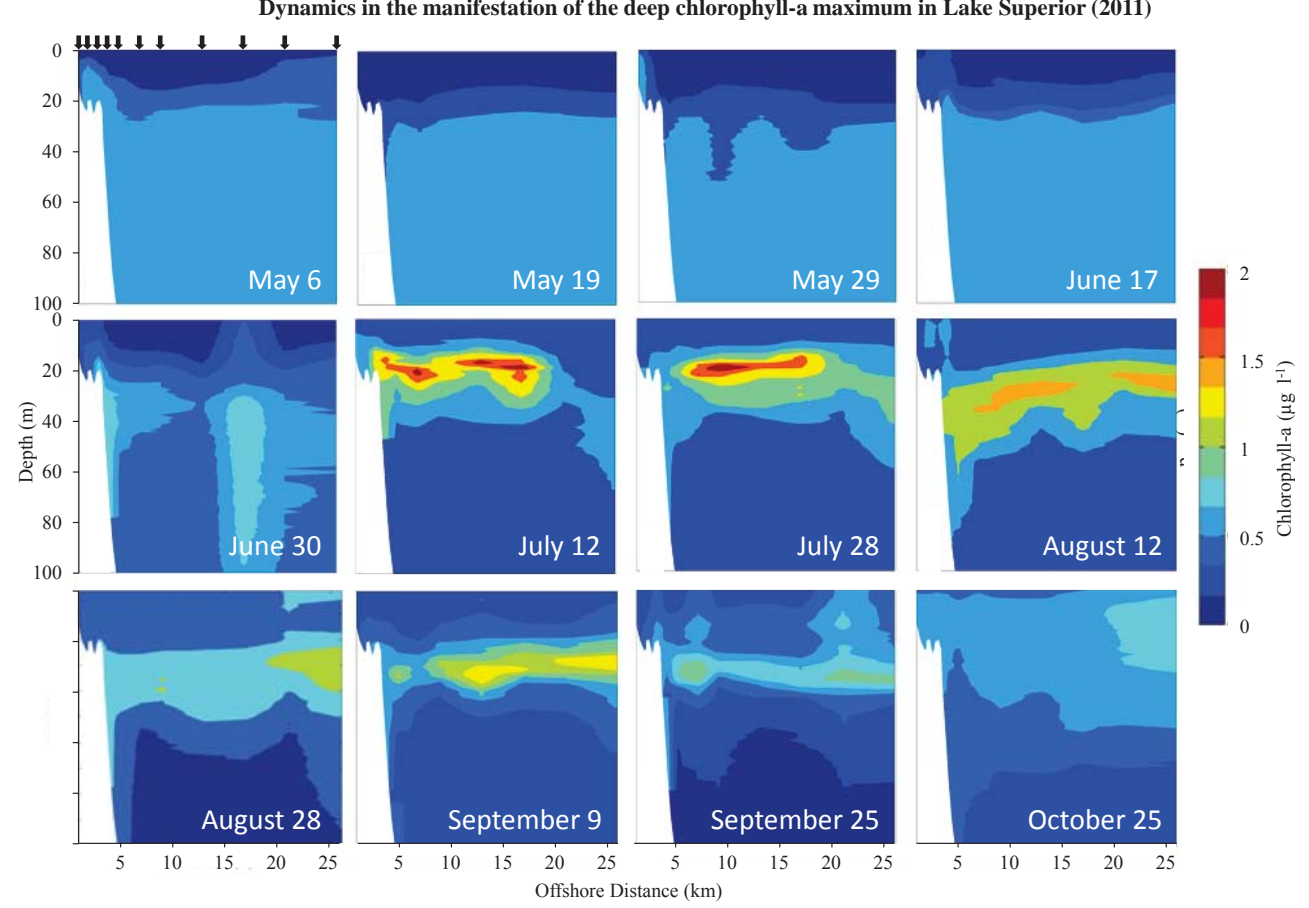

Figure 3-10. Dynamics in the manifestation of the deep chlorophyll-a maximum.

Spatiotemporal development of the formation and dissipation of the deep chlorophyll-a maximum in 2011. Sampling stations are indicated by arrows in top left panel. 
Water column dynamics attending the DCM - quantification of the contribution of the DCM to water column primary production is challenging due to the offsetting effects of proximity to the compensation depth (reducing production) and variable C:Chl-a ratios (increasing production), due to shade adaptation. Here we seek to describe primary production within the water column, including the DCM, by characterizing growth mediating factors (i.e. temperature, light and nutrient conditions) and biomass over the vertical profile.

Thermal structure - in 2011, waters remained completely mixed until early July (Fig. 3-11a). Following stratification, the epilimnion deepened, rapidly at first and then more gradually through the August - September interval. By late September the epilimnion reached a depth of $\sim 18 \mathrm{~m}$ and increased to $60 \mathrm{~m}$ by late October.

Composite forcing conditions - growth limitation, quantified through the $f_{(\mathrm{TIN})}$ parameter, manifested the distinct surface water pattern described previously and also displayed considerable variation with depth. Cooler temperatures and lower C:P ratios in the metalimnion result in more favorable $f_{\text {(TIN) }}$ values there than in the epilimnion (Fig. 311b). Subsequent deepening of the thermocline and an increase in the depth of the DCM centroid later placed phytoplankton at less favorable light intensities, smaller $f_{\text {(TIN) }}$. Deterioration of conditions supporting primary production in the metalimnion results in an interval of severe growth limitation, comparable to that concomitantly experienced in the surface waters, i.e. the "summer desert". Values of $f_{(\mathrm{TIN})}$ increased again in fall but did not recover to the levels observed in early summer.

Biomass distribution - organic carbon (as opposed to chlorophyll-a) is the preferred metric for biomass as it better represents the energy available for transfer to higher trophic 
levels. Like chlorophyll-a, the vertical distribution of particulate organic carbon in the water column manifested a distinct seasonal pattern. Biomass concentrations in 2011 were low and homogeneous across the water column in early spring, increasing over the photic zone as the season progressed (Fig. 3-11c). Subsurface biomass increased rapidly after the onset of stratification while biomass in the surface waters decreased. Subsurface biomass continued to accumulate in the metalimnion $(\sim 25 \mathrm{~m})$ during August and September. Increased fall mixing entrained the aggregated biomass from the metalimnion, increasing biomass in the surface waters. By late October, biomass was uniformly distributed to a depth of $60 \mathrm{~m}$.

Primary production - measurements of volumetric primary production reported for Lake Superior historically have ranged between $0.5-70 \mathrm{mg} \mathrm{C} \mathrm{m}^{-3} \mathrm{~d}^{-1}$ (see summary by Sterner 2010). More recently, Sterner (2010) performed in-situ measurements of production, yielding rates as high as $\sim 21 \mathrm{mg} \mathrm{C} \mathrm{m}^{-3} \mathrm{~d}^{-1}$ during summer stratification and not exceeding $10 \mathrm{mg} \mathrm{C} \mathrm{m}^{-3} \mathrm{~d}^{-1}$ during the spring and fall (Sterner 2010). These measurements provide a frame of reference for considering the model-calculated rates of primary production (Dijkstra and Auer, in review) presented here.

The impact of the "summer desert" and the aggregation of biomass in the metalimnion during stratification resulted in three distinct phases in water column primary production. The first period represents pre-stratified conditions when the waters are cold (below optimum) and homogenous and support low levels of phytoplankton biomass (Fig. 3-11d). At this time rates of primary production are low, ranging from $<1.5 \mathrm{mg} \mathrm{C} \mathrm{m}^{-3} \mathrm{~d}^{-1}$ in April to a maximum of $8 \mathrm{mg} \mathrm{C} \mathrm{m}^{-3} \mathrm{~d}^{-1}$ in late June. 
The second period is that of thermal stratification. Here, conditions in the epilimnion initially improve as temperature limitation eases and phosphorus reserves remain adequate. However, as stratification continues, conditions deteriorate in the epilimnion reducing production to $<1.5 \mathrm{mg} \mathrm{C} \mathrm{m}^{-3} \mathrm{~d}^{-1}$ and the "summer desert" is made manifest. A different situation develops in the metalimnion where phytoplankton biomass is high, temperatures remain close to optimum and light and phosphorus reserves are not strongly limiting. This combination results in the highest predicted rates of primary production occurring in late-July at a depth of $\sim 17 \mathrm{~m}\left(\sim 20 \mathrm{mg} \mathrm{C} \mathrm{m}^{-3} \mathrm{~d}^{-1}\right.$, PAR $\sim 15 \%$ of surface radiation), well above the depth of the chlorophyll-a maximum $(29 \mathrm{~m})$. Despite the fact that biomass is high at these depths light has been largely attenuated (PAR $\sim 4 \%$ of surface radiation) and the resulting primary production is substantially lower $\left(5 \mathrm{mg} \mathrm{C} \mathrm{m}^{-3} \mathrm{~d}^{-1}\right)$ than at the $17 \mathrm{~m}$ depth.

The third and last period is that of deep fall mixing. Here, productivity in the surface waters recovered to some extent but remained low $\left(<6 \mathrm{mg} \mathrm{C} \mathrm{m}^{-3} \mathrm{~d}^{-1}\right)$ due to continued Plimitation and the reduction in surface radiation and compensation depth as day length shortened.

Subsurface production maxima, like that reported here, were also observed in 1979 (Fahnenstiel and Glime 1983) and seen in several of the profiles reported by Sterner (2010). The highest rates of areal primary production (see below) occur in July and August as the system approaches the "summer desert", with $80 \%$ of that production occurring in the metalimnion. Even in September, when rates of production have declined, $47 \%$ of the production originates within the metalimnion. Further deepening of the epilimnion and elongation of thermal stratification may alter the pattern and magnitude of primary 
production. The juxtaposition of a poorly productive surface desert and a highly productive subsurface is one of the fascinating features of Lake Superior's limnology.

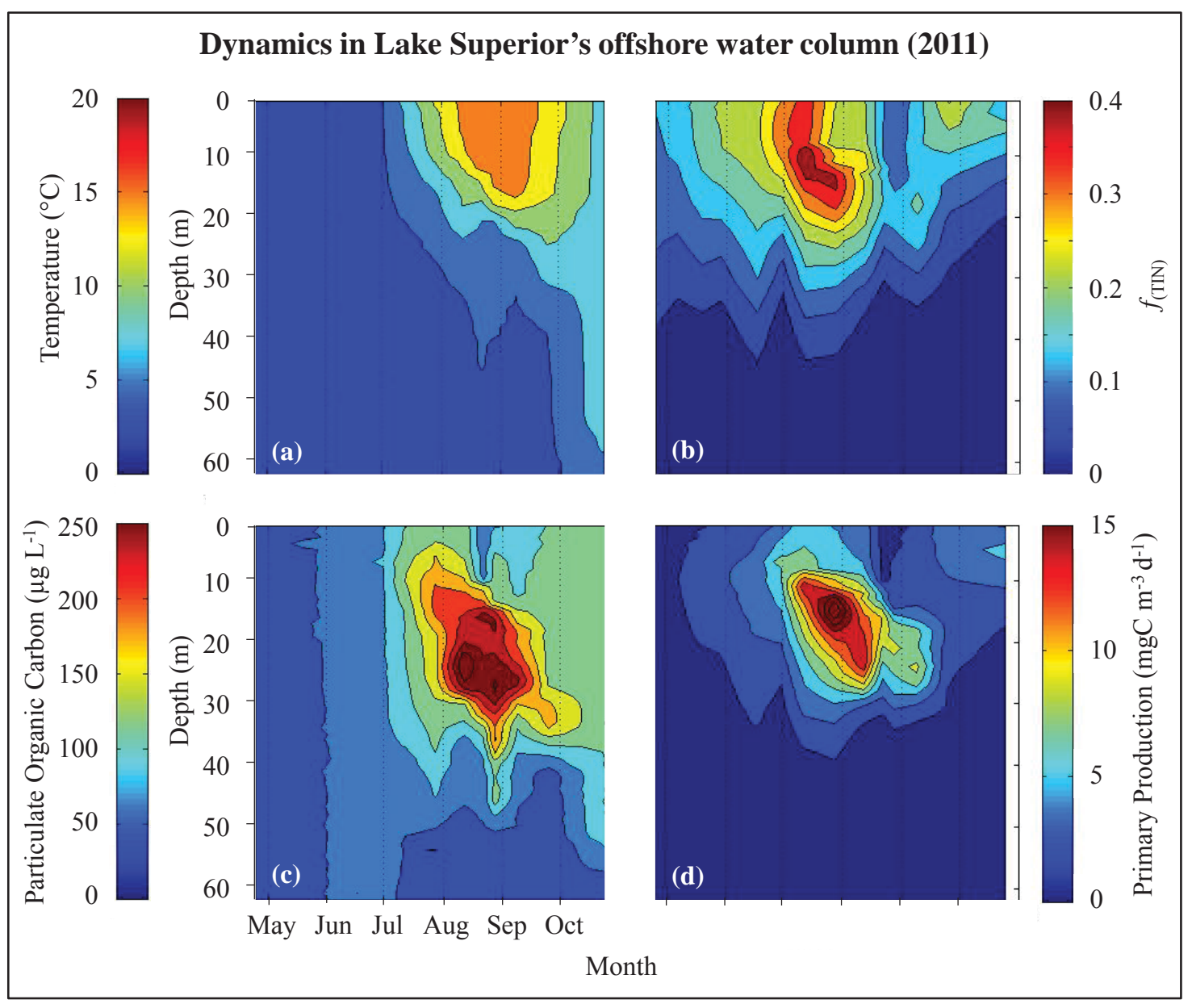

Figure 3-11. Offshore water column dynamics.

Panel: (a) temperature, (b) growth limiting forcing conditions represented by f(TIN), (c) particulate organic carbon biomass and, $(d)$ derived primary production indicating the "summer desert" in the epilimnion and elevated metalimnetic production. 


\subsubsection{Areal primary production}

To this point, we have focused on spatiotemporal patterns in primary production in Lake Superior. Monthly areal primary production serves to integrate water column dynamics providing a more macro scale description of the process. Calculated nearshore rates of areal primary production in 2011 ranged from $19-104 \mathrm{mg} \mathrm{C} \mathrm{m}^{-2} \mathrm{~d}^{-1}$ and fell within ranges reported by Urban et al. (2005) $\sim 20 \mathrm{mg} \mathrm{C} \mathrm{m}^{-2} \mathrm{~d}^{-1}$ in early spring to $\sim 75 \mathrm{mg}$ $\mathrm{C} \mathrm{m}^{-2} \mathrm{~d}^{-1}$ in fall and Auer et al. (2010) $\sim 10$ in early spring to $\sim 250 \mathrm{mg} \mathrm{C} \mathrm{m}^{-2} \mathrm{~d}^{-1}$ late spring, Fig. 3-12. Calculated offshore production ranged from $38-253 \mathrm{mg} \mathrm{C} \mathrm{m}^{-2} \mathrm{~d}^{-1}$ and is bracketed by rates reported by Fee et al. (1992) $100-200 \mathrm{mg} \mathrm{C} \mathrm{m}^{-2} \mathrm{~d}^{-1}$ in summer and Urban et al. (2005) $10 \mathrm{mg} \mathrm{C} \mathrm{m}^{-2} \mathrm{~d}^{-1}$ in spring - $200 \mathrm{mg} \mathrm{C} \mathrm{m}^{-2} \mathrm{~d}^{-1}$ in summer, and by Sterner (2010) $250 \mathrm{mg} \mathrm{C} \mathrm{m}^{-2} \mathrm{~d}^{-1}$ in early spring and $\sim 325 \mathrm{mg} \mathrm{C} \mathrm{m}^{-2} \mathrm{~d}^{-1}$ in summer.

Seasonally, nearshore areal primary production in Lake Superior manifested increasing rates in early spring, reaching a maximum in May, decreased to a midsummer low in August (due to the "summer desert") and recovered again in fall. A very different pattern was observed in offshore areal primary production. Here, a negatively skewed bellshaped distribution was exhibited with low rates of production in spring lagging that of the nearshore by $\sim$ four weeks, essentially reflecting more rapid warming in the nearshore. Highest production rates occurred in July, falling in September in response to the "summer desert" in the epilimnion and continued to decline toward October.

Patterns in primary production described here indicate that changes in climatic regime are impacting production directly through temperature limitation and indirectly by altering phosphorus conditions. In 2011, although nearshore and offshore driving forces in the surface waters remained similar, significant differences were displayed in areal primary 
production. Spatiotemporal fluctuations in the flux of primary production to secondary producers as described here may become accentuated under extreme climate conditions and cause cascading effects throughout the food web.

\section{Areal primary production in the nearshore and offshore of Lake Superior in 2011}

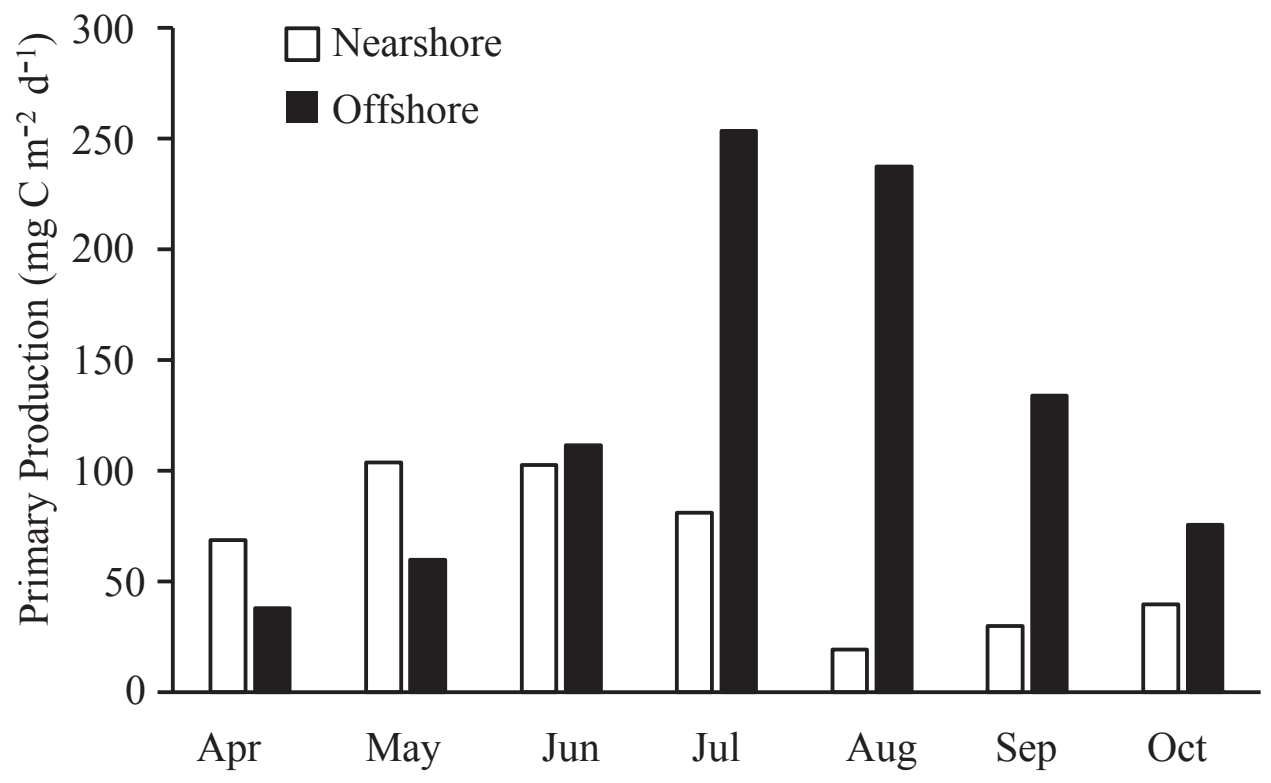

Figure 3-12. Seasonality in calculated areal primary production.

Open bars represent dynamics in the nearshore and solid bars the dynamics in the offshore. 


\subsection{Conclusions}

The analysis of factors mediating primary production in the surface waters of Lake Superior (i.e. temperature, light, phosphorus and biomass) identified the formation of a "summer desert"; a period of low productivity driven by suboptimal water temperatures and a high degree of phosphorus limitation. In 2011, thermal bar formation in the nearshore occurred after the spring runoff event (low potential for trapping nutrient loadings in the nearshore) and no spring phytoplankton bloom was observed. This in contrast to 1999 where thermal bar formation coincided with the spring runoff event (large tapping potential) and a spring bloom was manifested. In the offshore waters, calculated primary production in summer manifested a maximum in the metalimnion at a depth of $\sim 17 \mathrm{~m}$, well above the depth of the deep chlorophyll-a maximum (29 m). Each of these signals is subject to the effects of climate driven variation in the thermal regime of the lake and in turn impact the timing and magnitude of energy transfer to the pelagic and benthic communities and could cause cascading effects throughout the food web. 


\subsection{Acknowledgments}

The authors would like to thank Captain Stephen Roblee and the numerous deckhands for their assistance with sampling aboard Michigan Technological University's $R / V$ Agassiz and those that helped with sample processing and analysis especially Chuck Ouellette, Miles Corcoran and Ben Downer. The authors are also very grateful to Dr. Dale Robertson for calculating TP loadings of the Ontonagon River. Funding for this research was provided by the EPA Great Lakes Research Initiative (\#GL-00E00560/0). 


\subsection{References}

Agassiz, L., Cabot, J.E., 1850. Lake Superior. With a Narrative of the Tour by J. Elliot Cabot. RE Krieger Publishing Company.

APHA American Public Health Association, American Water Works Association, Water Environment Federation 2005. Standard methods for the examination of water \& wastewater. American Public Health Association, Washington, D.C.

Auer, M.T., Auer, N.A., Urban, N.R., Auer, T. 2013. Distribution of the Amphipod Diporeia in Lake Superior: The Ring of Fire. Journal of Great Lakes Research 39, 33-46. doi:10.1016/j.jglr.2012.12.020

Auer, M.T., Auer, N.A., Urban, N.R., Bub, L.A. 2010. Primary production, carbon flux and the distribution of the amphipod Diporeia in Lake Superior. Verh. Internat. Verein. Limnol. 30, 1499-1504.

Auer, M.T., Bub, L.A. 2004. Selected features of the distribution of chlorophyll along the southern shore of Lake Superior. Journal of Great Lakes Research 30, 269284.

Auer, M.T., Gatzke, T.L. 2004. The Spring Runoff Event, Thermal Bar Formation, and Cross Margin Transport in Lake Superior. Journal of Great Lakes Research 30, 64-81. doi:10.1016/S0380-1330(04)70378-0

Auer, N.A., Cannon, B.A., Auer, M.T. 2009. Life history, distribution, and production of Diporeia near the Keweenaw Peninsula Lake Superior. Journal of Great Lakes Research 35, 579-590. doi:10.1016/j.jglr.2009.08.004

Austin, J., Colman, S. 2008. A century of temperature variability in Lake Superior. Limnology and Oceanography 2724-2730.

Baehr, M.M., McManus, J. 2003. The Measurement of Phosphorus and Its Spatial and Temporal Variability in the Western Arm of Lake Superior. Journal of Great Lakes Research 29, 479-487. doi:10.1016/S0380-1330(03)70452-3

Barbiero, R.P., Tuchman, M.L. 2001. Results from the U.S. EPA's Biological Open Water Surveillance Program of the Laurentian Great Lakes: I. Introduction and Phytoplankton Results. Journal of Great Lakes Research 27, 134-154. doi:10.1016/S0380-1330(01)70628-4

Barbiero, R.P., Tuchman, M.L. 2004. The deep chlorophyll maximum in Lake Superior. Journal of Great Lakes Research 30, 256-268. 
Behrenfeld, M.J., Boss, E., 2006. Beam attenuation and chlorophyll concentration as alternative optical indices of phytoplankton biomass. Journal of Marine Research $64,431-451$.

Bennett, E.B., 1978. Characteristics of the Thermal Regime of Lake Superior. Journal of Great Lakes Research 4, 310-319. doi:10.1016/S0380-1330(78)72200-8

Bub LA. 2001. Spatial and temporal distribution of phytoplankton in Lake Superior. M.S. Thesis. Michigan Technological University, Houghton, MI.

Chapra, S.C. 2008. Surface water-quality modeling, Waveland press.

Cloern, J.E., 1977. Effects of Light Intensity and Temperature on Cryptomonas Ovata (cryptophyceae) Growth and Nutrient Uptake Rates1. Journal of Phycology 13, 389-395. doi:10.1111/j.1529-8817.1977.tb02947.x

Depew, D.C., Guildford, S.J., Smith, R.E.. 2006. Nearshore-offshore comparison of chlorophyll a and phytoplankton production in the dreissenid-colonized eastern basin of Lake Erie. Can. J. Fish. Aquat. Sci. 63, 1115-1129. doi:10.1139/f06-016

Dolan, D.M., Chapra, S.C. 2012. Great Lakes total phosphorus revisited: 1. Loading analysis and update (1994-2008). Journal of Great Lakes Research 38, 730-740. doi:10.1016/j.jglr.2012.10.001

Droop, M.R., 1974. The nutrient status of algal cells in continuous culture. Journal of the Marine Biological Association of the United Kingdom 54, 825-855.

Effler, S.W., Perkins, M.G., Peng, F., Strait, C., Weidemann, A.D., Auer, M.T. 2010. Light-absorbing components in Lake Superior. Journal of Great Lakes Research $36,656-665$.

EPA 2010. Sampling and Analytical Procedures for GLNPO's Open Lake Water Quality Survey of the Great Lakes [WWW Document]. URL http://www.epa.gov/glnpo/monitoring/sop/ (accessed 8.21.13).

Fahnenstiel, G.L., Glime, J., 1983. Subsurface chlorophyll maximum and associated Cyclotella pulse in Lake Superior. Internationale Revue der gesamten Hydrobiologie und Hydrographie 68, 605-616.

Fahnenstiel, G.L., Sicko-Goad, L., Scavia, D., Stoermer, E.F., 1986. Importance of picoplankton in Lake Superior. Canadian Journal of Fisheries and Aquatic Sciences 43, 235-240. 
Fee, E.J., Shearer, J.A., DeBruyn, E.R., Schindler, E.U., 1992. Effects of lake size on phytoplankton photosynthesis. Canadian Journal of Fisheries and Aquatic Sciences 49, 2445-2459.

Flynn, K.J. 2010. Ecological modelling in a sea of variable stoichiometry: Dysfunctionality and the legacy of Redfield and Monod. Progress in Oceanography, Special Issue: Parameterisation of Trophic Interactions in Ecosystem Modelling 84, 52-65. doi:10.1016/j.pocean.2009.09.006

Healey, F.P., Hendzel, L.L., 1980. Physiological indicators of nutrient deficiency in lake phytoplankton. Canadian Journal of Fisheries and Aquatic Sciences 37, 442453.

Keough, J.R., Sierszen, M.E., Hagley, C.A., 1996. Analysis of a Lake Superior coastal food web with stable isotope techniques. Limnol. Oceanogr. 41, 136-146. doi:10.4319/1o.1996.41.1.0136

Miller, R.L., Belz, M., Del Castillo, C., Trzaska, R. 2002. Determining CDOM absorption spectra in diverse coastal environments using a multiple path length, liquid core waveguide system. Continental Shelf Research 22, 1301-1310.

Moll, R.A., Bratkovich, A., Chang, W.Y., Pu, P., 1993a. Physical, chemical, and biological conditions associated with the early stages of the Lake Michigan vernal thermal front. Estuaries 16, 92-103.

Moll, R., Johengen, T., Bratkovich, A., Saylor, J., Meadows, G., Meadows, L., Pernie, G., 1993b. Vernal thermal fronts in large lakes: A case study from Lake Michigan. Proceedings-International Association of Theoretical and Applied Limnology 25, 65-65.

Munawar, M., Munawar, I.F., Fitzpatrick, M., Niblock, H., Lorimer, J., Munawar, M., Munawar, I.F. 2009. The base of the food web at the top of the Great Lakes: structure and function of the microbial food web of Lake Superior. State of Lake Superior 289-318.

Munawar, I.F., Munawar, M. 2009. Phytoplankton communities of Lake Superior 2001: Changing species composition and biodiversity of a pristine ecosystem. State of Lake Superior 319-359.

Munawar, M., Munawar, I.F., 1978. Phytoplankton of Lake Superior 1973. Journal of Great Lakes Research 4, 415-442.

Olson, T.A., Odlaug, T.O., 1966. Limnological observations on western Lake Superior. Proc. 9th Conf. Great Lakes Res. 109-118. 
Ramin, M., Perhar, G., Shimoda, Y., Arhonditsis, G.B. 2012. Examination of the effects of nutrient regeneration mechanisms on plankton dynamics using aquatic biogeochemical modeling. Ecological Modelling 240, 139-155.

Reavie, E.D., Barbiero, R.P., Allinger, L.E., Warren, G.J. 2014. Phytoplankton trends in the Great Lakes 2001-2011. Journal of Great Lakes Research 40, 618-639. doi:10.1016/j.jglr.2014.04.013

Sato, M., Sakuraba, R., Hashihama, F. 2013. Phosphate monoesterase and diesterase activities in the North and South Pacific Ocean. Biogeosciences 10, 7677-7688.

Siew, P.F. 2003. Phosphorus distribution and cycling in the Keweenaw Peninsula region of Lake Superior. M.S. thesis, Mich. Technol. Univ., Houghton.

Spain, J.D., Wernert, G.M., Hubbard, D.W., 1976. The Structure of the Spring Thermal Bar in Lake Superior, II. Journal of Great Lakes Research 2, 296-306. doi:10.1016/S0380-1330(76)72294-9

Sterner, R.W. 2011. C: N: P stoichiometry in Lake Superior: Freshwater sea as end member. Inland Waters 1, 29-46.

Sterner, R.W. 2010. In situ-measured primary production in Lake Superior. Journal of Great Lakes Research 36, 139-149.

Sterner, R.W., Smutka, T.M., McKay, R.M.L., Xiaoming, Q., Brown, E.T., Sherrell, R.M. 2004. Phosphorus and Trace Metal Limitation of Algae and Bacteria in Lake Superior. Limnology and Oceanography 49, 495-507.

Urban, N.R., Auer, M.T., Green, S.A., Lu, X., Apul, D.S., Powell, K.D., Bub, L. 2005. Carbon cycling in Lake Superior. J. Geophys. Res. 110, 17 PP. doi:10.1029/2003JC002230

Urban, N.R., Lu, X., Chai, Y., Apul, D.S. 2004. Sediment trap studies in Lake Superior: Insights into resuspension, cross-margin transport, and carbon cycling. Journal of Great Lakes Research 30, 147-161.

Urban, N.R., Munawar, M., Munawar, I.F. 2009. Nutrient cycling in Lake Superior: a retrospective and update. State of Lake Superior. New Delhi (India): Goodword Books 83-115.

Watson, N.H.F., Thomson, K.P.B., Elder, F.C., 1975. Sub-thermocline biomass concentration detected by transmissometer in Lake Superior. Verhandlungen Internationale Vereinigung Limnologie 19, 682-688. 
Wetzel, R.G., Hatcher, P.G., Bianchi, T.S., 1995. Natural photolysis by ultraviolet irradiance of recalcitrant dissolved organic matter to simple substrates for rapid bacterial metabolism. Limnology and Oceanography 40, 1369-1380.

White, B., Austin, J., Matsumoto, K. 2012. A three-dimensional model of Lake Superior with ice and biogeochemistry. Journal of Great Lakes Research 38, 6171. doi:10.1016/j.jglr.2011.12.006 


\section{Chapter 4}

\section{Ecosystem function in Lake Superior during a meteorologically extreme warm (2012) and cold year (2014)}

"If I have seen further it is by standing on the shoulders of Giants."
Isaac Newton (1642-1727)

In preparation for submission to the Journal of Great Lakes Research. 


\subsection{Abstract}

Extensive field measurements, made during two meteorologically extreme and contrasting years (2012: warm and 2014: cold), were used to evaluate interannual differences in thermal regime, driving forces attenuating primary production (i.e. temperature, light and nutrients) and primary production of Lake Superior. Measurements, taken along a $26 \mathrm{~km}$ transect extending lakeward from Michigan's Keweenaw Peninsula, included temperature, solar radiation, transparency, beam attenuation, chlorophyll-a fluorescence, colored dissolved organic matter and phosphorus and carbon constituents. Calculations of primary production were made with a Lake Superior specific 1D model and confirmed to published in-situ measurements of primary production. Differences between years were especially striking in the offshore where in 2012 thermal stratification lasted $\sim 65$ days longer and the epilimnion became $>5^{\circ} \mathrm{C}$ warmer and $\sim 17 \mathrm{~m}$ deeper than in 2014. In 2012 biomass concentrations in the photic zone were higher ( $29 \%)$ and primary production, especially in summer, differed as well. In this year an extensive "desert" (a period of severe growth limitation in the surface mixed layer driven by phosphorus depletion and suboptimal temperatures) formed while none was observed in 2014. Rates of volumetric production in the metalimnion, an important location in the water column in summer, were higher in 2012 than in 2014 and maximized at $16.8 \mathrm{mg} \mathrm{Cm}^{-3} \mathrm{~d}^{-1}$ and 11.6 mg $\mathrm{Cm}^{-3} \mathrm{~d}^{-1}$, respectively. The temporal pattern in areal primary production in 2012 deviated from the negatively skewed bell-shape pattern observed in 2014, manifesting elevated production in April and decreased production in September. Calculated areal production in 2012 was 61\% higher over the May-September interval with summer production (July and August) peaking at $\sim 320 \mathrm{mg} \mathrm{Cm}^{-2} \mathrm{~d}^{-1}$. Production in 2014 peaked in 
August $\left(\sim 265 \mathrm{mg} \mathrm{Cm}^{-2} \mathrm{~d}^{-1}\right)$. The dynamics in forces driving primary production were different in the warm (2012) and cold (2014) year, resulting in alternate patterns in primary production which might cause cascading effects throughout the food-web.

Keywords: Lake Superior, ecosystem dynamics, primary production, DCM, thermal bar, $\mathrm{C}: \mathrm{P}$ ratio 


\subsection{Introduction}

Temporally climate change can manifest itself in two forms. The first and most studied, is characterized by long term, incremental changes observed in historical averages. Much attention has been given to determining the impact of gradual changing conditions on natural systems and these are found in all continents and most oceans, often as increases in temperature (IPCC 2014). The impact of incremental change in climate in the Great Lakes region is evidenced in the reduction of ice cover, lake warming and longer summer stratification (Wang et al. 2012; McCormick and Fahnenstiel 1999). Lake Superior, by virtue of its location and bathymetry is expected to experience the most severe changes of the Great Lakes (Lehman 2002). Some of these have already caused striking alterations; for example annual mean ice cover reduced by $71 \%$ or $2.1 \% \cdot \mathrm{yr}^{-1}$ (1973-2010; Wang et al. 2012), summer surface water temperature rose by $3.5^{\circ} \mathrm{C}$ or $0.035^{\circ} \mathrm{C} \cdot \mathrm{yr}{ }^{-1}$ (20th century; Austin and Colman 2008) and the duration of summer stratification increased $>17 \%$ at 4 hours $\cdot \mathrm{yr}^{-1}$ (20th century; Austin and Coleman 2008). Several researchers have employed model simulations to project the impacts of such changes on primary production (e.g. Hill and Magnuson 1990; Lehman 2002; White et al. 2012) and higher trophic levels (e.g. Meisner et al. 1987; Mandrak 1989; Hill and Magnuson 1990; Magnuson et al. 1997) in Lake Superior.

The second manifestation of climate change relates to short term variability, i.e. the magnitude, timing, frequency and duration of extreme events (Karl et al. 2009). The ecological impact of extreme weather events may be particularly severe, simply because they are extreme, but also because ecosystems have rarely been exposed to such events. 
Changes due to these events are not incremental but rather immediate, leaving little time for adaptation and recovery (Karl et al. 2009). For example, extreme weather events can impact light, temperature and nutrient conditions in aquatic ecosystems leading to changes in phytoplankton community structure (Beaver et al. 2012 and Beaver et al. 2013). Extreme events have recently been experienced in the Lake Superior watershed and include the record breaking warm year of $2012(<9 \%$ ice cover and lake averaged surface water temperatures reaching $>20^{\circ} \mathrm{C}$; NOAA-GLSEA data) followed in close succession by 2014 , a very cold year $\left(>95 \%\right.$ ice cover and lake averaged surface water temperatures $<15^{\circ} \mathrm{C}$; NOAA-GLSEA data).

Ecosystem model calibration and confirmation to extreme conditions would render these models more robust and improve predictive capacity concerning climate driven changes in the ecosystem. All of the papers cited above simulating climate change impacts on Lake Superior focused exclusively on long term changes. Thus, as Brooks and Zastrow (2002) recommended, our understanding of climate change effects would benefit from an improved and mechanistic understanding of extreme events and related system dynamics. Finally, due to the inherent unpredictability of extreme events vis-à-vis demands on monitoring programs, few studies have reported on the ecosystem response attending climate anomalies.

Here, we present field data describing spatiotemporal dynamics in primary production and their governing factors (i.e. temperature, light, phosphorus and primary producer biomass) across a nearshore to offshore gradient in Lake Superior for 2012 and 2014, two climatologically extreme years. 


\subsection{Methods}

Field sampling and sample analysis - water samples were collected and measurements made along a transect perpendicular to shore consisting of 11 stations and extending $26 \mathrm{~km}$ lakeward (N 47 26.354, W -88 46.816) off the Keweenaw Peninsula near Houghton, Michigan. This transect covers shelf $(<30 \mathrm{~m})$, slope $(30-125 \mathrm{~m})$ and profundal habitats (depth $>125 \mathrm{~m}$, Auer et al. 2009) and was used in several other Lake Superior studies (e.g. Auer and Bub 2004, Auer and Kahn 2004, Urban et al. 2004). In this work the nearshore equates with the shelf, slope with a transitional region and offshore with the profundal. The transect was sampled on a bi-weekly basis: 13 times in 2012 (4 April - 19 November) and 12 times in 2014 (23 May - 26 September).

Water column profiles of temperature, chlorophyll-a fluorescence, transmissivity and photosynthetically available radiation (PAR) were measured with a Seabird Electronics (SBE-25). Log linearized PAR data were used to derive the light extinction coefficients excluding non-log linear near surface values. Calibration of the fluorescence probe was conducted according to the Great Lakes National Program Office procedure LG405 (GLNPO, EPA 2010); the depth, temperature and PAR sensors were calibrated by the manufacturer. A pre-rinsed acid washed PE bucket was used to collect surface water samples, similarly a 20-liter Niskin bottle was used to sample the metalimnion and hypolimnion. Samples were transferred to acid-washed PE carboys and transported to onshore facilities for immediate processing.

Filtration of these samples was conducted with $0.4 \mu \mathrm{m}$ Polycarbonate Track-Etched Membrane filters. The retentate was used for particulate phosphorus (PP) analysis and the filtrate for determination of soluble reactive phosphorus (SRP), total dissolved phosphorus 
(TDP) and colored dissolved organic matter (CDOM). Samples for chlorophyll-a and particulate organic carbon (POC) were filtered using $0.7 \mu \mathrm{m}$ Binder-Free Glass Microfiber GF/F type filters (GLNPO procedures LG404, LG210 and LG206; EPA 2010). Preservation of samples followed GLNPO procedures (LG204, LG209, LG405, LG210 and LG211; EPA 2010). Chlorophyll-a measurements were made using a Shimadzu RF1501 spectrofluorometer and followed procedures outlined by Eaton and Franson (2005; Method 10200H). Quenching of surface water algae was accounted for by adjusting the data by $6.9 \%$ to a depth of 8 meters as indicated from the regression of mid-day CTD casts of chlorophyll-a fluorescence against night casts. Phosphorus samples were measured on a Perkin Elmer Lambda-2 spectrophotometer using the ascorbic acid method (Eaton and Franson 2005; Method 4500P). Prior to measurement all PP and TDP samples were digested with acid-persulfate (Eaton and Franson 2005; Method 4500P). Detection limits were as follows: phosphorus $0.3 \mu \mathrm{g} \mathrm{P} \mathrm{L}{ }^{-1}$, POC $4.6 \mu \mathrm{g} \mathrm{C} \mathrm{L}^{-1}$ and Chlorophyll-a $0.1 \mu \mathrm{g} \mathrm{L}-1$.

Calculation of primary production - primary production is calculated as the product of a maximum specific growth rate attenuated by the rate-mediating conditions of temperature, light and nutrients and phytoplankton biomass (Chapra 2008),

$$
P=\quad \mu_{\max } \cdot f_{(T)} \cdot f_{(I)} \cdot f_{(N)} \cdot P O C \quad \text { Equation } 1 .
$$

where:

$P=\quad$ rate of primary production $\quad \mathrm{mg} \mathrm{C} \mathrm{m}^{-3} \mathrm{~d}^{-1}$

$\mu_{\max }=$ maximum specific rate of primary production $\mathrm{d}^{-1}$

$f_{(T)}=$ attenuation function for temperature dimensionless ( 0 to 1$)$

$f_{(I)}=\quad$ attenuation function for light (PAR) dimensionless ( 0 to 1$)$

$f_{(N)}=$ attenuation function for nutrient conditions dimensionless ( 0 to 1$)$

$P O C=$ particulate organic carbon concentration $\quad \mathrm{mg} \mathrm{C} \mathrm{m}^{-3}$ 
Following the method described by Behrenfeld and Boss (2006) a proxy for phytoplankton biomass, expressed as carbon, was derived by correlating beam attenuation with measurements of POC (2012: $\mathrm{r}^{2} 0.75, \mathrm{n}=28$ and 2014: $\left.\mathrm{r}^{2} 0.80, \mathrm{n}=14\right)$. The cumulative effect of temperature $\left(f_{(\mathrm{T})}\right)$, light $\left(f_{(\mathrm{I})}\right)$ and nutrient $\left(f_{(\mathrm{N})}\right)$ limitation, representing the combined effect of environmental forcing conditions in the multiplicative model, is represented here by the parameter $f_{\text {(TIN) }}$. Parameterization of the model (Eq. 1) was performed exclusively with site specific kinetic coefficients and confirmed to an independent dataset of in-situ measured rates of primary production as described in Dijkstra and Auer (in review). Examples of normalized response functions are shown in Fig. 4-1. 


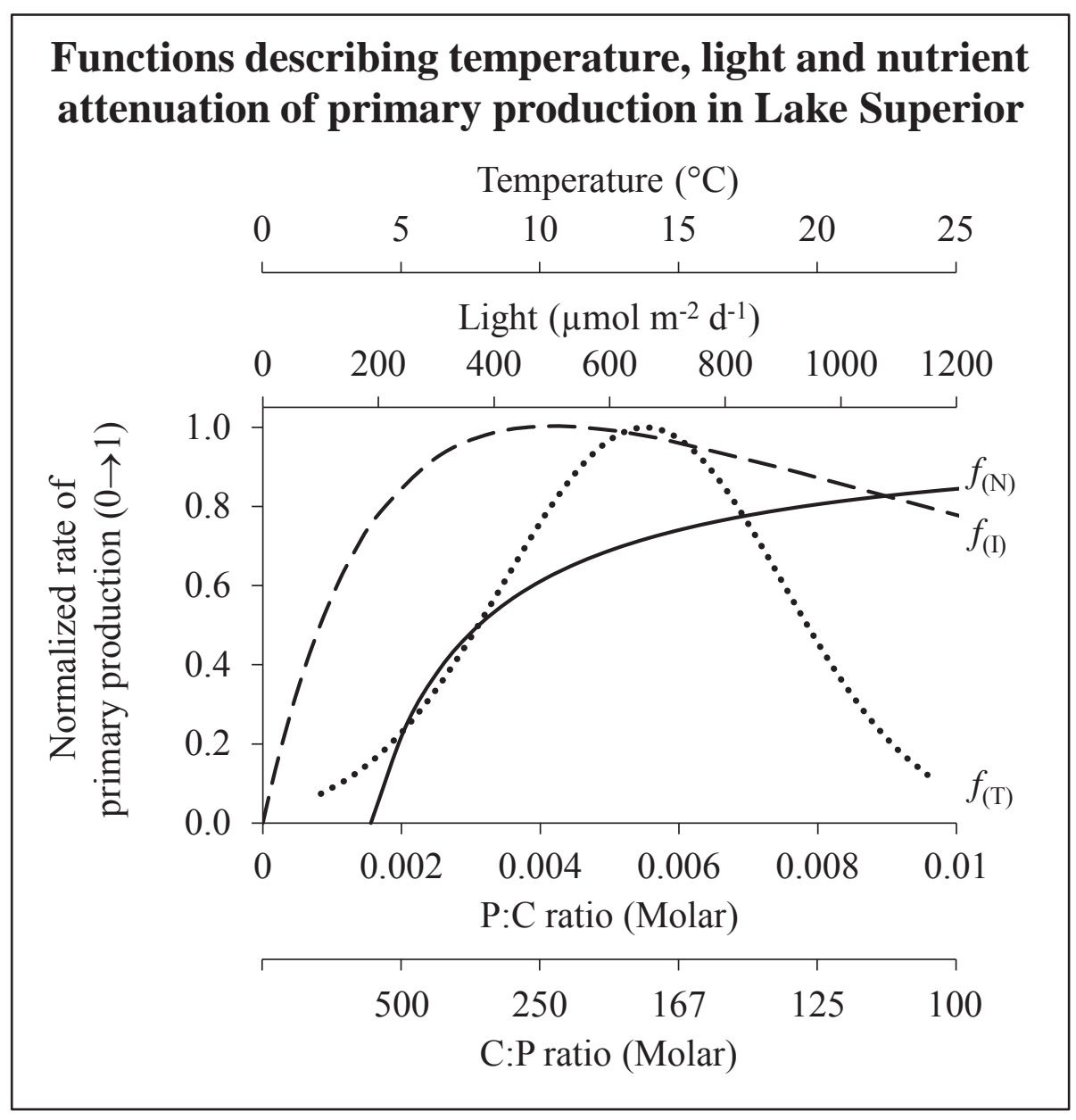

Figure 4-1. Temperature, light and nutrients effects on production

Normalized dimensionless attenuation functions, representing the growth limiting effect on phytoplankton due to temperature $(f(T)$, dotted line), light $(f(I)$, dashed line $)$ and nutrients $(f(N)$, solid line; axis expressed in the molar C:P and P:C ratio). Values range from 0 - 1 and represent complete limitation and no limitation, respectively. Functions are based on field measurements and lab experiments made by Bub (2001) and Siew (2003) in 1998-2000 on the natural phytoplankton assemblage of Lake Superior as described in Dijkstra and Auer (inreview). 


\subsection{Results and discussion}

\subsubsection{Temporal Dynamics in the surface water}

Temperature, light and nutrient conditions, factors driving primary production, not only vary seasonally, resulting in distinct seasonal patterns (Dijkstra and Auer, in review) but also differ between years. These interannual differences in forcing conditions will ultimately become manifested in primary production. Here we compare patterns in phytoplankton biomass and forcing conditions, including stoichiometry, that were observed in the nearshore and offshore of Lake Superior during the climatologically extreme years of 2012 (warm) and 2014 (cold).

\subsubsection{Dynamics in climate and thermal regime}

In January of 2012 lake-averaged surface water temperatures approached the 19922014 average (hereafter referred to as average). An anomalous increase in March air temperatures $\left(>15^{\circ} \mathrm{C}\right.$ above the 1981-2010 average; NOAA-ESRL physical science division) resulted in a seven day period where surface water temperatures exceeded $4^{\circ} \mathrm{C}$. Water temperatures remained well above average until late fall when temperatures became again similar to the average. Surface water temperatures in 2012 were, on average, $2.0^{\circ} \mathrm{C}$ above the $1992-2014$ average and were at times $>7.5^{\circ} \mathrm{C}$ higher. Temperatures in 2014 , on the other hand, averaged $1.5^{\circ} \mathrm{C}$ below the average, at times falling by as much as $4.6^{\circ} \mathrm{C}$ below average (Fig. 4-2). Differences were also manifested in the duration of thermal stratification; lasting 233 days in 2012 (17 March thru 23 March and May 5th thru December $16^{\text {th }}$ ) and 168 days in 2014 (10 June thru 25 November). 


\section{Surface water temperature of Lake Superior (2012, 2014 and 1992-2014)}

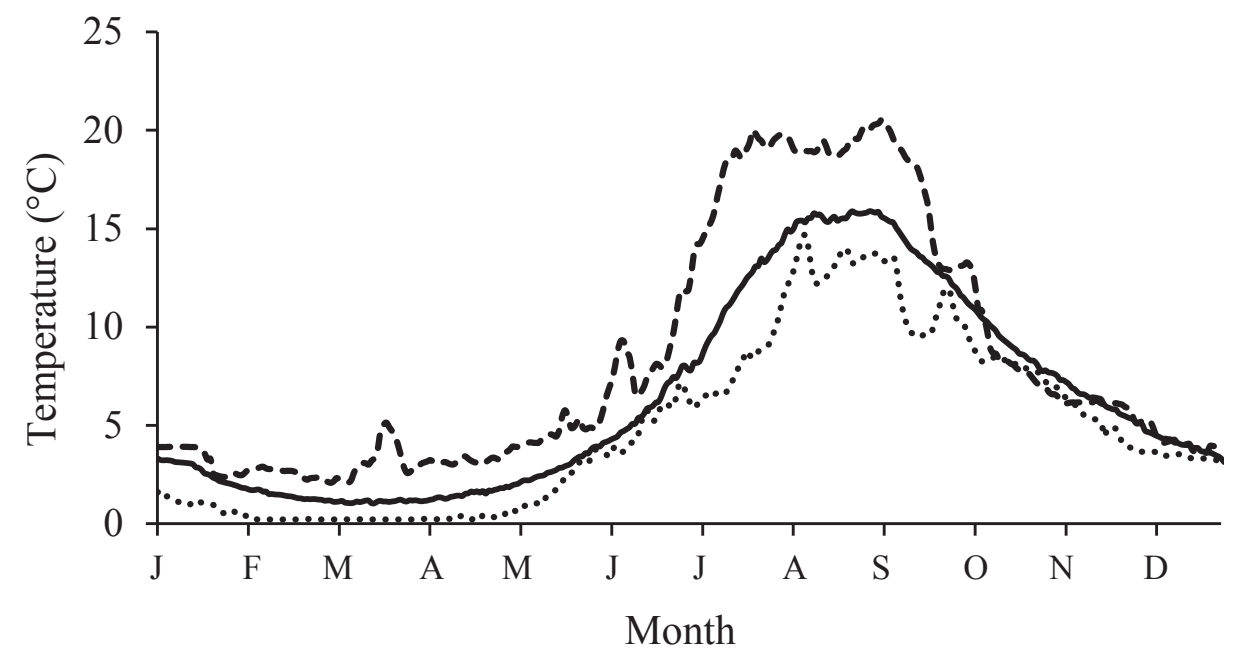

Figure 4-2. Pattern in lake averaged surface water temperature.

Temporal dynamics for 2012 (dashed line) 2014 (dotted line) and the average of the $1992-2014$ period (solid line, GLSEA Surface Water Temperature Data).

Similar patterns were observed in the surface water temperatures along the sampling transect (Fig. 4-3a). In 2012, spring warming in the nearshore resulted in stratification by early May while in 2014 spring warming lagged by $\sim 4$ weeks, delaying stratification until early June. Temperatures increased rapidly after stratification and became similar in both years during summer and fall. In both years the pattern in summer was broken by an upwelling of cold water that reduced the temperature temporarily by $>4^{\circ} \mathrm{C}$. Offshore surface water temperatures increased slowly in spring and accelerated after thermal stratification was established (late May in 2012 and mid-June in 2014). Spring and summer temperatures in 2014 lagged those observed in 2012 by almost 6 weeks and unlike temperatures in the nearshore, did not become similar between years. In the fall of 2014 cooling of the surface waters preceded that in 2012 by $\sim 2$ weeks. 


\subsubsection{Dynamics in phytoplankton biomass}

Nearshore chlorophyll-a concentrations (serving as a proxy for phytoplankton biomass) were elevated in the spring of $2012\left(1.2 \mu \mathrm{g} \mathrm{L}{ }^{-1}\right.$; Fig 4-3b). Concentrations generally decreased toward summer with the exception of a spring peak in late May (0.9

$\left.\mu \mathrm{g} \mathrm{L}^{-1}\right)$. Minimum levels were reached in late June $\left(0.3 \mu \mathrm{g} \mathrm{L}^{-1}\right)$ and returned in fall to concentrations observed in spring.

The pattern manifested in 2014 was similar yet more dynamic. Here, a spring peak was observed in late June $\left(1.0 \mu \mathrm{g} \mathrm{L}^{-1}\right)$ possibly aided by resuspension of sedimented phytoplankton as the water column was completely mixed at that time. Concentrations declined to $\left(0.2 \mu \mathrm{g} \mathrm{L}^{-1}\right)$ in early August, followed by a sharp peak in late August when waters were well stratified indicating that this increase did not result from resuspension. Concentrations decreased again in early September $\left(0.6 \mu \mathrm{g} \mathrm{L}^{-1}\right)$ and reached $1.7 \mu \mathrm{g} \mathrm{L}^{-1}$ by November; levels not seen in 2012.

Patterns in the offshore tended to be more gradual (Fig. 4-3b). The 2012 pattern tracked that of the nearshore where spring concentrations $\left(0.8 \mu \mathrm{g} \mathrm{L}^{-1}\right)$ tended to decrease with the exception of a peak in mid-May $\left(0.6 \mu \mathrm{g} \mathrm{L}^{-1}\right)$ and reached a low of $0.2 \mu \mathrm{g} \mathrm{L}^{-1}$ by late May. Concentrations gradually increased toward fall reaching $1.3 \mu \mathrm{g} \mathrm{L}^{-1}$ by early October. Concentrations in spring 2014 remained around $0.6 \mu \mathrm{g} \mathrm{L}^{-1}$ and did not manifest a significant spring high. Lowest concentrations were observed in late July $\left(0.2 \mu \mathrm{g} \mathrm{L}^{-1}\right)$ and increased again as the season progressed with a sharp increase in mid-September to $2.3 \mu \mathrm{g}$ $\mathrm{L}^{-1}$. Concentrations of chlorophyll-a in both years tended to be higher in the nearshore than in the offshore but manifested a greater difference in 2012 than in $2014 \sim 30 \%$ and $\sim 20 \%$, respectively. 
Chlorophyll-a fluorescence however is impacted by a plethora of factors described by Cullen (1982; e.g. antecedent light regime, seasonal changes in species composition, nutrient status) that obfuscate true biomass. A more accurate representation of the caloric energy available to higher trophic levels is that of organic carbon (Platt and Irwin 1973) which is insensitive to inter cellular changes in chlorophyll-a content. Dynamics in cellular chlorophyll-a content will be discussed in the following section. The nearshore pattern of particulate organic carbon (POC, seston-based) in 2012 largely tracked that observed in chlorophyll-a, with the exception of concentrations in August and September (Fig. 4-3c). Here, POC concentrations were elevated while the chlorophyll-a pool remained relatively constant, indicating that the difference is likely due to resuspension of detrital matter enabled by an isothermal water column. The 2014 pattern in the nearshore did not manifest a spring peak as seen in chlorophyll-a and may reflect a change in the carbon to chlorophyll ratio $(\mathrm{C}: \mathrm{Chl}$ ratio) rather than an increase in biomass. Similarly, fluctuation of the $\mathrm{C}: \mathrm{Chl}$ ratio can explain the sharp increase in chlorophyll-a concentrations observed in late September and October while no such increase was manifested in the POC pool.

Deeper offshore waters are less susceptible to resuspension events, resulting in a closer resemblance of chlorophyll-a and POC patterns. In 2012 the POC pool remained constant until early June after which concentrations gradually increased, manifesting a 95\% increase over the June - October interval. In 2014 no spring peak in POC concentrations was observed in the chlorophyll-a pool but POC concentrations did manifest an increase. This would suggest the entrainment of particulate matter with reduced chlorophylla content followed by its sedimentation. POC concentrations reduced toward August contrasting with the pattern observed in 2012 and increased rapidly by a factor $\sim 3$ over 
the August to September interval. The surface water averages in 2012 and 2014 of the particulate organic carbon pool in the nearshore and offshore were similar, $\sim 126 \mu \mathrm{g}$ POC $\mathrm{L}^{-1}$ and $\sim 92 \mu \mathrm{g}$ POC $\mathrm{L}^{-1}$, respectively.

\subsubsection{Dynamics in the carbon to chlorophyll-a ratio}

Changes in the surface water cellular chlorophyll-a content are reflected in the carbon to chlorophyll-a ratio $(\mathrm{C}: \mathrm{Chl}$ ratio) and are driven by numerous factors as stated before. These variations in the $\mathrm{C}$ :Chl ratio make chlorophyll-a a challenging biomass metric. However, its ease of measurement and exclusion of non-primary producer biomass offers significant advantages and a better understanding of the dynamics in C:Chl ratio may enhance its interpretation. In general the $\mathrm{C}$ : $\mathrm{Chl}$ ratio is highest in early spring, declines as the season progresses, interrupted by a short peak, and reaches a minimum in mid-summer (Fig. 4-3d). Rates return again to spring levels by late fall.

The nearshore $\mathrm{C}$ :Chl ratio in 2012 ranged between $2.7 \mu \mathrm{g} \mathrm{Chl} \mathrm{mg} \mathrm{C}^{-1}$ to $9.6 \mu \mathrm{g} \mathrm{Chl}$ $\mathrm{mg} \mathrm{C}^{-1}$, was more erratic in 2014 , manifesting a larger range $\left(1.9 \mu \mathrm{g} \mathrm{Chl} \mathrm{mg} \mathrm{C}^{-1}\right.$ to $11.3 \mu \mathrm{g}$ Chl mg $\mathrm{C}^{-1}$ ). Offshore dynamics manifested in 2012 ranged between $2.1-11.4 \mu \mathrm{g}$ Chl $\mathrm{mg} \mathrm{C}^{-1}$ while in 2014 the range was somewhat larger fluctuating from $3.2-13.5 \mu \mathrm{g}$ Chl $\mathrm{mg} \mathrm{C}^{-1}$. The largest difference between 2012 and 2014, however, was of a temporal nature where the pattern in 2014 was manifested in $\sim 1 / 2$ the period of that observed in 2012. 


\subsubsection{Dynamics in the light regime}

Variability in attenuation of surface radiation is driven by dynamics in dissolved and particulate constituents which are known to vary seasonally and interannually. Dynamics in the underwater light field are described here by the light extinction coefficient $\left(\mathrm{K}_{\mathrm{e}}\right)$ and by Secchi-disk (SD) depth. Light extinction coefficients manifested the expected inverse correlation with $Z_{\mathrm{SD}}$, was strongest in the nearshore in $2014\left(\mathrm{r}^{2}=0.88\right)$ and weakest in the offshore where fluctuations in transparency were bounded in a narrow range, $<40 \%$ of that observed in the nearshore.

On average, nearshore waters were, as in 2011 (Dijkstra and Auer, in review), significantly (t-test: $\mathrm{P}<0.1$ ) less transparent than those in the offshore (Table 2).

Table 2. Nearshore and offshore water transparency.

\begin{tabular}{c|l|l|l|l|}
\multicolumn{2}{c}{} & \multicolumn{2}{c}{2011} & \multicolumn{2}{c}{2012} & \multicolumn{1}{c}{2014} \\
\cline { 2 - 5 }$K_{e}$ & Nearshore & $0.16 \pm 0.04$ & $0.15 \pm 0.04$ & $0.25 \pm 0.14$ \\
\cline { 2 - 5 }$Z_{s d}$ & Offshore & $0.13 \pm 0.03$ & $0.12 \pm 0.02$ & $0.12 \pm 0.02$ \\
\cline { 2 - 5 } & Nearshore & $10.5 \pm 2.8$ & $9.1 \pm 3.3$ & $7.3 \pm 2.8$ \\
\cline { 2 - 5 } & Offshore & $13.3 \pm 3.9$ & $13.7 \pm 1.2$ & $12.1 \pm 1.6$ \\
\cline { 2 - 5 } & &
\end{tabular}

Average light extinction coefficient and secchi disk depth for nearshore and offshore Lake Superior for the 2011, 2012 and 2014 sampling seasons and the standard deviation in measurements. No secchi disk depth was measured in the nearshore in May 2014 due to high seas. As Ke was exceptionally high at that time an exceptionally low ZSD could be expected, reducing the average secchi disk depth for 2014.

Temporal dynamics in nearshore and offshore water transparency generally tracked the pattern observed in plankton biomass (Chl and POC, Fig. 4-3b and c, respectively). For example, the 2012 nearshore spring peak manifested in chlorophyll-a and POC coincided with a reduction in $\mathrm{SD}$ depth and an increase in $\mathrm{K}_{\mathrm{e}}$ (reduced transparency), consistent with 
an increase in primary producer biomass. Similarly, the nearshore 2014 summer dip in chlorophyll-a and POC agreed with an increase in SD depth and a decrease in $\mathrm{K}_{\mathrm{e}}$ (increased transparency), consistent with a decrease in standing stock biomass.

Transparency did not always track the dynamics in POC and chlorophyll-a. For example, in the nearshore in 2012 a large increase in late summer POC (not tracked by chlorophyll-a) resulted in a decrease in SD depth and to a lesser extent an increase in $\mathrm{K}_{\mathrm{e}}$. The water column at this time was isothermal (i.e. well mixed) and suggests resuspension of detritus. Another example is the low nearshore water transparency in late May and early June of 2014 which was not consistent with levels in POC or chlorophyll-a. Here, transparency was likely impacted by a large influx of terrestrial minerals delivered by the spring runoff event occurring shortly before sampling. No such event was observed in 2012 (further discussed in section 4.4.2.1).

In the offshore waters the range in SD depth and light extinction coefficient was marginally larger in 2014 than in 2012, indicating that the offshore was similarly or slightly more dynamic in 2014. In the nearshore, however, the range in SD depth and light extinction coefficient was far greater in 2014 and was manifested over a shorter interval than in 2012. These observations suggest that conditions in 2014 were more variable than in 2012, especially in the nearshore. 


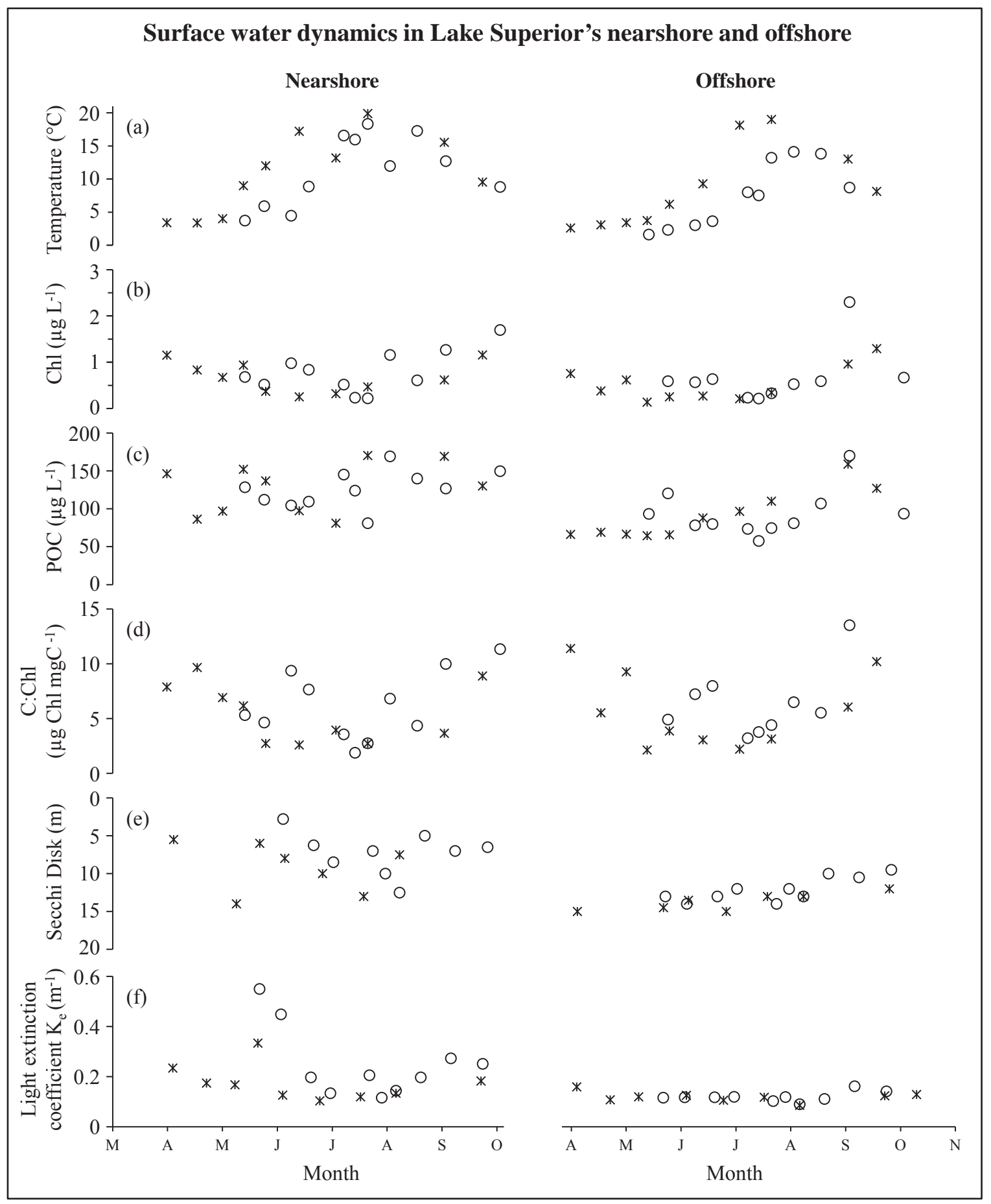

Figure 4-3. Dynamics in surface water parameters.

Temporal patterns in (a): temperature, $(b)$ : chlorophyll-a, $(c)$ : particulate organic carbon, $(d)$ : carbon to chlorophyll-a ratio, (e): secchi disk and (f): light extinction coefficient. Stars represent 2012 measurements and open circles those for 2014. 


\subsubsection{Dynamics in phosphorus}

The limiting nutrient in Lake Superior is phosphorus (Sterner et al. 2004 and Sterner 2011) and seasonality in phosphorus constituents was described by Dijkstra and Auer (in review) for 2011, basically an "average" year. In 2011, particulate phosphorus (PP) dynamics in the nearshore were greatly impacted by resuspension and sedimentation episodes while strong seasonality was observed in offshore PP, manifesting a concave pattern with a minimum in late-summer. No pattern was observed in offshore and nearshore total dissolved phosphorus (TDP) but soluble reactive phosphorus (SRP) and dissolved organic phosphorus (DOP), constituents making up this fraction, manifested complementary signals, indicating the importance of biogeochemical cycling (see also Benitez-Nelson 2015).

Nearshore PP concentrations in 2012 and 2014 generally described a decreasing trend towards summer and increasing concentrations toward fall (Fig. 4-4a). Deviations from this pattern were observed in early July of 2012 where an increase in PP was likely driven by the lingering flux of mineral bound phosphorus delivered to the nearshore by the Ontonagon River resulting from a 12 fold increase in river flow the week prior to sampling (see Fig. 4-6). Likewise, well mixed waters in early September of 2014 suggest that the sudden increase in PP may be the result of resuspension. The seasonal average concentrations were $1.2 \pm 0.6 \mu \mathrm{g} \mathrm{P} \mathrm{L}^{-1}$ and $1.6 \pm 0.7 \mu \mathrm{g} \mathrm{P} \mathrm{L}^{-1}$ in 2012 and 2014 , respectively and were not significantly different (t-test: $\mathrm{P}$ value $>0.15)$.

Offshore PP dynamics in 2012 and 2014 were very different from that observed in 2011. In $2012 \mathrm{PP}$ concentrations tended to remain constant at $\sim 0.8 \mu \mathrm{g} \mathrm{P} \mathrm{L}{ }^{-1}$ over the April - September interval, while concentrations in 2014 followed an increasing trend over the 
late May - early August interval only interrupted by a brief period in late July when losses due to sedimentation $>$ than SRP uptake. This increase was then followed by a decrease over the August - September interval. The seasonal average offshore PP concentrations in 2012 and 2014 were significantly different $(\mathrm{t}$-test: $\mathrm{P}<0.05)$ and measured: $0.8 \pm 0.2 \mu \mathrm{g} \mathrm{P}$ $\mathrm{L}^{-1}$ and $1.2 \pm 0.4 \mu \mathrm{g} \mathrm{L} \mathrm{L}^{-1}$, respectively.

Nearshore SRP concentrations in 2012 fluctuated from April until early August around $0.4 \mu \mathrm{g} \mathrm{P} \mathrm{L}^{-1}$, after which concentrations dropped below detection (Fig. 4-4b). In 2014 concentrations also fluctuated around $0.4 \mu \mathrm{g} \mathrm{L} \mathrm{L}^{-1}$ at the beginning of the season, dropping below detection limit in early August, were above detection limit in early September and decreased again below detection for the remainder of the season. The seasonal averages were similar in 2012 and 2014 and measured $0.4 \pm 0.2 \mu \mathrm{g} \mathrm{L} \mathrm{L}^{-1}$. In both years, concentrations in the offshore remained close to or below detection limit, manifested no season pattern and averaged $0.3 \pm 0.2 \mu \mathrm{g} \mathrm{P} \mathrm{L}^{-1}$.

DOP concentrations in the nearshore did not seem to manifest any seasonality in 2012 and 2014 but were significantly higher (t-test: $\mathrm{P}<0.01$ ) in 2014 than in 2012, averaging $1.5 \pm 0.5 \mu \mathrm{g} \mathrm{P} \mathrm{L}{ }^{-1}$ and $0.9 \pm 0.3 \mu \mathrm{g} \mathrm{P} \mathrm{L}{ }^{-1}$, respectively (Fig. 4-4c). Dynamics observed in the offshore in 2012 manifested a decreasing trend over the season starting at $1.1 \mu \mathrm{g} \mathrm{P} \mathrm{L}{ }^{-1}$ in April and ending below detection limit $\left(0.3 \mu \mathrm{g} \mathrm{P} \mathrm{L}{ }^{-1}\right)$ in late September (Fig. 4-4c). The seasonal averaged concentration was $0.9 \pm 0.4 \mu \mathrm{g} \mathrm{P} \mathrm{L}{ }^{-1}$, similar to that observed in the nearshore. A different picture emerged in 2014 where spring concentrations in DOP were high $>4 \mu \mathrm{g} \mathrm{P} \mathrm{L}^{-1}$ and decreased to below detection limit in fall (a single measurement of $6.1 \mu \mathrm{g} \mathrm{P} \mathrm{L}{ }^{-1}$ made in late May was discarded as this measurement did not pass QC standards). The buildup of the DOP pool in 2014 may reflect an interruption in the cycling 
of DOP to SRP not manifested in 2011 and 2012. DOP cycling in conjunction with dynamics observed in the C:P ratio is discussed in section 4.4.1.6.

Dynamics in the size of the TDP pool are driven by biogeochemical cycling and reflect the balance between SRP uptake by phytoplankton, DOP remineralization and respiratory losses from the PP pool. The TDP concentrations $(\mathrm{TDP}=\mathrm{SRP}+\mathrm{DOP})$ in the nearshore in 2012 manifested higher concentrations in spring while concentrations in summer remained around $1.1 \mu \mathrm{g} \mathrm{P} \mathrm{L}^{-1}$ (Fig. 4-4d). The pattern in 2014 was more dynamic as it was largely driven by the DOP fraction (previously discussed) and manifested highest levels in spring and fall and lowest in mid-summer. Seasonal averaged concentrations in the nearshore for 2012 and 2014 were significantly different (t-test: P >0.05) and measured $1.3 \pm 0.3 \mu \mathrm{g} \mathrm{P} \mathrm{L}^{-1}$ and $1.8 \pm 0.5 \mu \mathrm{g} \mathrm{P} \mathrm{L}^{-1}$, respectively. In the offshore the 2012 pattern was similar to that observed in DOP with spring concentrations being highest $\left(\sim 1.7 \mu \mathrm{g} \mathrm{P} \mathrm{L}{ }^{-1}\right)$

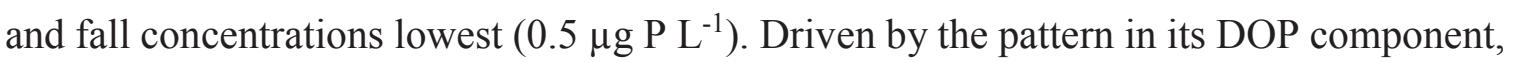
offshore TDP concentrations in 2014 were high in early June $\left(>4.3 \mu \mathrm{g} \mathrm{P} \mathrm{L}^{-1}\right)$, fluctuated during summer around $2 \mu \mathrm{g} \mathrm{P} \mathrm{L}{ }^{-1}$ after increasing again to $\sim 4 \mu \mathrm{g} \mathrm{P} \mathrm{L}{ }^{-1}$ in fall.

Total phosphorus (TP) consists of particulate and dissolved fractions and routinely serves as a metric of trophic status. The pattern in nearshore concentrations was similar in 2012 and 2014, both manifesting a concave pattern where concentrations decreased in spring and increased in fall (Fig. 4-4e). The initial concentration in April 2012 was $3.3 \mu \mathrm{g}$ $\mathrm{P} \mathrm{L}^{-1}$ and decreased to $1.4 \mu \mathrm{g} \mathrm{P} \mathrm{L}^{-1}$ in early June and by late October had returned to levels observed in spring. Concentrations in 2014 where $\sim 4 \mu \mathrm{g} \mathrm{P} \mathrm{L}^{-1}$ in early June, reduced to 1.5 $\mu \mathrm{g} \mathrm{P} \mathrm{L}^{-1}$ by early August and returned to spring levels by late October. Average concentrations in 2012 and 2014 were $2.4 \pm 0.7 \mu \mathrm{g} \mathrm{P} \mathrm{L}^{-1}$ and $3.1 \pm 1.2 \mu \mathrm{g} \mathrm{P} \mathrm{L}^{-1}$, respectively 
(not significantly different at $\mathrm{P}=0.1$ ). In the offshore, patterns were different between

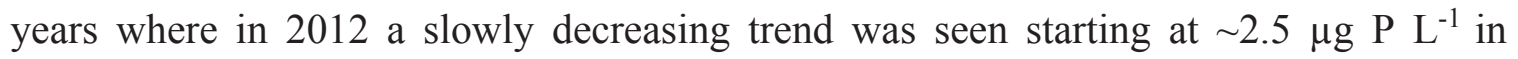
April and reducing to $1.2 \mu \mathrm{g} \mathrm{P} \mathrm{L} \mathrm{L}^{-1}$ by October, the average for the season was $1.9 \pm 0.4$ $\mu$ g P L ${ }^{-1}$ (Fig. 4-4e). In 2014 concentrations were far more erratic and tended to oscillate

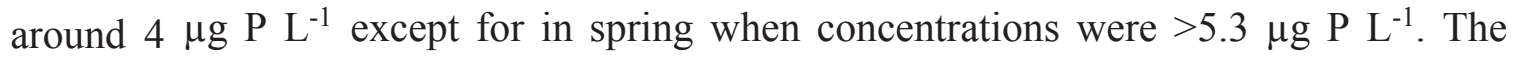

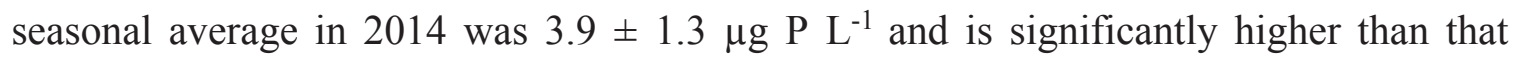
observed in 2012 (t-test: $\mathrm{P}<0.01)$.

\subsubsection{Dynamics in the carbon to phosphorus ratio}

Uptake of phosphorus beyond that required to meet immediate needs (i.e. luxury uptake; Droop 1974) is also observed in Lake Superior as seen in the range of carbon to phosphorus (C:P) ratios (e.g. Sterner 2010 and Dijkstra and Auer in publication). The C:P ratio changes when luxury uptake and dilution through growth are unbalanced. In general, phosphorus is considered to be not or marginally limiting at $\mathrm{C}: \mathrm{P}$ ratios $<130$ while ratios ranging from $130-260$ and $>260$ are reflective of moderate and severe limitation, respectively (Healey and Hendzel 1980). Temporal dynamics in the C:P ratio during a meteorologically average year (2011) were described for Lake Superior by Dijkstra and Auer (in review). In this year, phytoplankton were least nutrient starved in spring (C:P ratio: nearshore $\sim 150$ and offshore $\sim 100$ ), became increasingly phosphorus depleted during summer ultimately reaching extreme starvation in late summer $(\mathrm{C}: \mathrm{P}$ ratio nearshore $>470$ and offshore $>550$ ). The $\mathrm{C}: \mathrm{P}$ ratio reduced in fall as nutrient replete phytoplankton from the pelagic waters became entrained in the surface $(\mathrm{C}: \mathrm{P}$ ratio: nearshore and offshore $<260)$.

In the nearshore in early April of 2012 phytoplankton were already moderately 
starved, likely due to growth that occurred prior to sampling (Fig. 4-4f). Phytoplankton became increasingly phosphorus starved as the season progressed reaching levels of extreme starvation by early June (C:P > 720), levels far exceeding those observed in 2011 . The C:P ratio recovered by late June $(\mathrm{C}: \mathrm{P}<165)$ likely due to the increase in phosphorus loading from the Ontonagon River (Fig. 4-6 and also manifested in the PP pool). Hereafter, phytoplankton diluted their reserves again, becoming once more severely phosphorus limited by early August. Conditions improved again in fall ultimately resulting in a C:P ratio $<140$. Nearshore phytoplankton in 2014 were moderately starved in late May, when waters were still below $4^{\circ} \mathrm{C}$. The C:P ratio increased slowly over the June - early August interval, reaching levels indicative of severe phosphorus starvation (C:P 308). The C:P ratio decreased, coincident with an upwelling event, to nutrient replete conditions (C:P $\sim 100$ ) and increased again to levels indicative of severe starvation prior to recovering to moderate starvation in fall. On average, nearshore phytoplankton were far more phosphorus starved in 2012 than in 2014 and manifested greater dynamics $331 \pm 180$ and $204 \pm 73$, respectively (nearshore C:P ratio in 2011: $298 \pm 142$ ).

In the offshore dynamics in 2012 were similar to those observed in 2011, although more extreme in magnitude. Spring phytoplankton were moderately phosphorus starved (C:P 200) and gradually increased in phosphorus starvation as the season progressed climaxing at a C:P ratio of 538 by late September after which the C:P ratio recovered again to 234 , still indicative of moderate starvation. A very different pattern, however, was observed in 2014. In this year, offshore phytoplankton were extremely phosphorus deficient (C:P 756) in spring and became phosphorus replete towards summer, reaching a low C:P ratio ( 100) in early August. Hereafter phosphorus reserves became depleted again 
and reached levels indicative of starvation by late September (C:P ratio of 371). Severe spring starvation coincides with the observed elevation in DOP concentrations at a time when SRP concentrations remained very low suggesting that remineralization of DOP to SRP was hindered, possibly due to the large degree of ice cover that year, impacting photo degradation. As the DOP pool diminished over spring no increase was observed in the SRP pool, indicating that all mineralized SRP was taken up. This is confirmed by the sharp reduction of the $\mathrm{C}: \mathrm{P}$ ratio indicating that uptake of $\mathrm{SRP}>$ than dilution by growth. A reduction of the DOP pool is likely tracked by a reduction in the SRP flux (from the DOP pool) so that eventually SRP uptake $<$ than dilution by growth. This dynamic was observed in late summer when the $\mathrm{C}: \mathrm{P}$ ratio increased again. 
Dynamics in Lake Superior's surface water phosphorus constituents in 2012 and 2014

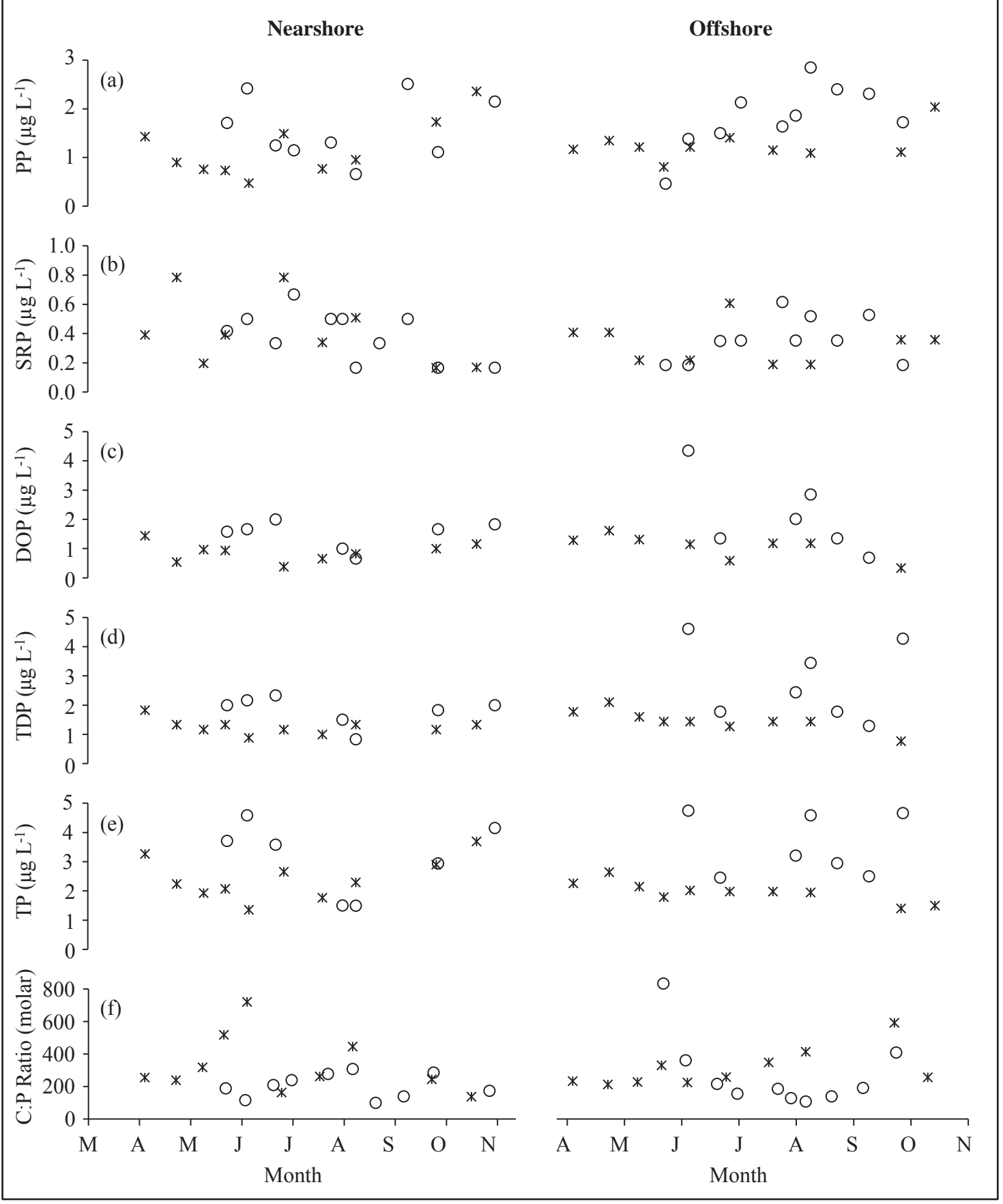

Figure 4-4. Temporal patterns in phosphorus.

Panel (a): particulate phosphorus (PP), (b): soluble reactive phosphorus (SRP), (c): dissolved organic phosphorus (DOP), (d): total dissolved phosphorus (TDP), (e): total phosphorus (TP) and $(f)$ : molar carbon to phosphorus ratio (C:P). Dynamics in 2012 are marked by stars and 2014 by open circles. 


\subsubsection{Spatial dynamics}

The previous section examined differences in temporal structure in water temperature, driving forces of growth (i.e. temperature, light and nutrient status) and biomass for 2012 and 2014. In this section the focus will shift to differences in spatial signals of the Lake Superior ecosystem; the thermal bar (TB) formation and its impact on the nearshore and the dynamics of the deep chlorophyll-a maximum (DCM).

\subsubsection{Thermal bar dynamics in 2012 and 2014}

The development of a TB (a barrier of dense $4^{\circ} \mathrm{C}$ water separating the cold offshore waters from the warmer nearshore waters) and its potential to entrain-nutrient rich spring runoff in the nearshore was described for 2011 and contrasted with dynamics observed in 1999 (Dijkstra and Auer in review). The formation of the thermal bar in 1999 partially overlapped the spring runoff event creating a high potential for nutrient entrainment in the nearshore, coincident with the formation of a nearshore bloom. In contrast, in 2011 the thermal bar occurred after the spring runoff event (low trapping potential) and no increase in standing stock (chlorophyll-a) was observed.

In 2012, based on field sampling and satellite images, a thermal bar was first observed $\sim 9$ May and traversed the nearshore by $\sim$ May 22, lasting about 2 weeks (Fig. 45). In 2014 , the thermal bar formed on $\sim 23$ May and lasted until $\sim 2$ July and maintained its presence in the nearshore for approximately 5 weeks. Considering the great difference between years in antecedent conditions (i.e. ice cover and water temperatures) the delay of about two weeks in the onset of TB formation in 2014 is striking. A greater difference was observed in the duration of its presence in the nearshore where in 2014 the TB remained $>$ twice as long in the nearshore area. 


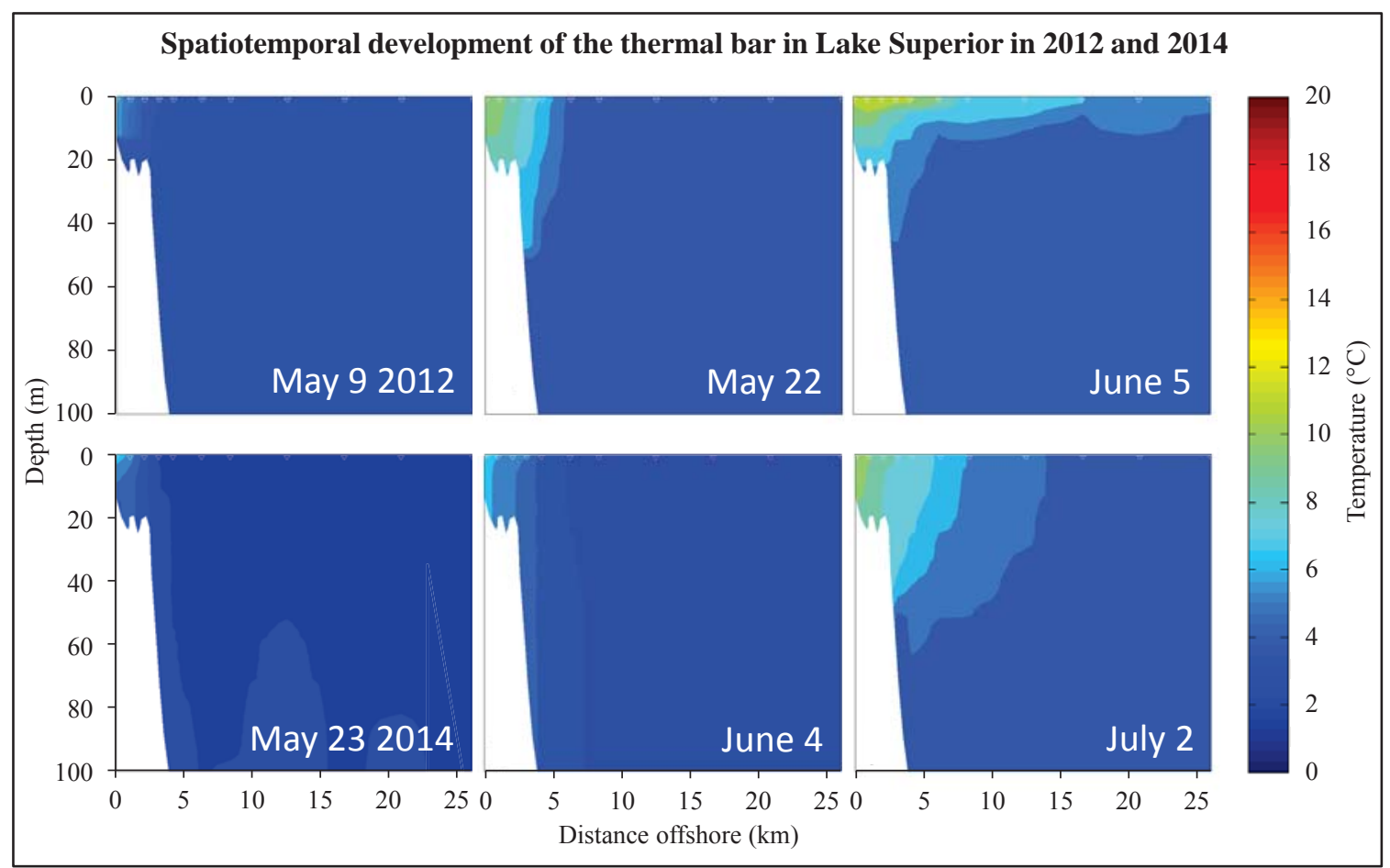

Figure 4-5. Spatiotemporal development of the thermal bar in 2012 and 2014.

\subsubsection{Thermal bar mediated phosphorus retention in the nearshore}

Over half of the phosphorus loading to Lake Superior is received in the nearshore (the remainder is received across the lake via atmospheric deposition, Dolan and Chapra 2012). Nearshore loading, however, is not received evenly throughout the year and is highest in spring when flow rates are elevated due to snowmelt. Differences in nearshore nutrient conditions may stem from variability in the magnitude of the spring runoff event and the duration of its retention in the nearshore prior to lakeward dispersal. In some years, a spring chlorophyll-a surge suggests the effects of nearshore phosphorus enrichment (Auer and Bub 2004; Depew et al. 2006 and references therein; Auer et al. 2010). The spring bloom, however, has become largely absent from Lake Superior as is the case for Lake Huron and Lake Michigan (Barbiero et al. 2012) suggesting that the primary 
producers in the nearshore are not benefitting from the spring runoff event. Here we discuss the dynamics in thermal bar formation in relation to nearshore nutrient retention, standing stock biomass $(\mathrm{Chl})$ and primary production.

Phosphorus loading to the near shore in 2012 was very different than in 2014 (Fig. 4-6). In 2012 snow accumulation was less than in 2014 and consequently spring runoff was lower than in 2014. The spring runoff event in 2012 occurred from mid-March until early April and lasted for 22 days. Loading of total phosphorus (TP) from the Ontonagon River in this year peaked at $\sim 10,000 \mathrm{~kg} \mathrm{~d}^{-1}$ and totaled $\sim 67,000 \mathrm{~kg}$ over that period (Robertson, USGS, personal communication). Spring runoff in 2014 lasted 66 days (from early April late May) and substantially more TP was discharged into Lake Superior. TP loading from the Ontonagon River to Lake Superior during this period peaked at $>17,500 \mathrm{~kg} \mathrm{~d}^{-1}$ totaling $\sim 344,000 \mathrm{~kg}$ over that period, 5 times more than that observed in 2012 (Robertson, USGS, personal communication).

In both years, the formation of the TB occurred after the spring runoff event, $(\sim 4$ weeks in 2012 and $\sim 2$ weeks in 2014) indicating that both years had a low trapping potential. In 2012, during the presence of the TB in the nearshore standing stock in chlorophyll-a and POC doubled while in 2014 standing stock chlorophyll-a and POC both decreased by $\sim 15 \%$ suggesting that a spring bloom occurred in 2012 and not in 2014 . A closer examination however reveals that the bloom in 2012 is not driven by an increase in primary production. In 2012 calculated nearshore primary production at the onset of the thermal bar was $61 \mathrm{mg} \mathrm{C} \mathrm{m}^{2} \mathrm{~d}^{-1}$ and reduced to $20 \mathrm{mg} \mathrm{C} \mathrm{m}^{2} \mathrm{~d}^{-1}$ by the end of its presence in the nearshore. The reduction in levels of primary production was largely driven by diminishing internal phosphorus stores which reached levels indicative of severe 
phosphorus starvation by the end of the TB manifestation $(\mathrm{C}: \mathrm{P}$ went from 240 to 519). In 2014, primary production on the other hand increased from $45 \mathrm{mg} \mathrm{C} \mathrm{m}^{2} \mathrm{~d}^{-1}$ to $80 \mathrm{mg} \mathrm{C} \mathrm{m}^{2} \mathrm{~d}^{-1}$ by 4 June to $128 \mathrm{mg} \mathrm{C} \mathrm{m}^{2} \mathrm{~d}^{-1}$ by 21 June and to $188 \mathrm{mg} \mathrm{C} \mathrm{m}^{2} \mathrm{~d}^{-1}$ by 2 July when its presence in the nearshore ended. C:P ratios during this period remained below levels indicative of severe starvation $(\mathrm{C}: \mathrm{P}<240)$ while SRP concentrations during this period averaged $\sim 0.5 \mu \mathrm{g} \mathrm{L^{-1 }}$ and were only marginally higher than levels observed during the presence of the TB in $2012\left(\sim 0.3 \mu \mathrm{g} \mathrm{L}^{-1}\right)$. The DOP pool in 2014 , however, was significantly higher in 2014 than in $2012, \sim 1.7 \mu \mathrm{g} \mathrm{L}^{-1}$ and $<1.0 \mu \mathrm{g} \mathrm{L}^{-1}$, respectively.

The dynamics previously described demonstrate that the use of fluctuations in standing stock biomass does not serve well as an indicator of increased primary production. Fluctuations in standing stock biomass need to be interpreted carefully and include the consideration of dynamics in the sources and sinks. Application of a linked 3D waterquality and hydrodynamic model (that includes advection and losses like grazing) may allow a more complete (and more quantitative) description of the impact of the thermal bar on nutrient entrainment and the resulting impact on primary production. 


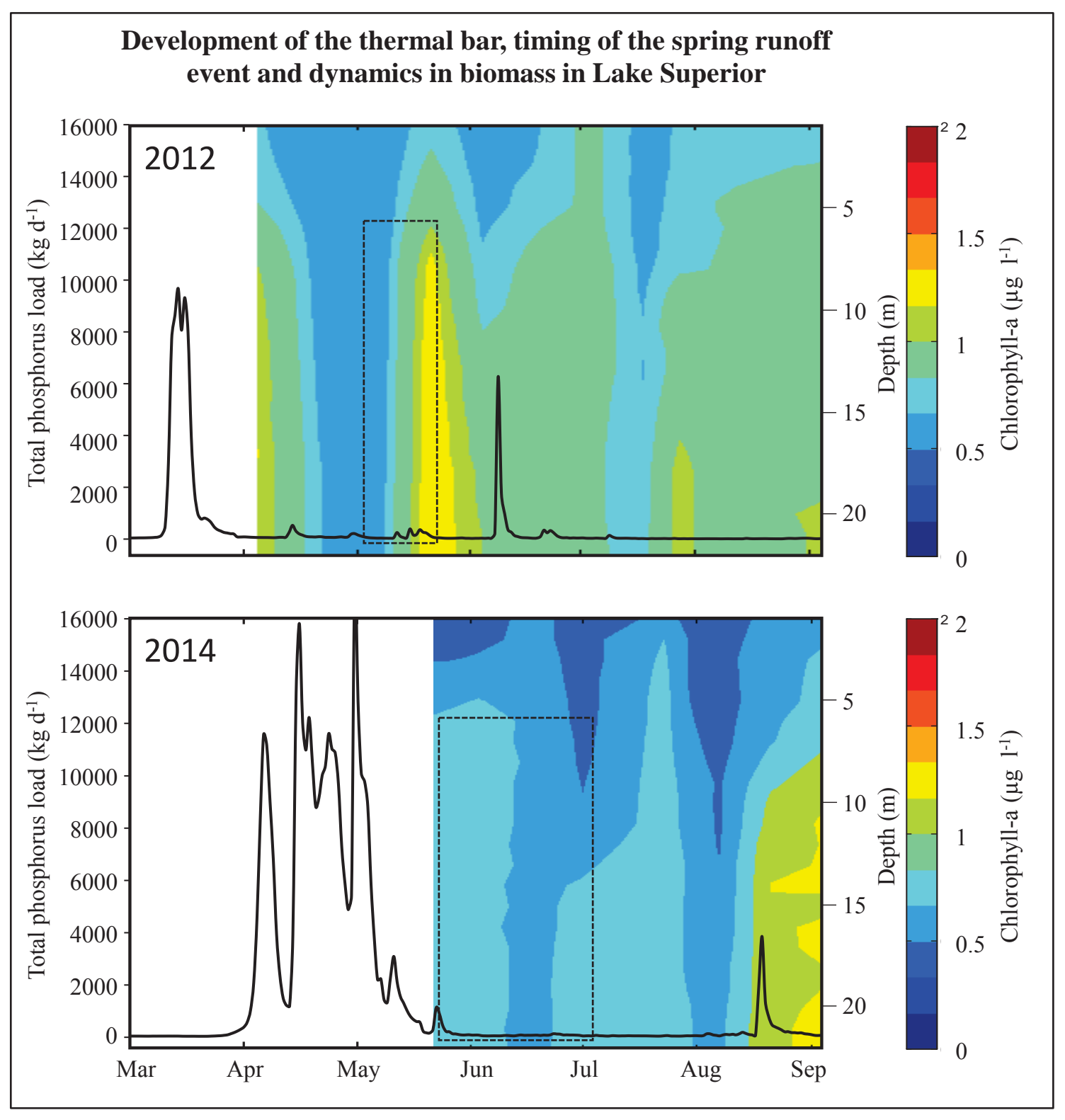

Figure 4-6. Timing of thermal bar formation in relation to the spring runoff event.

Intensity of nearshore nutrient loading is indicated by total phosphorus loadings from the Ontonagon River, and nearshore chlorophyll-a concentrations; in 2012 and in 2014 both manifesting a low potential for entrainment of nearshore loadings from the spring runoff event. 


\subsubsection{The Deep Chlorophyll-a Maximum}

The occurrence of sub-surface chlorophyll-a maxima (i.e. the deep chlorophyll-a maximum, DCM) were recorded for Lake Superior starting in the 1960's (e.g. Olson and Odlaug 1966). Since then many investigators have characterized its dynamics in a spatial fashion with limited temporal resolution (e.g. Barbiero and Tuchman 2001 and 2004). Dynamics of the phenomenon were described in a spatiotemporal fashion, spanning the nearshore to offshore gradient of an entire sampling season, for 1999 and 2000 (Auer and Bub 2004) and for a meteorologically average year (2011; Dijkstra and Auer, in review). From these descriptions a picture emerges of a chlorophyll-a signal that follows a similar pattern in the offshore waters of Lake Superior although fluctuations in depth, signal strength and timing certainly occur. Here we seek to characterize dynamics of this phenomenon during two meteorologically extreme years (2012; warm and 2014; cold).

Two distinct patterns in the vertical distribution of chlorophyll-a were observed in the offshore waters: one during pre-stratification and one during the stratified period (Fig. 4-7). During pre-stratification, in 2012 surface water chlorophyll-a levels $\left(<0.8 \mu \mathrm{g} \mathrm{L}^{-1}, 0\right.$ $20 \mathrm{~m}$ ) were lower than at depths $>20 \mathrm{~m}$, approaching $0.9 \mu \mathrm{g} \mathrm{L}^{-1}$. Offshore surface water concentrations were lower in $2014\left(\sim 0.6 \mu \mathrm{g} \mathrm{L}{ }^{-1}, 0-20 \mathrm{~m}\right)$ while concentrations at depths $>20 \mathrm{~m}$ were similar to 2012 and approached $0.9 \mu \mathrm{g} \mathrm{L}^{-1}$.

With the onset of stratification a DCM formed in both years, first close to shore ( $\sim 6$ $\mathrm{km}$, depth $>90 \mathrm{~m}$ ) followed in the deeper waters further offshore, similar dynamics were observed in 2011. The change in position of its centroid, deepening as the season progressed (starting at $<20 \mathrm{~m}$ closer to shore and ultimately reaching a depth of $40 \mathrm{~m}$, $\sim 17 \mathrm{~km}$ offshore), also followed dynamics observed in 2011. The strongest DCM signal 
was observed in early summer (19 July) with concentrations up to $1.6 \mu \mathrm{g} \mathrm{L}^{-1}, 2$ times higher than surface concentrations. The pattern was different in 2014 where the DCM tended to fluctuate in depth and concentration, with a deeper DCM generally manifesting a stronger signal. The DCM depth ranged between $20-40$ meters and manifested the strongest signal $\sim 7$ weeks later than in 2012 (8 September). Concentrations were as high as $1.9 \mu \mathrm{g} \mathrm{L}^{-1}$ and measured 3.3 times higher than those at the surface. In addition to differences in depth and strength of signal, 2012 differed from 2014 in that the onset of formation occurred $\sim 4$ weeks earlier and had $\sim 6$ week longer manifestation, similar to differences in onset of thermal stratification and timing of fall mixing.

Comparing chlorophyll-a profiles for 2011, 2012 and 2014 at the time of its maximum intensity indicates that the DCM in 2011 and 2014 were similar in concentration $\left(\sim 1.9 \mu \mathrm{g} \mathrm{L}^{-1}\right)$ while that in 2012 was marginally weaker $\left(\sim 1.6 \mu \mathrm{g} \mathrm{L}{ }^{-1}\right.$, Fig. $\left.4-8\right)$. The depth of the centroid differed in all years with 2011 being the shallowest ( $25 \mathrm{~m})$ followed by 2014 ( $\sim 32 \mathrm{~m})$ and 2012 being deepest ( 37depth). The width of the DCM was narrowest in 2011 ( 26 m) and was similar in 2012 and 2014 ( $\sim 35$ and $\sim 34 \mathrm{~m}$, respectively). The timing of its maximum manifestation and the duration of its presence in the offshore in 2011 fell between that observed in 2012 and 2014. 


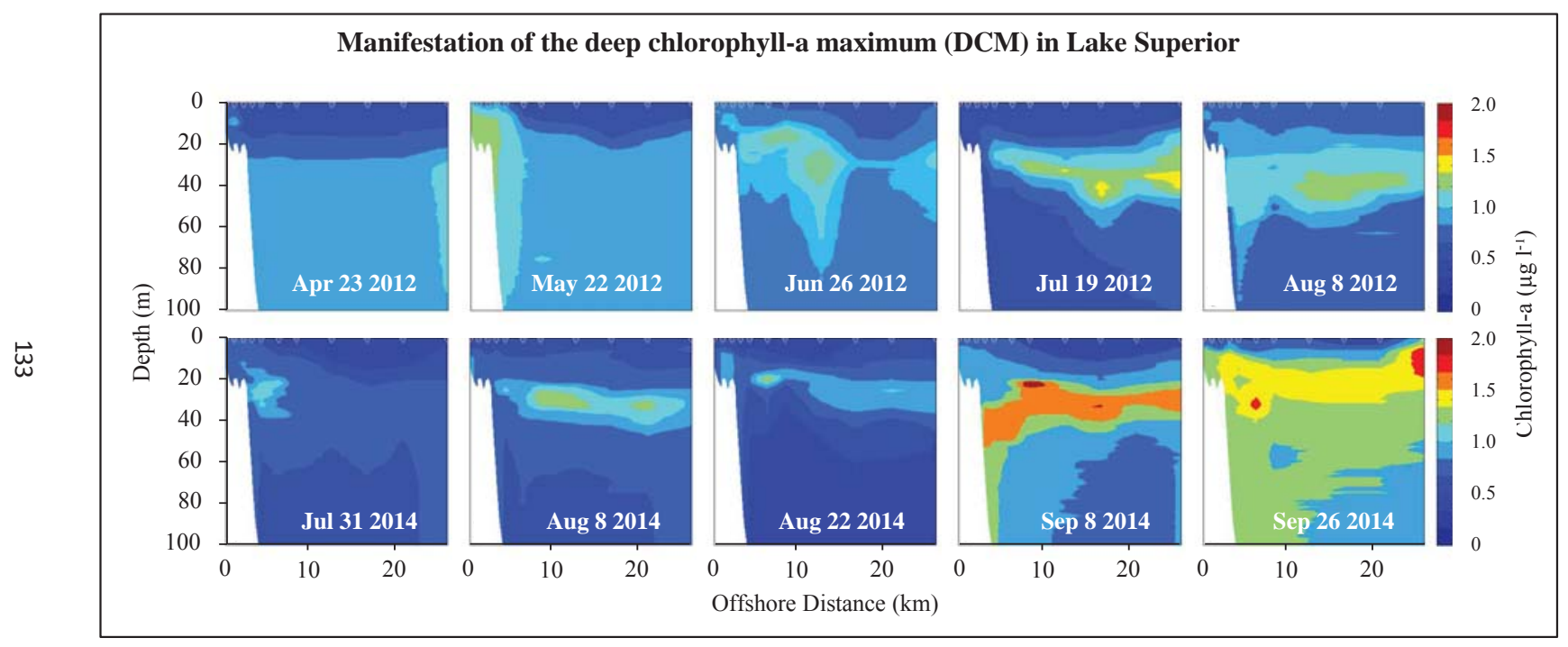

Figure 4-7. Spatiotemporal dynamics in the manifestation of the deep chlorophyll-a maximum(DCM) in 2012 and 2014. 


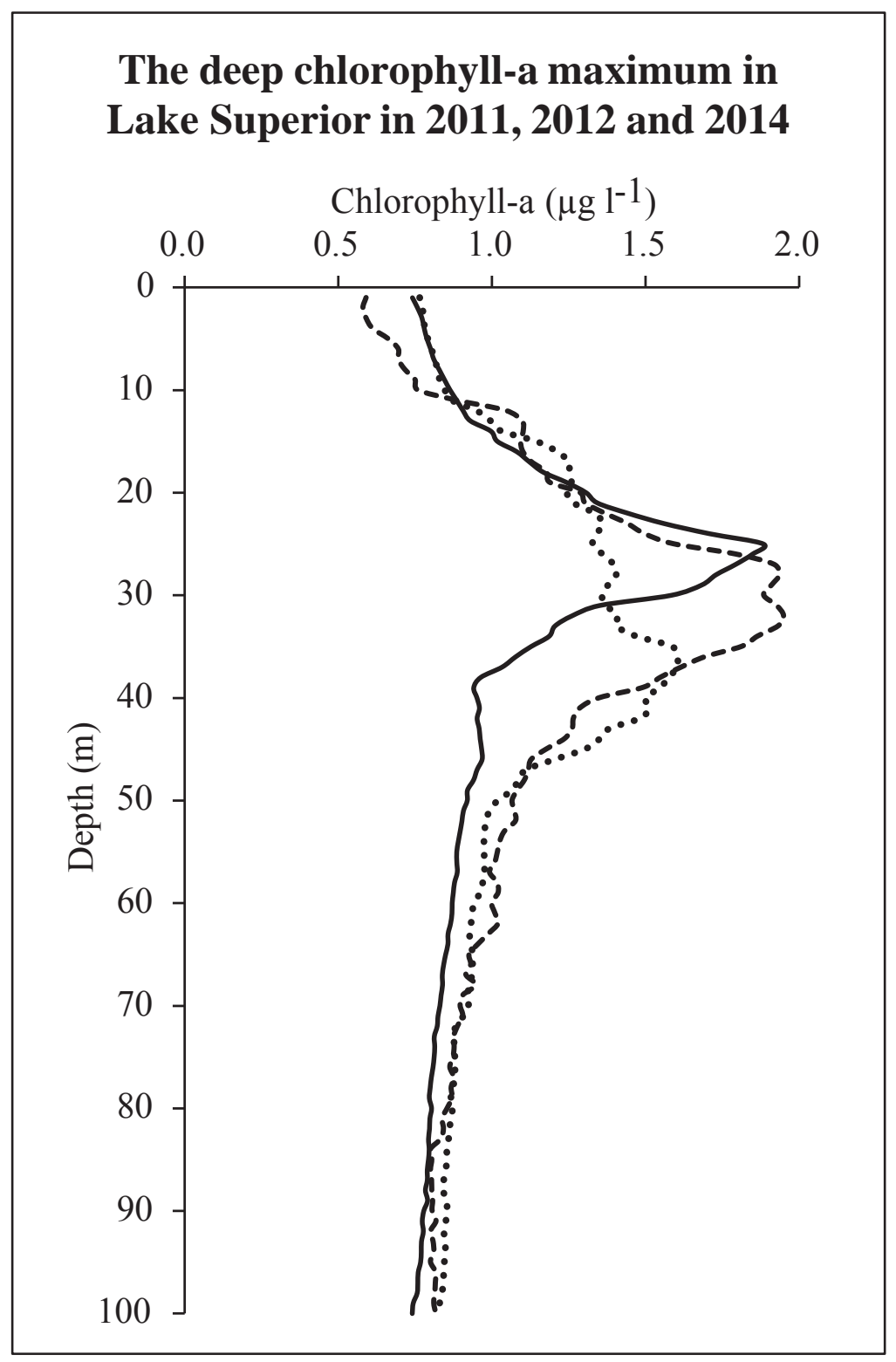

Figure 4-8. Manifestation of the deep chlorophyll-a maximum in 2011, 2012 and 2014.

Maximum development of the DCM on August 122011 (solid line) July 192012 (dotted line) and September 82014 (dashed line), 26 km offshore. 


\subsubsection{Climatic impacts on water column biomass, forcings and production}

Quantification of the contribution of the DCM to water column primary production was described for 2011 (Dijkstra and Auer, in review) and included a temporal description of the dynamics in growth mediating factors (i.e. temperature, light and nutrient conditions) and biomass over the vertical profile.

In 2011 primary production manifested a distinct pattern where low productivity under completely mixed conditions was followed by elevated production in the metalimnion directly above the DCM and reduced productivity in the epilimnion. It was suggested that a further deepening of the epilimnion and extension of thermal stratification could alter the pattern and magnitude of primary production. Here we seek to evaluate the direct and indirect impact of differences in thermal structure (as observed in 2012 and 2014) on driving forces mediating primary production and biomass.

Thermal structure - in 2012 thermal stratification (until mixing exceeded $60 \mathrm{~m}$ ) lasted $\sim 32$ days longer and the thermocline reached a greater depth than in $2014 ; 31 \mathrm{~m}$ and $14 \mathrm{~m}$ in late September, respectively (Fig. 4-9). The average epilimnetic temperature in August 2012 was $>5^{\circ} \mathrm{C}$ warmer than in $2014\left(2012: 18.7^{\circ} \mathrm{C}\right.$ and $\left.2014: 13.5^{\circ} \mathrm{C}\right)$. The differences in thermal structure observed between 2011, 2012 and 2014 coincide with the general consensus that climate warming will lead to an extended duration of thermal stratification (e.g Lehman 2002; Brooks and Zastrow 2002). The greater depth of the epilimnion during the warm year concurs with projections made by Lehman (2002) and the coinciding increase in mixed layer temperature confirms modeling results reported by White et al. (2012). No support was found for an increase in hypolimnion temperature as projected by Lehman (2002). 
Composite forcing conditions - growth limitation, quantified through the $f_{(\mathrm{TIN})}$ parameter, and calculated as described in the methods section (see also Dijkstra and Auer, in review), differed considerably between years. In 2012 limitation in the epilimnion (the "summer desert") became far more extensive in duration and depth than that observed in 2011, extending by the end of September to a depth where only $2.5 \%$ of surface radiation remained (Fig. 4-9).

Limitation in the metalimnion in 2012 was more severe than that observed in 2011. In 2014 limitation described an entirely different pattern than that manifested in 2011 and 2012. In 2014 a shorter growing season was evidenced with substantially less limitation compared to 2011 and 2012. In 2014 no "summer desert" formed in the epilimnion but the effects of the high spring C:P ratios (phosphorus starved phytoplankton, Fig. 4-4) were manifested in the epilimnion and limitation eased towards summer as the C:P ratio improved.

Biomass distribution - the vertical distribution of particulate organic carbon (POC) in the water column like chlorophyll-a, manifested distinct seasonal patterns in 2012 and 2014 (Fig. 4-9). On average 8\% more biomass was present in the photic zone in 2012 than in 2011 and $29 \%$ more compared to that in 2014 . The sub-surface biomass maximum as seen in 2011 and 2012 was virtually absent in 2014 where concentrations in 2012 and 2011 were $\sim 29 \%$ and $\sim 50 \%$ higher, respectively. 


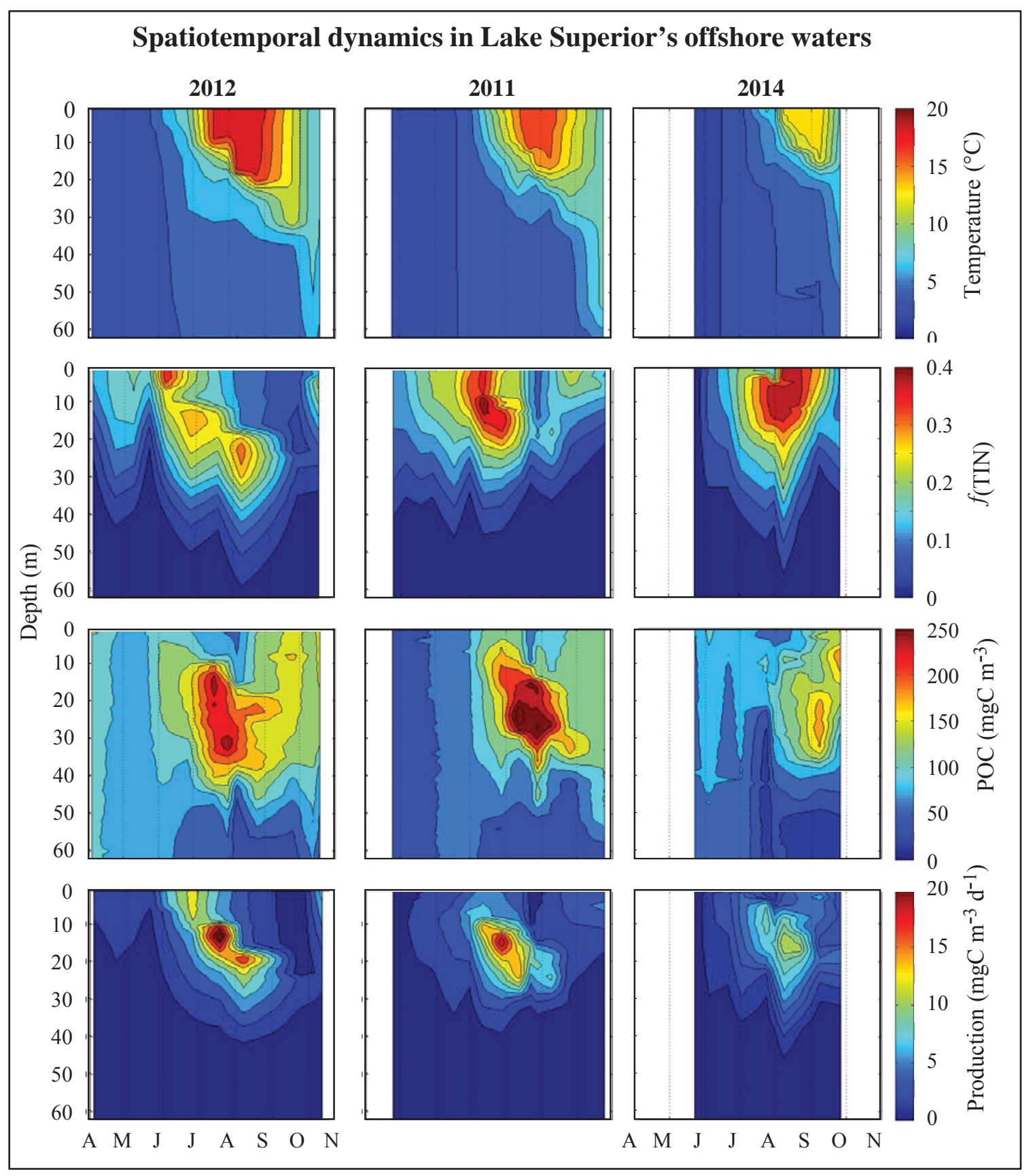

Figure 4-9. Offshore spatiotemporal dynamics in temperature, growth limitation indicated by $f(T I N)$, particulate organic carbon biomass and primary production for 2011, 2012 and 2014. 
Primary production - in 2011, based on model calculations, three distinct periods of primary production became manifested (Dijkstra and Auer, in review). The first phase represents pre-stratified conditions where homogenous and cold (below optimum) waters support low levels of production. The second phase represents the period of thermal stratification. In this period conditions initially improve in the epilimnion as temperatures become more favorable and phosphorus reserves remain sufficient. As stratification continues temperature and phosphorus limitation increase and a "summer desert" is manifested. In the metalimnion dynamics are different as temperatures remain close to optimum, light is still sufficient and phosphorus reserves are not yet depleted. Here, elevated phytoplankton biomass is able to benefit from improved conditions and manifests elevated levels of production. The third and last period is that of deep fall mixing, characterized by a modest improvement in conditions but under continued P-limitation and reducing surface radiation production levels remain modest.

A similar but more extreme pattern was manifested in 2012 (Fig. 4-9). Here, metalimnetic production was higher, especially when the metalimnion remained well above the compensation depth as in July and early August $\left(\sim 17 \mathrm{mg} \mathrm{C} \mathrm{m}^{-3} \mathrm{~d}^{-1}\right.$ at a depth of $26 \mathrm{~m}$ ). In the epilimnion the effects of the more extensive "summer desert" (extending deeper and lasting longer) became manifested in low levels of production $\left(\sim 1 \mathrm{mg} \mathrm{C} \mathrm{m}^{-3} \mathrm{~d}^{-}\right.$ $\left.{ }^{1}\right)$. Recovery of conditions in fall occurred late in the season and did not result in substantial production.

As in the composite forcing conditions, the pattern of production manifested in 2014 was different. The extension of the pre-stratified season and its associated lower rates of production, amplified by the low levels of primary producer biomass, became clearly 
evident. Intense phosphorus limitation in the epilimnion at the onset of stratification impeded epilimnetic production $\left(<1 \mathrm{mg} \mathrm{C} \mathrm{m}^{-3} \mathrm{~d}^{-1}\right)$. Although conditions in the metalimnion were consistently superior to those observed in 2011 and 2012, production remained lower due to the absence of intense subsurface peaks in biomass as were manifested in 2011 and 2012. The increase in primary producer biomass during late fall occurred at a time when the conditions had already deteriorated and consequently production remained low.

From the patterns described above it becomes evident that dynamics in the thermal structure not only impact the distribution of biomass and growth attenuation in the water column but are ultimately also evidenced in the pattern and magnitude of primary production as well. 


\subsubsection{Areal primary production}

Interannual differences in the pattern of calculated areal primary production, occurring under two extreme and contrasting years, may serve to identify the range and pattern in the flux of bioenergy available to higher trophic levels.

In 2011, the pattern in areal primary production described a negatively skewed bellshaped pattern. Production rates were low in spring (38 $\left.\mathrm{mg} \mathrm{C} \mathrm{m}^{2} \mathrm{~d}^{-1}\right)$, highest in July (253

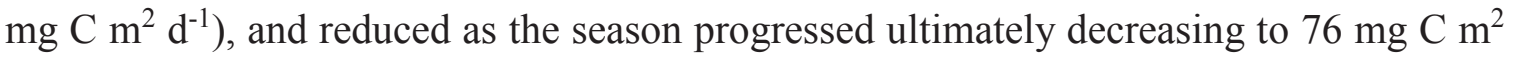
$\mathrm{d}^{-1}$ by October (Fig. 4-10). Primary production in 2012 was generally higher $(\sim 61 \%$ over the May - September interval) than in 2011 and described a pattern of rapidly increasing production early in the season, reaching levels of $239 \mathrm{mg} \mathrm{C} \mathrm{m}^{2} \mathrm{~d}^{-1}$ by June. High levels of production were maintained in July and August $\left(\sim 320 \mathrm{mg} \mathrm{C} \mathrm{m}^{2} \mathrm{~d}^{-1}\right)$ and plummeted in September to $53 \mathrm{mg} \mathrm{C} \mathrm{m} \mathrm{d}^{-1}$ due to the effects of the "summer desert". Production recovered to some extent in October $\left(131 \mathrm{mg} \mathrm{C} \mathrm{m}^{2} \mathrm{~d}^{-1}\right)$.

In 2014, May production was low $\left(<5 \mathrm{mg} \mathrm{C} \mathrm{m}^{2} \mathrm{~d}^{-1}\right)$, due to extreme phosphorus starvation brought on by inhibited DOP recycling. Levels increased over the season as conditions improved, reaching $265 \mathrm{mg} \mathrm{C} \mathrm{m}^{2} \mathrm{~d}^{-1}$ in August, slightly above levels observed in June of 2012. Production in September decreased to $113 \mathrm{mg} \mathrm{C} \mathrm{m}^{2} \mathrm{~d}^{-1}$; a level double that observed in September 2012 (no calculations were made for April and October). Calculated levels of offshore production reported here fell within ranges reported by Fee et al. (1992: 100 - $200 \mathrm{mg} \mathrm{C} \mathrm{m}^{-2} \mathrm{~d}^{-1}$ in summer) and Urban et al. (2005: $10 \mathrm{mg} \mathrm{C} \mathrm{m}^{-2} \mathrm{~d}^{-1}$ in spring - 200 mg C m $\mathrm{m}^{-2}$ in summer), and by Sterner (2010; 250 $\mathrm{mg} \mathrm{C} \mathrm{m}^{-2} \mathrm{~d}^{-1}$ in early spring and $\sim 325$ $\mathrm{mg} \mathrm{C} \mathrm{m} \mathrm{m}^{-2} \mathrm{~d}^{-1}$ in summer). 


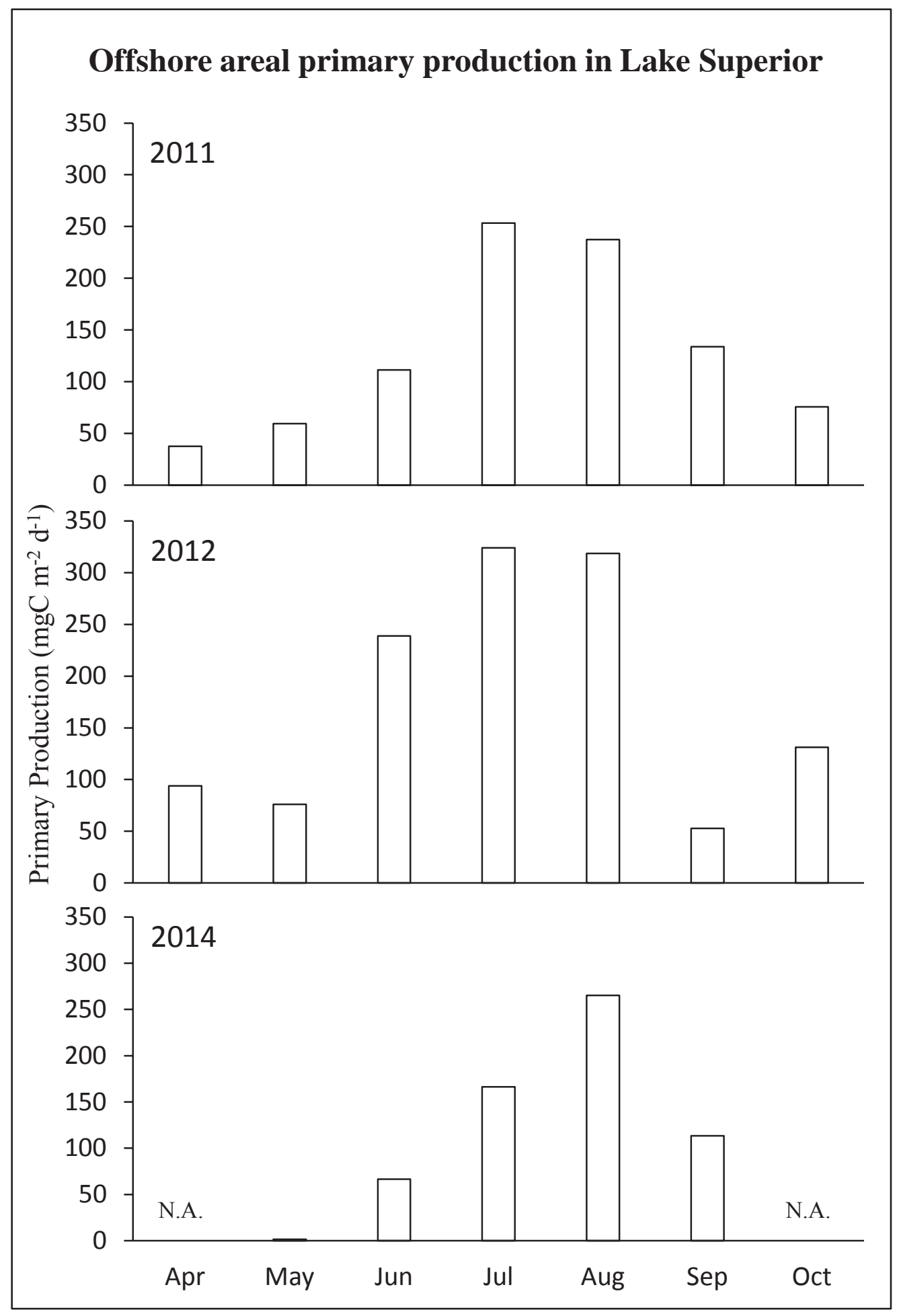

Figure 4-10. Temporal dynamics in offshore areal primary production in 2011, 2012 and 2014. 


\subsubsection{Quality of primary production}

Descriptions of dynamics in phytoplankton biomass are generally focused on standing stock and production (i.e. flux of primary production) overlooking temporal dynamics in quality as described by the elemental ratios, especially that of phosphorus (Brett et al. 2000). Zooplankton cell stoichiometry tends to be relatively constant (Sterner 1993), reducing feeding efficiency at elevated (phytoplankton) C:P ratios. This can decrease herbivorous zooplankton production (Brett et al. 2000, Malzhan and Boersma 2012) and reduce growth efficiency in fish by as much as $90 \%$ (Hood et al. 2005). Higher trophic levels are thus not only impacted by the reduction in primary production resulting from phosphorus starvation but also by its reduced quality (high C:P ratios). Dynamics in the $\mathrm{C}: \mathrm{P}$ ratio, described in this work, indicate that the seasonal patterns in primary production should therefore not only be interpreted in a quantitative fashion but also in a qualitative fashion. The compounding effect of coinciding reductions in quantity and quality, as for example occurred during the "summer desert" (Fig. 4-9), could have a far greater impact on the food web then the reduction in quantity alone would suggest. The impact on higher trophic levels of interannual and seasonal dynamics in primary production (quantity and quality) would merit further investigation. 


\subsection{Summary and Conclusions}

The impact of two meteorologically extreme and contrasting years (2012: warm and 2014: cold) resulted in differing characteristics in thermal regime, driving forces attenuating primary production (i.e. temperature, light and nutrients) and ultimately primary production. In the warm year, offshore thermal stratification lasted $\sim 32$ days longer, the epilimnion became $>5^{\circ} \mathrm{C}$ warmer by mid-summer and reached $\sim 17 \mathrm{~m}$ deeper by the end of summer. The response of the ecosystem to alternate thermal regimes was evidenced in its driving forces and resulted in an extensive summer "desert" (period of severe growth limitation in the surface mixed layer) in 2012 while no desert was observed in 2014. Biomass concentrations in the photic zone in 2012 were on average $~ 29 \%$ higher than in 2014 and the subsurface biomass maximum (particulate organic carbon) developed a month earlier (July) containing $\sim 50 \%$ more biomass than in 2014 . Calculated volumetric production rates were greatest in early August, in 2012 at a depth of $26 \mathrm{~m}\left(16.8 \mathrm{mg} \mathrm{C} \mathrm{m}^{-3}\right.$ $\left.\mathrm{d}^{-1}\right)$ and in 2014 at a depth of $14 \mathrm{~m}\left(11.6 \mathrm{mg} \mathrm{C} \mathrm{m}^{-3} \mathrm{~d}^{-1}\right)$. Areal primary production in 2014 described a negatively skewed bell shape pattern with peak production occurring in August ( $\left.\sim 265 \mathrm{mg} \mathrm{C} \mathrm{m}^{2} \mathrm{~d}^{-1}\right)$. In 2012 the pattern in areal primary production manifested elevated levels in April. Summer production (July and August) peaked at $\sim 320 \mathrm{mg} \mathrm{C} \mathrm{m}^{2} \mathrm{~d}^{-1}$, while production decreased considerably in September due to the extensive "summer desert". Production, over the May-September interval, was significantly higher in 2012 than in $2014(61 \%)$.

Inter-annual and seasonal variations in magnitude of energy flux to pelagic and benthic communities could cause cascading effects throughout the food web. Diminished quality of primary producer biomass at times of extreme phosphorus deficiency, as 
transpired in September of 2012, may amplify the impact of fluctuations in primary production.

The trapping potential of nutrients, delivered to the nearshore during the spring runoff event, by the timely formation of a thermal bar was evaluated and revealed a low trapping potential in both years. Yet, in 2012 a bloom was observed while primary production decreased and in 2014 no bloom was observed while primary production increased. These contrasting dynamics demonstrate that, in these years, standing stock was not an accurate gauge for the occurrence of a spring bloom. 


\subsection{Acknowledgments}

The authors would like to thank Stephen Roblee Captain of the R/V Agassiz and the numerous deckhands for their assistance with sampling and those that helped with sample processing and analysis especially: Miles Corcoran, Ben Downer, Rasika Gawde, Anika Kuczynski, Chuck Ouellette, Varsha Raman and Nate Zgnilec. Authors are also very grateful for the calculations of the TP loadings from the Ontonagon River to Lake Superior made by Dr. Dale Robertson. Funding for this research was provided by the EPA Great Lakes Research Initiative (\#GL-00E00560/0) and the Great Lakes Observing System. 


\subsection{References}

Auer, M.T., Bub, L.A. 2004. Selected features of the distribution of chlorophyll along the southern shore of Lake Superior. Journal of Great Lakes Research 30, 269284.

Auer, M.T., Tomlinson, L.M., Higgins, S.N., Malkin, S.Y., Howell, E.T., Bootsma, H.A. 2010. Great Lakes Cladophora in the 21st century: same algae-different ecosystem. Journal of Great Lakes Research 36, 248-255.

Auer, N.A., Cannon, B.A., Auer, M.T. 2009. Life history, distribution, and production of Diporeia near the Keweenaw Peninsula Lake Superior. Journal of Great Lakes Research 35, 579-590. doi:10.1016/j.jglr.2009.08.004

Auer, N.A., Kahn, J.E. 2004. Abundance and Distribution of Benthic Invertebrates, with Emphasis on Diporeia, along the Keweenaw Peninsula, Lake Superior. Journal of Great Lakes Research 30, Supplement 1, 340-359. doi:10.1016/S0380-1330(04)70396-2

Austin, J., Colman, S. 2008. A century of temperature variability in Lake Superior. Limnology and Oceanography 2724-2730.

Barbiero, R.P., Lesht, B.M., Warren, G.J. 2012. Convergence of trophic state and the lower food web in Lakes Huron, Michigan and Superior. Journal of Great Lakes Research 38, 368-380.

Barbiero, R.P., Tuchman, M.L. 2004. The deep chlorophyll maximum in Lake Superior. Journal of Great Lakes Research 30, 256-268.

Barbiero, R.P., Tuchman, M.L. 2001. Results from the U.S. EPA's Biological Open Water Surveillance Program of the Laurentian Great Lakes: I. Introduction and Phytoplankton Results. Journal of Great Lakes Research 27, 134-154. doi:10.1016/S0380-1330(01)70628-4

Beaver, J.R., Casamatta, D.A., East, T.L., Havens, K.E., Rodusky, A.J., James, R.T., Tausz, C.E., Buccier, K.M. 2013. Extreme weather events influence the phytoplankton community structure in a large lowland subtropical lake (Lake Okeechobee, Florida, USA). Hydrobiologia 709, 213-226.

Beaver, J.R., Scotese, K.C., Minerovic, A.D., Buccier, K.M., Tausz, C.E., Clapham, W.B. 2012. Ecoregion, land use and phytoplankton relationships in productive Ohio reservoirs. Inland Waters 2, 101-108. 
Behrenfeld, M.J., Boss, E. 2006. Beam attenuation and chlorophyll concentration as alternative optical indices of phytoplankton biomass. Journal of Marine Research $64,431-451$.

Benitez-Nelson, C., 2015. The missing link in oceanic phosphorus cycling? Science $348,759-760$.

Brett, M.T., Muller-Navarra, D.C., Park, S.-K. 2000. Empirical analysis of the effect of phosphorus limitation on algal food quality for freshwater zooplankton. Limnology and Oceanography 45, 1564-1575.

Brooks, A.S., Zastrow, J.C. 2002. The Potential Influence of Climate Change on Offshore Primary Production in Lake Michigan. Journal of Great Lakes Research 28, 597-607. doi:10.1016/S0380-1330(02)70608-4

Bub LA. 2001. Spatial and temporal distribution of phytoplankton in Lake Superior. M.S. Thesis. Michigan Technological University, Houghton, MI.

Carpenter, S.R., Kitchell, J.F., Hodgson, J.R., 1985. Cascading Trophic Interactions and Lake Productivity. BioScience 35, 634-639. doi:10.2307/1309989

Chapra, S.C. 2008. Surface water-quality modeling, Waveland press.

Cullen, J.J., 1982. The deep chlorophyll maximum: comparing vertical profiles of chlorophyll a. Canadian Journal of Fisheries and Aquatic Sciences 39, 791-803.

Depew, D.C., Guildford, S.J., Smith, R.E.. 2006. Nearshore-offshore comparison of chlorophyll a and phytoplankton production in the dreissenid-colonized eastern basin of Lake Erie. Can. J. Fish. Aquat. Sci. 63, 1115-1129. doi:10.1139/f06-016

Dolan, D.M., Chapra, S.C. 2012. Great Lakes total phosphorus revisited: 1. Loading analysis and update (1994-2008). Journal of Great Lakes Research 38, 730-740. doi:10.1016/j.jglr.2012.10.001

Droop, M.R., 1974. The nutrient status of algal cells in continuous culture. Journal of the Marine Biological Association of the United Kingdom 54, 825-855.

Eaton, A., Franson, M. 2005. Standard methods for the examination of water \& wastewater. Amer. Public Health Assoc. 20th Rev Ed. Washington, DC, USA.

EPA 2010. Sampling and Analytical Procedures for GLNPO's Open Lake Water Quality Survey of the Great Lakes [WWW Document]. URL http://www.epa.gov/glnpo/monitoring/sop/ (accessed 8.21.13). 
Fee, E.J., Shearer, J.A., DeBruyn, E.R., Schindler, E.U., 1992. Effects of lake size on phytoplankton photosynthesis. Canadian Journal of Fisheries and Aquatic Sciences 49, 2445-2459.

Healey, F.P., Hendzel, L.L., 1980. Physiological indicators of nutrient deficiency in lake phytoplankton. Canadian Journal of Fisheries and Aquatic Sciences 37, 442453.

Hill, D.K., Magnuson, J.J., 1990. Potential Effects of Global Climate Warming on the Growth and Prey Consumption of Great Lakes Fish. Transactions of the American Fisheries Society 119, 265-275. doi:10.1577/15488659(1990)119<0265:PEOGCW >2.3.CO;2

Hood, J.M., Vanni, M.J., Flecker, A.S. 2005. Nutrient recycling by two phosphorusrich grazing catfish: the potential for phosphorus-limitation of fish growth. Oecologia 146, 247-257. doi:10.1007/s00442-005-0202-5

IPCC, Pachauri, R.K., Allen, M.R., Barros, V.R., Broome, J., Cramer, W., Christ, R., Church, J.A., Clarke, L., Dahe, Q., Dasgupta, P., others 2014. Climate Change 2014: Synthesis Report. Contribution of Working Groups I, II and III to the Fifth Assessment Report of the Intergovernmental Panel on Climate Change.

Karl, T.R., Melillo, J.M., Peterson, T.C. 2009. Global Climate Change Impacts in the United States. Cambridge University Press.

Lehman, J.T. 2002. Mixing patterns and plankton biomass of the St. Lawrence Great Lakes under climate change scenarios. Journal of Great Lakes Research 28, 583596.

Magnuson, J.J., Webster, K.E., Assel, R.A., Bowser, C.J., Dillon, P.J., Eaton, J.G., Evans, H.E., Fee, E.J., Hall, R.I., Mortsch, L.R., 1997. Potential effects of climate changes on aquatic systems: Laurentian Great Lakes and Precambrian Shield Region. Hydrological processes 11, 825-871.

Malzahn, A.M., Boersma, M. 2012. Effects of poor food quality on copepod growth are dose dependent and non-reversible. Oikos 121, 1408-1416. doi:10.1111/j.1600-0706.2011.20186.x

Mandrak, N.E., 1989. Potential invasion of the Great Lakes by fish species associated with climatic warming. Journal of Great Lakes Research 15, 306-316.

McCormick, M.J., Fahnenstiel, G.L., 1999. Recent climatic trends in nearshore water temperatures in the St. Lawrence Great Lakes. Limnology and Oceanography 44, 530-540. 
Meisner, J.D., Goodier, J.L., Regier, H.A., Shuter, B.J., Christie, W.J., 1987. An Assessment of the Effects of Climate Warming on Great Lakes Basin Fishes. Journal of Great Lakes Research 13, 340-352. doi:10.1016/S03801330(87)71656-6

Olson, T.A., Odlaug, T.O., 1966. Limnological observations on western Lake Superior. Proc. 9th Conf. Great Lakes Res. 109-118.

Platt, T., Irwin, B., 1973. Caloric content of phytoplankton. Limnology and Oceanography 306-310.

Siew, P.F. 2003. Phosphorus distribution and cycling in the Keweenaw Peninsula region of Lake Superior. M.S. thesis, Mich. Technol. Univ., Houghton.

Sterner, R.W., Smutka, T.M., McKay, R.M.L., Xiaoming, Q., Brown, E.T., Sherrell, R.M. 2004. Phosphorus and Trace Metal Limitation of Algae and Bacteria in Lake Superior. Limnology and Oceanography 49, 495-507.

Sterner, R.W. 2010. In situ-measured primary production in Lake Superior. Journal of Great Lakes Research 36, 139-149.

Sterner, R.W. 2011. C: N: P stoichiometry in Lake Superior: Freshwater sea as end member. Inland Waters 1, 29-46.

Sterner, R.W., 1993. Daphnia Growth on Varying Quality of Scenedesmus: Mineral Limitation of Zooplankton. Ecology 74, 2351. doi:10.2307/1939587

Urban, N.R., Jeong, J., Chai, Y. 2004. The Benthic Nepheloid Layer (BNL) North of the Keweenaw Peninsula in Lake Superior: Composition, Dynamics, and Role in Sediment Transport. Journal of Great Lakes Research 30, 133-146. doi:10.1016/S0380-1330(04)70382-2

Urban, N.R., Auer, M.T., Green, S.A., Lu, X., Apul, D.S., Powell, K.D., Bub, L. 2005. Carbon cycling in Lake Superior. J. Geophys. Res. 110, 17 PP. doi:10.1029/2003JC002230

Wang, J., Bai, X., Hu, H., Clites, A., Colton, M., Lofgren, B. 2012. Temporal and Spatial Variability of Great Lakes Ice Cover, 1973-2010*. Journal of Climate 25, 1318-1329.

White, B., Austin, J., Matsumoto, K. 2012. A three-dimensional model of Lake Superior with ice and biogeochemistry. Journal of Great Lakes Research 38, 6171. doi:10.1016/j.jglr.2011.12.006 


\section{Chapter 5}

\section{Contributions to science}

All things excellent are as difficult as they are rare.

Baruch Spinoza (1632-1677) 


\subsection{Summary of contributions to science}

To date, no consensus exists in Lake Superior's scientific community in regards to which algorithms are most suitable to capture the impact of fluctuations in temperature, light and nutrients on primary production.

For example phosphorus limitation is modeled with Monod kinetics by White et al. (2012) while Sterner (2010) indicates that a high correlation ( $\mathrm{r} 2>0.9)$ was obtained between in-situ measured rates of primary production and those modeled with just temperature and light algorithms, negating any nutrient effects. As discussed in chapter 3 and 4, no seasonality was observed in offshore soluble reactive phosphorus (SRP) in 2011, 2012 and 2014. Concentrations frequently dropped below detection limit while strong seasonal patterns were manifested in the C:P ratio. Application of Monod kinetics assumes fixed stoichiometry (constant C:P ratio) making this metric, apart from the uncertainty in SRP concentrations, a less favorable metric. Droop (1974) kinetics on the other hand are able to accommodate variable stoichiometry and experimental data confirmed its utility in modeling the impact of variations in the C:P ration on levels of primary production.

Likewise several alternate algorithms are available to describe the effects of temperature and light limitation (e.g. Bowie et al. 1985, Tian 2006 and Chapra 2008). Based on lab experiments, performed on the natural phytoplankton assemblage of Lake Superior, the optimum temperature algorithm described by Cerco and Cole (1994) and the light algorithm developed by Platt (1980) best represented phytoplankton response to alterations in these conditions.

After algorithm selection kinetic coefficients were determined including the (net) maximum growth rate and confirmed to in-situ measured rates of primary production 
reported by Sterner (2010). These algorithms and their kinetic coefficients were then applied to calculate primary production for August 1998 at EPA's 19 offshore sites in Lake Superior. These calculations indicated that primary production in the offshore waters of Lake Superior manifested considerable heterogeneity.

Next to offering confirmed site specific kinetic coefficients and appropriate algorithms supporting primary production modeling in Lake Superior a spatiotemporal rich data set was developed supporting calibration and confirmation of models developed for Lake Superior. Field measurements for this data set were made with a bi-weekly frequency during the sampling seasons of 2011, 2012 and 2014, considered to be meteorologically average, extremely warm and cold years, respectively. Measurements were made on a transect perpendicular to shore, extending 26km lakeward off Michigan's Keweenaw Peninsula and consisted of 11 stations covering the nearshore to offshore gradient. Field measurements included: temperature, solar radiation, transparency, beam attenuation, chlorophyll-a fluorescence, colored dissolved organic matter, suspended solids and phosphorus and carbon constituents. Additional measurements (not included in this work) were made during field sampling, often in collaboration with visiting scientists, and included: phytoplankton and zooplankton species composition, Diporeia densities, sediment composition, larval tows and hydroacoustic measurements of Mysis densities, flow cytometry as was the composition of the light field. The data presented in this work is currently supporting the development of an extensive 3D hydrodynamic model for Lake Superior developed by Dr. Xue. The data set, in a similar fashion, supports the development of a 1D lower food web model including nutrient cycling, primary production and zooplankton interactions by Dr. Chapra. Measurements of TP concentrations from the 
Ontonagon River were shared with Dr. Robertson from the USGS in support of model calibration.

Analysis of the data set resulted in the description of spatiotemporal dynamics in biomass, forces driving primary production, and in conjunction with the developed 1D primary production model (chapter 2) dynamics in primary production.

Several, thus far, unidentified signals were reported including seasonality in the surface water $\mathrm{C}: \mathrm{P}$ ratio indicating that these phytoplankton become progressively more phosphorus starved as the summer progresses. A strikingly different pattern in the C:P ratio was observed in 2014, a year with an extremely cold winter and extensive ice-cover, and coincided with a deviation in the pattern of the dissolved organic phosphorus pool, indicating a disturbance in nutrient cycling.

The signal feature in the surface waters was the development of a summer "desert" representing a period of extreme growth limitation due to sub optimal temperatures and high nutrient limitation. During the extreme warm year (prolonged stratification) the "summer desert" was larger (reaching a greater depth) and lasted longer than in the average year. In the cold year no "summer desert" was observed. Metalimnetic production, to some extent, was able to compensate for the loss of production in the epilimnion and manifested a subsurface maximum well above the deep chlorophyll-a maximum. In the warm year, production decreased toward the end of the summer due to low production in the epilimnion and reduced production in the metalimnion resulting from increased light limitation (driven by a deepening of the epilimnion).

Extreme nutrient limitation (high C:P ratios) as seen in late summer may, in addition to reduced production, also impact the quality of biomass available to higher 
trophic levels.

Development of the thermal bar (TB) in the nearshore did not coincide with the spring runoff event in 2011, 2012 and 2014, indicating a low potential for trapping and contrasted with dynamics observed in 1999. Dynamics in primary production during the presence of the TB, however, indicated that an increase in production as seen in 2014 did not result in the manifestation of a spring bloom. Likewise, a decrease in production, as occurred in 2012, during the presence of the TB coincided with an increase in chlorophylla concentrations, thus signaling that standing stock biomass was not a trustworthy indicator for the occurrence of a spring bloom.

Dynamics observed in the thermal regime during these climatologically divergent years seem to indicate that projections regarding the impact of climate change (i.e. increase in epilimnion temperature, extended duration of thermal stratification and deepening of the thermocline; Lehman 2002 and Brooks and Zastrow 2002) concurred with field observations. Differences in dynamics between the climatologically extreme years described in this work may serve to improve projections regarding the effect of climate change on the Lake Superior ecosystem. 


\subsection{Recommendations for future work}

Development of the kinetics presented in this work was based on temperature and light experiments performed on the natural phytoplankton assemblage of Lake Superior in conjunction with measurements of chlorophyll-a, carbon and phosphorus constituents. The chosen sampling frequency and experimental design generated excellent data allowing for the determination of these kinetics thus far largely unknown for Lake Superior. The available data, however, did constrain a more accurate determination and additional experiments and field measurements could improve temperature attenuation functions and potentially develop a family of functions and include the winter season. Likewise, additional sampling could be tailored to develop a more accurate nutrient function by reducing the range in sampling locations and improving sampling frequency. Furthermore, the developed kinetics and algorithms were confirmed to one (extensive) set of in-situ measured rates of primary production and further confirmation may be possible in the near future as new (in-situ) measured rates will be published.

The striking differences observed in timing, quantity and quality of primary production between the warm (2012) and cold year (2014) could cause cascading effects through the foodweb, warranting further exploration. Currently the Auer group, in cooperation with Dr. Chapra, is developing a 1D water quality model tailored to Lake Superior that includes nutrient cycling and zooplankton dynamics. The extensive data set developed for 2011, 2012 and 2014 will assist in model calibration and confirmation. Once this model is confirmed unique signals like the buildup of the DOP pool in the cold year (2014) and attendant high C:P ratios and the subsurface production maximum could be explored and lead to new insights. 


\subsection{References}

Bowie, G. L., Mills, W. B., Porcella, D. B., Campbell, C. L., Pagenkopf, J. R., Rupp, G. L., Johnson, K. M., Chan, P. W., Gherini, S. A., and Chamberlain, C. E. (1985). Rates, constants, and kinetics formulations in surface water quality modeling (second edition). United States Environmental Protection Agency, Athens, GA. EPA/600/3-85/040.

Brooks, A.S., Zastrow, J.C. 2002. The Potential Influence of Climate Change on Offshore Primary Production in Lake Michigan. Journal of Great Lakes Research 28, 597-607. doi:10.1016/S0380-1330(02)70608-4

Cerco, C.F., Cole, T.M., 1994. Three-Dimensional Eutrophication Model of Chesapeake Bay. Volume 1: Main Report. DTIC Document.

Chapra, S.C. 2008. Surface water-quality modeling. Waveland press.

Droop, M.R., 1974. The nutrient status of algal cells in continuous culture. Journal of the Marine Biological Association of the United Kingdom 54, 825-855.

Lehman, J.T. 2002. Mixing patterns and plankton biomass of the St. Lawrence Great Lakes under climate change scenarios. Journal of Great Lakes Research 28, 583596.

Platt, T., Gallegos, C.L., Harrison, W.G., 1980. Photoinhibition of photosynthesis in natural assemblages of marine phytoplankton. Journal of marine research 38 .

Sterner, R.W. 2010. In situ-measured primary production in Lake Superior. Journal of Great Lakes Research 36, 139-149.

Tian, R.C. 2006. Toward standard parameterizations in marine biological modeling. Ecological Modelling 193, 363-386. doi:10.1016/j.ecolmodel.2005.09.003

White, B., Austin, J., Matsumoto, K. 2012. A three-dimensional model of Lake Superior with ice and biogeochemistry. Journal of Great Lakes Research 38, 6171. doi:10.1016/j.jglr.2011.12.006 


\section{Appendix I: field and lab data}

Table 3. Field and lab data for 2011, 2012 and 2014 measured in the nearshore and offshore of Lake Superior.

\begin{tabular}{|c|c|c|c|c|c|c|c|c|c|c|c|c|c|c|c|}
\hline $\begin{array}{l}\text { Station / Cruise } \\
\text { date }\end{array}$ & $\begin{array}{c}\text { Sample } \\
\text { Depth }\end{array}$ & \begin{tabular}{|c|} 
Temp \\
$\left({ }^{\circ} \mathrm{C}\right)$ \\
\end{tabular} & $\begin{array}{c}\text { TSS (DW } \\
\mathrm{mg} / \mathrm{L})\end{array}$ & $\begin{array}{c}\mathrm{POC} \\
(\mu \mathrm{g} / \mathrm{L}) \\
\end{array}$ & \begin{tabular}{|c|}
$\mathrm{PP}$ \\
$(\mu \mathrm{g} / \mathrm{L})$ \\
\end{tabular} & $\begin{array}{c}\text { SRP } \\
(\mu \mathrm{g} / \mathrm{L}) \\
\end{array}$ & \begin{tabular}{|c|} 
TDP \\
$(\mu \mathrm{g} / \mathrm{L})$ \\
\end{tabular} & \begin{tabular}{|c|} 
DOP \\
$(\mu \mathrm{g} / \mathrm{L})$ \\
\end{tabular} & \begin{tabular}{|c|}
$\mathrm{TP}$ \\
$(\mu \mathrm{g} / \mathrm{L})$ \\
\end{tabular} & $\begin{array}{c}\mathrm{Chl} \\
(\mu \mathrm{g} / \mathrm{L})\end{array}$ & $\begin{array}{c}\text { CDOM } \\
\text { (abs 10cm) }\end{array}$ & \begin{tabular}{|l|l|} 
C:Chl \\
ratio
\end{tabular} & $\begin{array}{l}\text { C:P } \\
\text { ratio }\end{array}$ & \begin{tabular}{|c|}
$\mathrm{ke}$ \\
$(/ \mathrm{m})$ \\
\end{tabular} & \begin{tabular}{|l|} 
SD \\
$(\mathrm{m})$ \\
\end{tabular} \\
\hline \multicolumn{16}{|l|}{$\begin{array}{l}\text { Nearshore station } \\
\text { HNO30 }\end{array}$} \\
\hline $4 / 25 / 2011$ & 0 & & & & & & & & & & & & & & 12 \\
\hline $5 / 6 / 2011$ & 0 & 3.6 & 0.5 & 89 & 1.5 & 0.2 & 0.7 & 0.5 & 2.2 & 0.7 & 0.011 & 7.8 & 152 & & \\
\hline $5 / 19 / 2011$ & 0 & 3.6 & 0.3 & 87 & 1.2 & 0.6 & 1.8 & 1.3 & 3.0 & 0.6 & 0.003 & 7.2 & 195 & & 14.0 \\
\hline $5 / 29 / 2011$ & 0 & 3.2 & & 61 & 1.1 & 0.7 & 0.9 & 0.2 & 2.0 & 0.6 & 0.003 & 10.4 & 140 & & 13.5 \\
\hline $6 / 17 / 2011$ & 0 & 7.6 & 0.4 & 97 & 1.1 & 0.7 & 1.0 & 0.4 & 2.1 & 0.7 & 0.006 & 7.3 & 238 & 0.18 & \begin{tabular}{|l|}
10 \\
\end{tabular} \\
\hline $6 / 30 / 2011$ & 0 & 8.3 & 0.5 & 131 & 1.5 & 0.2 & 1.2 & 1.0 & 2.7 & 0.7 & 0.011 & 5.4 & 226 & 0.22 & \begin{tabular}{|l|}
6.5 \\
\end{tabular} \\
\hline $7 / 12 / 2011$ & 0 & 16.3 & 0.4 & 83 & 0.7 & 0.9 & & & 0.7 & 0.7 & 0.006 & 8.7 & 305 & 0.21 & 8 \\
\hline $7 / 28 / 2011$ & 0 & 14.6 & 0.3 & & 0.7 & 0.9 & 1.2 & 0.3 & 1.9 & 0.7 & 0.003 & & & 0.13 & 10 \\
\hline $8 / 12 / 2011$ & 0 & 19.5 & 0.5 & 99 & 0.7 & 0.0 & 0.7 & 0.7 & 1.4 & 0.9 & 0.003 & 9.1 & 365 & 0.11 & \\
\hline $8 / 28 / 2011$ & 0 & 20.6 & 0.5 & 170 & 0.8 & 0.2 & 1.0 & 0.8 & 1.8 & 0.8 & 0.0045 & 4.9 & 548 & 0.17 & 11.5 \\
\hline 9/9/2011 & 0 & 19.0 & 0.4 & 129 & 0.6 & 0.8 & 0.7 & 0.0 & 1.3 & 0.7 & 0.002 & 5.7 & 555 & 0.13 & 13 \\
\hline $9 / 25 / 2011$ & 0 & 15.6 & 0.5 & 99 & 1.0 & 0.4 & 1.3 & 0.9 & 2.3 & 0.9 & 0.009 & 9.2 & 253 & 0.13 & \\
\hline $10 / 25 / 2011$ & 0 & 9.9 & 0.9 & 175 & 1.5 & 0.4 & 1.0 & 0.6 & 2.5 & 0.9 & 0.007 & 5.2 & 301 & 0.19 & 6.5 \\
\hline $4 / 4 / 2012$ & 0 & 3.4 & 0.2 & 147 & 1.4 & 0.4 & 1.8 & 1.4 & 3.3 & 1.2 & 0.006 & 7.9 & 257 & 0.23 & \begin{tabular}{|l|}
5.5 \\
\end{tabular} \\
\hline $4 / 23 / 2012$ & 0 & 3.4 & 0.3 & 86 & 0.9 & 0.8 & 1.3 & 0.5 & 2.2 & 0.8 & 0.002 & 9.7 & 240 & 0.17 & \\
\hline $5 / 9 / 2012$ & 0 & 4.0 & 0.6 & 97 & 0.8 & 0.2 & 1.2 & 1.0 & 1.9 & 0.7 & 0.002 & 6.9 & 320 & 0.17 & 14.0 \\
\hline $5 / 22 / 2012$ & 0 & 9.0 & 0.3 & 152 & 0.7 & 0.4 & 1.3 & 0.9 & 2.1 & 0.9 & 0.009 & 6.2 & 519 & 0.33 & \begin{tabular}{|l|}
6.0 \\
\end{tabular} \\
\hline $6 / 5 / 2012$ & 0 & \begin{tabular}{|l|}
12.0 \\
\end{tabular} & 0.2 & 137 & 0.5 & & 0.9 & & 1.4 & 0.4 & 0.005 & 2.7 & 723 & 0.13 & 8 \\
\hline $6 / 26 / 2012$ & 0 & 17.2 & 0.2 & 98 & 1.5 & 0.8 & 1.2 & 0.4 & 2.7 & 0.3 & 0.005 & 2.6 & 164 & 0.10 & 10 \\
\hline $7 / 19 / 2012$ & 0 & 13.2 & 0.3 & 81 & 0.8 & 0.3 & 1.0 & 0.7 & 1.8 & 0.3 & 0.005 & 3.9 & 264 & 0.12 & 13 \\
\hline $8 / 8 / 2012$ & 0 & 19.9 & 0.3 & 170 & 1.0 & 0.5 & 1.3 & 0.8 & 2.3 & 0.5 & 0.004 & 2.7 & 447 & 0.13 & \begin{tabular}{|l|}
7.5 \\
\end{tabular} \\
\hline $9 / 25 / 2012$ & 0 & 15.5 & 0.7 & 169 & 1.7 & 0.2 & 1.2 & 1.0 & 2.9 & 0.6 & 0.007 & 3.6 & 245 & 0.18 & \\
\hline $10 / 19 / 2012$ & 0 & 9.5 & 0.5 & 130 & 2.4 & 0.2 & 1.3 & 1.2 & 3.7 & 1.2 & 0.008 & 8.9 & 139 & & \\
\hline & & & & & & & & & & & & & & & \\
\hline & & & & 125 & 4 & .4 & 2.0 & 1.0 & 0.1 & 0.1 & & $\frac{5.5}{4.6}$ & 100 & S & 28 \\
\hline & & & & & & & & & & & 0.00 & & & & \begin{tabular}{|l|}
6.25 \\
\end{tabular} \\
\hline & & 8.9 & & & 1.5 & 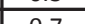 & & & & 08 & & 76 & 20 & 0.20 & \begin{tabular}{|l|}
8.5 \\
\end{tabular} \\
\hline $7 / 24 / 2014$ & 0 & 16.6 & & 145 & 1.3 & 0.5 & & & & 0.5 & 0.005 & 3.6 & \begin{tabular}{|l|}
278 \\
\end{tabular} & 0.21 & 7 \\
\hline $7 / 31 / 2014$ & 0 & 16.0 & & 124 & & 0.5 & 1.5 & 1.0 & 1.5 & 0.2 & 0.003 & 1.9 & & 0.11 & 10 \\
\hline $8 / 8 / 2014$ & 0 & 18.3 & & 81 & 0.7 & 0.2 & 0.8 & 0.7 & 1.5 & 0.2 & 0.004 & 2.7 & 308 & 0.14 & 12.5 \\
\hline $8 / 22 / 2014$ & 0 & 12.0 & & 169 & & 0.3 & & & & 1.2 & 0.017 & 6.8 & 100 & 0.20 & 5 \\
\hline $9 / 8 / 2014$ & 0 & 17.3 & & 140 & 2.5 & 0.5 & & & & 0.6 & 0.006 & 4.3 & 140 & 0.27 & 7 \\
\hline $9 / 26 / 2014$ & 0 & 12.7 & & 127 & 1.1 & 0.2 & 1.8 & 1.7 & 2.9 & 1.3 & 0.007 & 10.0 & 287 & 0.25 & 6.5 \\
\hline $10 / 30 / 2014$ & 0 & 8.8 & & 150 & 2.2 & 0.2 & 2.0 & 1.8 & 4.2 & 1.7 & 0.013 & 11.3 & 175 & 0.25 & 7.28 \\
\hline
\end{tabular}




\begin{tabular}{|c|c|c|c|c|c|c|c|c|c|c|c|c|c|c|c|}
\hline $\begin{array}{l}\text { Station / Cruise } \\
\text { date }\end{array}$ & $\begin{array}{c}\text { Sample } \\
\text { Depth }\end{array}$ & \begin{tabular}{|c|} 
Temp \\
$\left({ }^{\circ} \mathrm{C}\right)$ \\
\end{tabular} & $\begin{array}{l}\text { TSS (DW } \\
\mathrm{mg} / \mathrm{L} \text { ) }\end{array}$ & $\begin{array}{l}\mathrm{POC} \\
(\mu \mathrm{g} / \mathrm{L}) \\
\end{array}$ & \begin{tabular}{|c|}
$\mathrm{PP}$ \\
$(\mu \mathrm{g} / \mathrm{L})$ \\
\end{tabular} & $\begin{array}{c}\mathrm{SRP} \\
(\mu \mathrm{g} / \mathrm{L}) \\
\end{array}$ & \begin{tabular}{|c|} 
TDP \\
$(\mu \mathrm{g} / \mathrm{L})$ \\
\end{tabular} & $\begin{array}{c}\mathrm{DOP} \\
(\mu \mathrm{g} / \mathrm{L}) \\
\end{array}$ & \begin{tabular}{|c|}
$\mathrm{TP}$ \\
$(\mu \mathrm{g} / \mathrm{L})$ \\
\end{tabular} & \begin{tabular}{|c|}
$\mathrm{Chl}$ \\
$(\mu \mathrm{g} / \mathrm{L})$ \\
\end{tabular} & $\begin{array}{c}\text { CDOM } \\
\text { (abs 10cm) }\end{array}$ & \begin{tabular}{|l|}
$\mathrm{C}: \mathrm{Chl}$ \\
ratio \\
\end{tabular} & \begin{tabular}{|c|}
$\mathrm{C}: \mathrm{P}$ \\
ratio \\
\end{tabular} & \begin{tabular}{|c|}
$\mathrm{ke}$ \\
$(/ \mathrm{m})$ \\
\end{tabular} & \begin{tabular}{|l|}
$S D$ \\
$(\mathrm{~m})$ \\
\end{tabular} \\
\hline \multicolumn{16}{|l|}{$\begin{array}{l}\text { Offshore station } \\
\mathrm{HN} 260\end{array}$} \\
\hline $4 / 25 / 2011$ & & & & & & & & & & & & & & 0.09 & 20 \\
\hline $5 / 6 / 2011$ & 0 & 2.0 & 0.1 & 60 & 1.2 & 0.4 & 0.9 & 0.54 & 2.07 & 0.8 & 0.003 & \begin{tabular}{|l|}
13.6 \\
\end{tabular} & 129 & 0.11 & \\
\hline $5 / 19 / 2011$ & 0 & 2.6 & & 54 & 1.3 & 0.4 & 1.08 & 0.71 & 2.42 & & 0.003 & & 102 & 0.12 & 15.5 \\
\hline $5 / 29 / 2011$ & 0 & 2.9 & & 46 & 1.1 & 0.4 & 0.96 & 0.59 & 2.1 & 0.6 & 0.003 & 13.9 & 101 & 0.13 & 13 \\
\hline $6 / 17 / 2011$ & 0 & 3.4 & 0.3 & 70 & 1.1 & 0.7 & 1.62 & 0.88 & 2.72 & 0.6 & 0.004 & 7.9 & 160 & 0.10 & 20 \\
\hline $6 / 30 / 2011$ & 0 & 4.0 & 0.4 & 58 & 1.0 & 0.7 & 0.44 & & 1.44 & 0.4 & 0.003 & 6.8 & 144 & 0.16 & 12 \\
\hline $7 / 12 / 2011$ & 0 & 7.8 & 0.3 & 78 & 0.8 & 1.1 & & & & 0.4 & 0.004 & 4.7 & 234 & 0.11 & \\
\hline $7 / 28 / 2011$ & 0 & 12.6 & 0.2 & 111 & 0.8 & 0.2 & 0.88 & 0.68 & 1.66 & 0.4 & 0 & 4.0 & \begin{tabular}{|l|}
356 \\
\end{tabular} & 0.11 & 9 \\
\hline $8 / 12 / 2011$ & 0 & 15.7 & 0.4 & 111 & 0.8 & 0.0 & 0.74 & 0.74 & 1.54 & 0.4 & 0.002 & 3.9 & \begin{tabular}{|l|}
347 \\
\end{tabular} & 0.13 & 9.5 \\
\hline $8 / 28 / 2011$ & 0 & 17.5 & 0.4 & 113 & 0.6 & 0.2 & 1.03 & 0.83 & 1.63 & & 0.005 & & 409 & 0.16 & \\
\hline 9/9/2011 & 0 & 17.0 & 0.4 & 102 & 0.7 & 0.4 & 1.18 & 0.79 & 1.88 & 0.4 & 0.002 & 4.1 & 474 & 0.14 & 13 \\
\hline $9 / 25 / 2011$ & 0 & 14.2 & 0.6 & 107 & 1.0 & 0.6 & 1.03 & 0.44 & 2.07 & 0.8 & 0.007 & 7.1 & 364 & 0.13 & 14 \\
\hline \multirow[t]{3}{*}{$10 / 25 / 2011$} & 0 & 8.7 & 0.5 & 178 & 1.4 & 0.4 & 1.62 & 1.23 & 3.06 & 1.2 & 0.005 & 6.9 & 258 & 0.14 & 11 \\
\hline & & & & & & & & & & & & & 310 & 0.18 & 9.5 \\
\hline & & & & & & & & & & & & & & & \\
\hline $4 / 4 / 2012$ & 0 & 2.6 & 0.2 & 66 & 0.8 & 0.4 & 1.5 & 1.11 & 2.28 & 0.8 & 0.004 & \begin{tabular}{|l|}
11.4 \\
\end{tabular} & 212 & 0.16 & 15 \\
\hline $4 / 23 / 2012$ & 0 & 3.1 & 0.3 & 69 & 0.9 & 0.4 & 1.83 & 1.44 & 2.73 & 0.4 & 0.002 & \begin{tabular}{|l|}
5.5 \\
\end{tabular} & 194 & 0.11 & \\
\hline $5 / 9 / 2012$ & 0 & 3.4 & 0.6 & 67 & 0.8 & 0.2 & 1.33 & 1.13 & 2.14 & 0.6 & 0.002 & 9.3 & 207 & 0.12 & \\
\hline $5 / 22 / 2012$ & 0 & 3.7 & 0.3 & 65 & 0.5 & & 1.17 & & 1.71 & 0.1 & 0.002 & 2.1 & \begin{tabular}{|l|}
301 \\
\end{tabular} & & 14.5 \\
\hline $6 / 5 / 2012$ & 0 & 6.2 & 0.2 & 66 & 0.8 & 0.2 & 1.17 & 0.97 & 1.98 & 0.3 & 0.003 & 3.9 & 205 & 0.12 & 13.5 \\
\hline $6 / 26 / 2012$ & 0 & 9.3 & 0.2 & 88 & 0.9 & 0.6 & 1 & 0.41 & 1.94 & 0.3 & 0.004 & 3.0 & 235 & 0.11 & 15 \\
\hline $7 / 19 / 2012$ & 0 & 18.1 & 0.3 & 97 & 0.8 & 0.2 & 1.17 & 1 & 1.94 & 0.2 & 0.003 & 2.2 & 317 & 0.12 & 13 \\
\hline $8 / 8 / 2012$ & 0 & 19.0 & 0.3 & 110 & 0.7 & 0.2 & 1.17 & 1 & 1.9 & 0.3 & 0.001 & 3.1 & 376 & 0.08 & 13 \\
\hline $9 / 25 / 2012$ & 0 & 13.0 & 0.7 & 159 & 0.7 & 0.3 & 0.5 & 0.16 & 1.24 & 1.0 & 0.01 & 6.0 & 538 & 0.12 & 12 \\
\hline \multirow[t]{2}{*}{ 10/13/2012 } & 0 & 8.1 & 0.5 & 127 & 1.4 & 0.3 & & & 1.36 & 1.3 & 0.008 & \begin{tabular}{|l|}
10.2 \\
\end{tabular} & \begin{tabular}{|l|}
234 \\
\end{tabular} & 0.13 & \\
\hline & & & & & & & & & & & & & & & \\
\hline $5 / 23 / 2014$ & 0 & 1.6 & & 93 & 0.3 & 0.2 & 6.3 & 6.1 & 6.6 & & & & 756 & 0.12 & 13 \\
\hline $6 / 4 / 2014$ & 0 & 2.3 & & 121 & 0.9 & 0.2 & 4.3 & 4.2 & 5.3 & 0.6 & & 4.9 & 329 & 0.12 & 14 \\
\hline $6 / 21 / 2014$ & 0 & 3 & & 78 & 1.0 & 0.3 & 1.5 & 1.2 & 2.5 & 0.6 & 0.005 & 7.2 & 197 & 0.12 & 13 \\
\hline $7 / 2 / 2014$ & 0 & 3.6 & & 80 & 1.4 & 0.3 & & & & 0.6 & 0.003 & 8.0 & 141 & 0.12 & 12 \\
\hline $7 / 24 / 2014$ & 0 & 8 & & 74 & 1.1 & 0.6 & & & & 0.2 & 0.006 & 3.2 & 169 & 0.10 & 14 \\
\hline $7 / 31 / 2014$ & 0 & 7.5 & & 58 & 1.2 & 0.3 & 2.2 & 1.8 & 3.4 & 0.2 & 0.001 & 3.8 & 117 & 0.12 & 12 \\
\hline $8 / 8 / 2014$ & 0 & 13.2 & & 75 & 1.9 & 0.5 & 3.2 & 2.7 & 5.1 & 0.3 & 0.001 & 4.4 & 99 & 0.09 & 13 \\
\hline $8 / 22 / 2014$ & 0 & 14.1 & & 81 & 1.6 & 0.3 & 1.5 & 1.2 & 3.1 & 0.5 & 0.001 & 6.5 & 127 & 0.11 & 10 \\
\hline 9/8/2014 & 0 & 13.8 & & 107 & 1.5 & 0.5 & 1.0 & 0.5 & 2.6 & 0.6 & 0.002 & 5.5 & 174 & 0.16 & 10.5 \\
\hline \multirow[t]{2}{*}{$9 / 26 / 2014$} & 0 & 8.7 & & 170 & 1.2 & 0.2 & 4.0 & & 5.2 & 2.3 & 0.001 & 13.5 & 371 & 0.14 & 9.5 \\
\hline & & & & & & & & & & & & & & & \\
\hline $5 / 6 / 2011$ & 25 & & 0.4 & 102 & 2.1 & 0.4 & 1.5 & 1.1 & 3.6 & 0.8 & 0.004 & 7.9 & 121 & & \\
\hline $6 / 17 / 2011$ & 25 & & 0.2 & 75 & 1.8 & 0.9 & 1.5 & 0.5 & 3.2 & 0.9 & 0.004 & 11.4 & 108 & & \\
\hline $7 / 28 / 2011$ & 25 & & 0.3 & 75 & 1.5 & 0.9 & 1.2 & 0.3 & 2.7 & 1.0 & 0.001 & \begin{tabular}{|l|}
12.6 \\
\end{tabular} & 123 & & \\
\hline $8 / 28 / 2011$ & 25 & & 0.8 & 261 & 2.3 & 0.4 & 1.6 & 1.2 & 3.9 & & 0.0075 & & 284 & & \\
\hline \multirow[t]{2}{*}{$9 / 25 / 2011$} & 25 & & 0.6 & 122 & 1.5 & 0.4 & 1.2 & 0.8 & 2.7 & 0.9 & 0.008 & 7.2 & 202 & & \\
\hline & & & & & & & & & & & & & & & \\
\hline $5 / 22 / 2012$ & 25 & & 0.3 & 84 & 0.6 & 2.4 & 1.2 & 0.8 & 1.8 & 0.6 & 0.003 & 6.6 & \begin{tabular}{|l|}
364 \\
\end{tabular} & & \\
\hline $6 / 26 / 2012$ & 25 & & 0.3 & 130 & 1.1 & 0.4 & 1.5 & 1.1 & 2.6 & 0.7 & 0.004 & 5.1 & 287 & & \\
\hline $9 / 25 / 2012$ & 25 & & 0.7 & 200 & 1.3 & 0.2 & 1.4 & 1.2 & 2.7 & 1.0 & 0.004 & 5.0 & 380 & & \\
\hline $10 / 13 / 2012$ & 25 & & 0.5 & 162 & 1.9 & 0.2 & 1.0 & 0.8 & 2.9 & 1.3 & 0.006 & 7.7 & 215 & & \\
\hline \multirow[t]{2}{*}{$8 / 8 / 2012$} & 36 & & 0.6 & 140 & 1.9 & 0.2 & 1.2 & 1.0 & 3.0 & 0.8 & 0.002 & 5.8 & 190 & & \\
\hline & & & & & & & & & & & & & & & \\
\hline $7 / 31 / 2014$ & 25 & & & 77 & 2.0 & 0.3 & 2.8 & 2.5 & 4.8 & 0.8 & 0.001 & 10.7 & 99 & & \\
\hline $8 / 8 / 2014$ & 25 & & & 113 & 2.1 & 0.3 & 1.2 & 0.8 & 3.2 & 1.0 & 0.002 & 8.7 & 136 & & \\
\hline $8 / 22 / 2014$ & 25 & & & 202 & 2.4 & 0.5 & 1.3 & 0.8 & 3.7 & 2.0 & 0.002 & 9.7 & 215 & & \\
\hline $9 / 8 / 2014$ & 25 & & & 159 & 2.7 & 0.7 & 1.7 & 1.0 & 4.4 & 1.5 & 0.004 & 9.7 & 145 & & \\
\hline
\end{tabular}

